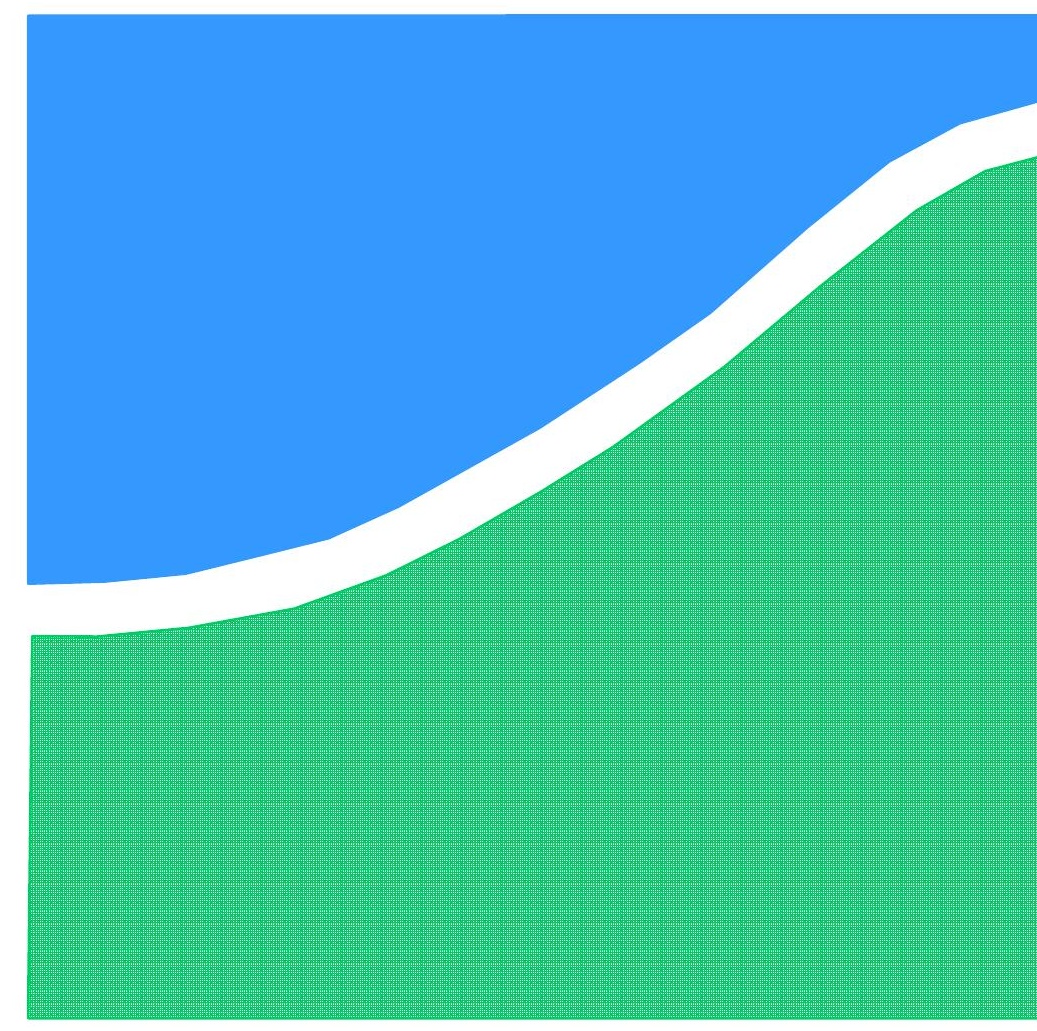

TRABALHO DE GRADUAÇÃO

\title{
ANÁLISE DE VIABILIDADE ECONÔMICA DE CENTRAIS GERADORAS HIDRELÉTRICAS
}

Guilherme Bertuol Rodrigues de Queiroz

UNIVERSIDADE DE BRASILIA

FACULDADE DE TECNOLOGIA 
UNIVERSIDADE DE BRASILIA

Faculdade de Tecnologia

\title{
TRABALHO DE GRADUAÇÃO
}

\section{ANÁLISE DE VIABILIDADE ECONÔMICA DE CENTRAIS GERADORAS HIDRELÉTRICAS}

\author{
Guilherme Bertuol Rodrigues de Queiroz \\ Relatório submetido como requisito parcial para obtenção \\ do grau de Engenheiro Eletricista
}

\begin{abstract}
Banca Examinadora
Prof. Dr. Ivan Marques de Toledo Camargo, UnB/ EnE

Prof. Dr. Mauro Moura Severino, UnB/EnE

Prof. Dr. Rafael Amaral Shayani, UnB/ EnE
\end{abstract}




\section{Dedicatória}

À Deus, aos meus pais, à minha família, à minha namorada e a todos que me ajudaram no decorrer da minha formação.

Guilherme Bertuol Rodrigues de Queiroz 


\section{Agradecimentos}

Primeiramente gostaria de agradecer à Deus por todas as oportunidades que tive ao longo da minha vida. Agradeço aos meus pais por terem me dado apoio, amor e exemplo de responsabilidade, determinação, honestidade e perseverança. Agradeço à minha família, que me acompanhou em todos os momentos da minha vida. Agradeço à minha namorada, pelo apoio nos momentos mais difíceis e pela compreensão nos momentos em que estive ausente. Agradeço aos meus professores que são responsáveis por parte da minha formação como pessoa e como profissional. Agradeço aos meus colegas e aos meus amigos que estiveram comigo nos momentos de dificuldade e de felicidade.

Agradeço todo apoio e ajuda que recebi do meu orientador Ivan Camargo e do professor Lúcio Salomon. Agradeço ao Carlos Roberto por ter autorizado o estudo das CGHs da sua propriedade e por ter disponibilizado documentos, estudos e projetos. Agradeço às ajudas recebidas dos professores do departamento de engenharia elétrica e do departamento engenharia mecânica. Agradeço a todos os membros da empresa júnior de engenharia elétrica - ENETEC. Agradeço às ajudas recebidas da Bruna, da Carolina, do Gabriel, do Luiz Raphael, do Rodrigo e da Sthephanie na construção desse trabalho.

Guilherme Bertuol Rodrigues de Queiroz 
A Central Geradora Hidrelétrica - $\mathrm{CGH}$ - é uma alternativa de geração de energia de baixo custo largamente utilizada para o suprimento de cargas isoladas na zona rural e em comunidades isoladas. Entretanto, o custo da energia gerada por uma CGH é alto quando comparado ao custo da energia comprada das concessionárias de distribuição. Isso ocorre em virtude do baixo fator de capacidade, uma vez que a CGH deve ser dimensionada para a demanda máxima. $\mathrm{O}$ custo da energia pode ser substancialmente reduzido quando a CGH é inserida em um ambiente de geração distribuída em que há a possibilidade de venda do excedente de energia para a concessionária local ou para outro consumidor. Este trabalho aborda a viabilidade econômica das CGHs em um cenário de geração distribuída e apresenta os principais aspectos construtivos, alternativas econômicas e tecnologias disponíveis no mercado. São apresentados dois desenvolvimentos de análise econômica que possibilitam a realização da estimativa do investimento inicial e do benefício anual, considerando diversas possibilidades de arranjos e potência instalada. É analisado um exemplo real de uma propriedade rural onde há duas CGHs instaladas e existe a possibilidade de instalação de uma nova CGH. Os desenvolvimentos de análise de viabilidade econômica apresentados nesse trabalho foram utilizados para a determinação do arranjo e da potência instalada que maximizam o retorno econômico desse empreendimento.

ABSTRACT

The Central Hydroelectric Generation - CGH - is an alternative source of low cost energy widely used to supply loads in countryside and in isolated communities. However, the cost of energy generated by a CGH is high when compared to the cost of purchased energy from distribution utilities. This is due to the low capacity factor, once the CGH should be sized for high demand. Energy costs can be substantially reduced when the CGH is placed in a distributed generation environment where there is the possibility of selling exceeding energy to local utility or to other consumer. This paper deals the economic viability of CGH in distributed generation scenario and presents the principal aspects of construction, economic alternatives and technologies available in the market. It is presented two different economic analyses to estimate the initial investment and the annual benefit, considering the different kind of arrangement and installed power. It is analyzed a real example of a farm where there are two CGH installed and there is the possibility of installing a new one. The developments of economic analysis presented in this work were used to determine the arrangement and the installed power that maximize the economic return of this enterprise. 


\section{LISTA DE FIGURAS}

3.1 Arranjos típicos de CGHs: (a) Central Hidrelétrica de Represamento - CHR; (b) Arranjo com turbina caixa aberta; (c) Central Hidrelétrica de Desvio - CHD; (d) Central Hidrelétrica de Derivação - CHV. Fonte: referência [12] e

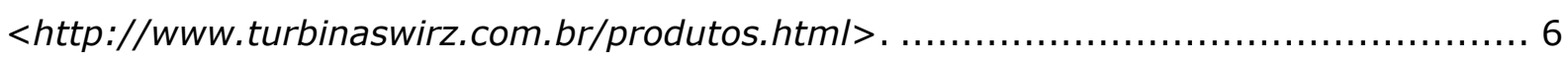

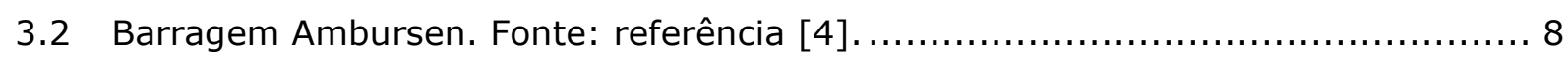

3.3 Geometria dos rotores das turbinas hidráulicas: (a) turbina Pelton; (b) turbina Michel-Banki; (c) turbina Francis; (d) turbina axial-hélice e Kaplan. Fonte: referência [12].

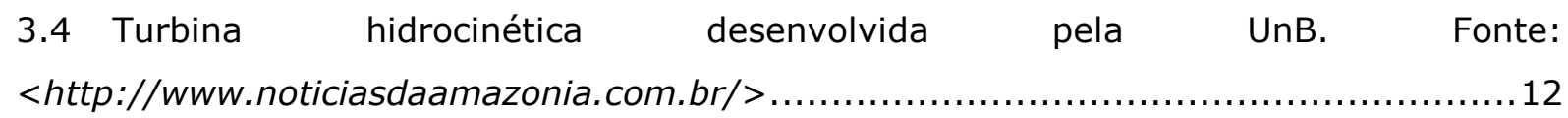

3.5 Campo de aplicação das turbinas hidráulicas CGHs. Fonte: referências [4] e [5]...13

4.1 Variação do rendimento do grupo gerador: (a) rendimento da turbina; (b)

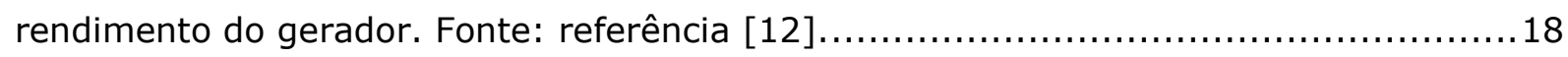

4.2 Exemplo para apresentação dos desenvolvimentos de análise de viabilidade econômica de CGH: (a) Arranjo CHR; (b) Arranjo CHD; (c) Arranjo CHV. .................24 4.3 Série de vazões médias mensais disponíveis do manancial do exemplo

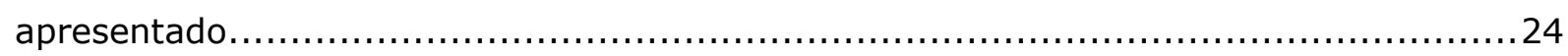

4.4 Curva de duração de vazões do exemplo apresentado. ............................27

4.5 Curvas de duração de potência do exemplo apresentado desconsiderando os limites operacionais do grupo gerador.

4.6 Curva de duração de potência do arranjo 3, do exemplo apresentado, para a

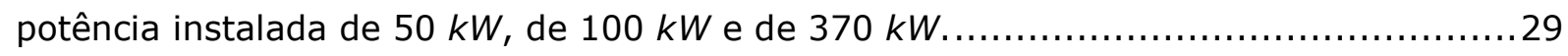

4.7 Energia gerada em função da potência instalada do exemplo apresentado. ...........30

4.8 Benefício anual em função da potência instalada do exemplo apresentado. ...........30

4.9 Relação entre a potência instalada e a vazão de projeto do exemplo apresentado. 31

4.10 Estimativa e de custo em função da potência instalada do exemplo apresentado. .31

4.11 Potência disponível média mensal para carda arranjo do exemplo apresentado. ...32

4.12 Fluxo de potência do arranjo 3 do exemplo apresentado, para potência instalada de

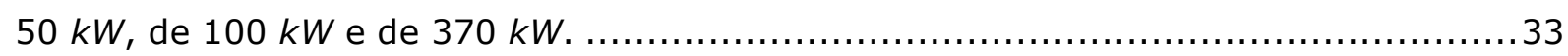

4.13 Energia excedente, energia fornecida para a concessionária e energia comprada da concessionária em um ano em função da potência instalada. Energia referente ao arranjo 3 do exemplo proposto.

4.14 Benefício anual para cada arranjo do exemplo proposto, em função da potência instalada.

4.15 Estimativa de custo para cada arranjo do exemplo proposto, em função da potência instalada. 
4.16 Indicadores econômicos do desenvolvimento de análise econômica utilizando a curva de duração de vazão: (a) Valor presente líquido (Mil $R \$$ ); (b) Índice de lucratividade; (c) Período de payback descontado (anos); (d) Taxa interna de retorno (\% aa).

4.17 Indicadores econômicos do desenvolvimento de análise econômica utilizando vazões médias mensais: (a) Valor presente líquido (Mil $R \$$ ); (b) Índice de lucratividade; (c) Período de payback descontado (anos); (d) Taxa interna de retorno (\% aa). 38 5.1 Bacia do Tocantins. Sub-Bacia 20 - Bacia do Rio Maranhão. Fonte: referência [15]. 41

5.2 Bacia do Rio Angicos. Fonte: referência [8] 42

5.3 Perfil longitudinal do Rio Angicos. Fonte: dados presentes na referência [8].

5.4 Vazões médias mensais de longo período do Rio Angicos no local de interesse. Fonte: referência [8]

5.5 Levantamento topográfico utilizado no projeto básico da $\mathrm{PCH}$ Santa Maria. Fonte: referência [7].

5.6 Projeto PCH Santa Maria. Fonte: referência [7].

5.7 Demanda futura da propriedade: (a) demanda do conjunto de residências 1 e do conjunto de residências 2; (b) Demanda da fábrica de gelo; (c) demanda do sistema de irrigação e demanda total. 46

5.8 Vazões médias mensais disponíveis atualmente para geração de energia. 48

5.9 Vazões médias mensais disponíveis para geração de energia após o projeto de irrigação. .48

5.10 Curva de duração de vazões disponíveis atualmente.

5.11 Curva de duração de vazões disponíveis para geração de energia após a execução do projeto de irrigação.

5.12 Energia hidráulica disponível no Rio Angicos entre as cotas de $925 m$ e $725 m . . .49$

5.13 Arranjo da CGH 1.

5.14 Sistema de adução da CGH 1: (a) entrada da lagoa de decantação; (b) lagoa de decantação; (c) captação para a câmara de carga e grades de proteção; (d) câmara de carga; (e) comporta de manutenção; (f) conduto de alta pressão. 52 5.15 Casa de Máquinas da CGH 1: (a) Parte externa casa de máquinas e início da linha de transmissão; (b) Turbina Pelton e volante de inércia; (c) sistema de atuação do sistema de controle; (d) Gerador principal; (e) quadro geral; (f) canal de restituição....53 5.16 Arranjo da CGH 2. 54

5.17 Sistema de captação da CGH 2: (a) barragem de terra e entrada da tomada d'água; (b) sistema de controle do nível d’água; (c) extravasador; (d) saída da tomada d'água.

5.18 Sistema de adução: (a) canal de escoamento livre; (b) desarenador; (c) grade de proteção e comporta de manutenção; (c) grade de proteção; (d) reservatório da câmara de carga; (e) Interior do reservatório da câmara de carga; (f) conduto de alta pressão. 56 
5.19 Casa de Máquinas: (a) Casa de máquinas e início da linha de transmissão; (b) turbina; (c) sistema de controle; (d) geradores; (e) quadro geral; (f) tubo de sucção da

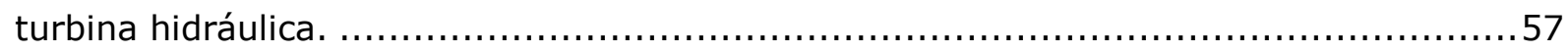

5.20 Possibilidades de arranjo para a análise do aproveitamento CGH 3. ................58

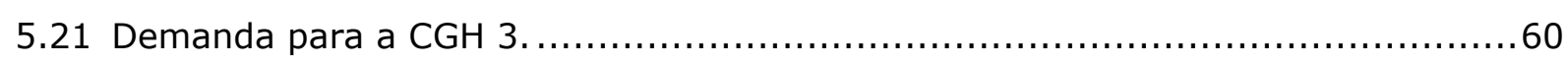

5.22 Resultados da análise econômica utilizando a curva de duração de vazões: (a) Benefício anual (Mil $R \$$ ); (b) Estimativa de custo (Mil $R \$$ ); (c) Valor presente líquido $(R \$)$; (d) Índice de lucratividade; (e) Período de payback descontado (anos); (f) Taxa interna de retorno (aa).

5.23 Resultado da análise econômica utilizando as vazões médias mensais: (a) Benefício anual (Mil $R \$$ ); (b) Estimativa de custo (Mil $R \$$ ); (c) Valor presente líquido $(R \$)$; (d) Índice de lucratividade; (e) Período de payback descontado (anos); (f) Taxa interna de retorno (aa) .64 


\section{LISTA DE TABELAS}

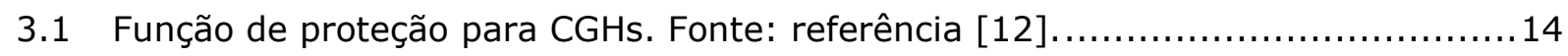

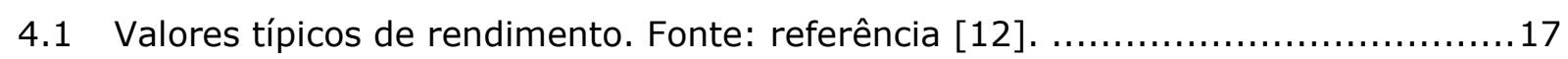

4.2 Limite inferior de operação. Fonte: referência [12] ............................... 18

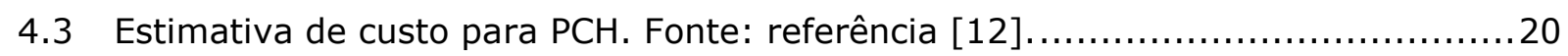

4.4 Custos percentuais médios das CGHs. Fonte: referência [13]. .......................21

4.5 Dados do exemplo apresentado...................................................... 26

4.6 Arranjo e a potência instalada que otimiza cada indicador da análise de viabilidade econômica utilizando a curva de duração de vazões.................................... 37

4.7 Arranjo e potência instalada que otimiza cada indicador do estudo de viabilidade econômica utilizando a série de vazões médias mensais. ................................ 38

5.1 Postos hidro-metereológico utilizados nos estudos. Fonte: referência [8]...........43

5.2 Vazões médias mensais de longo período no local de interesse. Fonte:

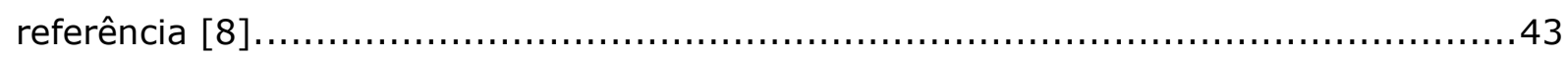

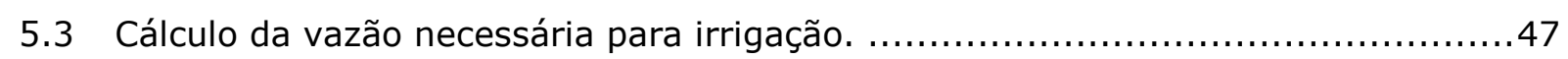

5.4 Comprimento do canal de escoamento livre e da adução em alta pressão para cada

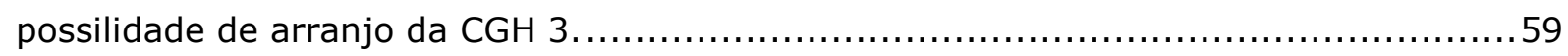

5.5 Dados utilizados para a análise de viabilidade econômica da CGH 3. ...............61

5.6 Valor referência anual e tarifa de venda calculada com base no VR. Fonte:

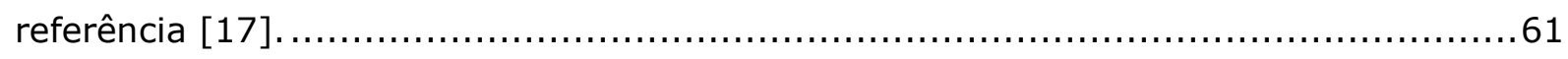

5.7 Tarifa média mensal rural para cada região em 2009. Fonte: referência [16]. .....62

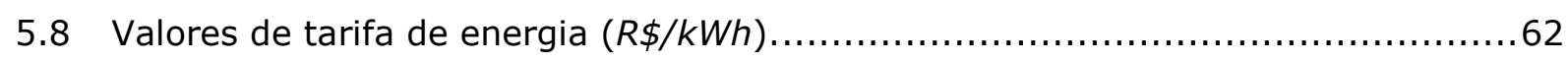

5.9 Arranjo e potência instalada que otimiza cada indicador do estudo de viabilidade econômica utilizando a curva de duração de vazões. ....................................63

5.10 Arranjo e potência instalada que otimiza cada indicador do estudo de viabilidade econômica utilizando a série de vazões médias mensal. ................................64

5.11 Dados utilizados para a análise de viabilidade econômica das CGHs. .................66

5.12 Resultado da análise de viabilidade econômica aplicada a CGH 1 . ..................67

5.13 Resultado da análise de viabilidade econômica aplicada a CGH 2. ..................67

5.14 Resultado da análise de viabilidade econômica aplicada a CGH 3..................67 


\section{LISTA DE SÍMBOLOS E SIGLAS}

A - Área da sessão transversal atravessada pela água;

$\mathrm{A}_{\mathrm{D}}$ - Área de drenagem $(h a)$;

ANEEL - Agência Nacional de Energia Elétrica;

$\mathrm{A}_{\mathrm{te}}$ - Área do terreno utilizado $(h a)$;

$\mathrm{B}$ - Benefício da CGH $(R \$)$;

$\mathrm{B}_{\mathrm{d}}$ - Largura do desarenador;

$\mathrm{C}_{\mathrm{ch}}-$ Custo total da $\mathrm{CGH}(R \$)$;

CEB - Companhia Energética de Brasília;

CELG - Companhia Energética de Goiás;

CGH - Central Geradora Hidrelétrica;

CHD - Central Hidrelétrica de Desvio;

CHR - Central Hidrelétrica de Represamento;

CHV - Central Hidrelétrica de Derivação;

CODI - Comitê de Distribuição;

CUT - Custo por unidade de terreno $(R \$ / h a)$;

DNAEE - Departamento Nacional de Águas e Energia Elétrica;

$\mathrm{E}_{\mathrm{B}}-$ Energia disponível;

$\mathrm{E}_{\mathrm{el}(k W h)}$ - Energia elétrica gerada $(k W h)$;

$\mathrm{f}_{\mathrm{c}}$ - Fator de capacidade;

g - Aceleração da gravidade;

$\mathrm{H}_{1 / 1}$ - Altura nominal;

$\mathrm{H}_{\mathrm{B}}$ - Altura bruta;

$\mathrm{h}_{\mathrm{b}}-$ Altura da barragem $(m)$;

$\mathrm{h}_{\mathrm{e}}-$ Altura da ensecadeira $(m)$;

INCC - Índice Nacional de Custo da Construção;

$\mathrm{L}$ - Comprimento da tubulação $(m)$;

$\mathrm{L}_{\mathrm{ap}}$ - Comprimento do conduto em alta pressão $(m)$;

$\mathrm{L}_{\mathrm{bp}}$ - Comprimento do conduto em baixa pressão $(m)$;

$\mathrm{L}_{\mathrm{c}}$ - Comprimento do canal $(m)$;

$\mathrm{L}_{\mathrm{e}}$ - Comprimento da ensecadeira $(m)$;

$\mathrm{L}_{\mathrm{lt}}$ - Comprimento da linha de transmissão $(m)$;

m - Massa da água;

$\mathrm{n}$ - Rotação;

$\mathrm{n}_{\mathrm{qA}}$ - Rotação específica da turbina no sistema internacional de unidades;

NTD - Norma Técnica de Distribuição;

$\mathrm{P}_{\mathrm{B}}$ - Potência disponível;

PCH - Pequena Central Hidrelétrica;

$\mathrm{P}_{\mathrm{el}}$ - Potência elétrica gerada;

$\mathrm{P}_{\mathrm{el}(k W)}$ - Potência elétrica gerada $(k W)$;

$\mathrm{P}_{\mathrm{i}}$ - Potência instalada;

$\mathrm{P}_{\mathrm{m}}$ - Potência média gerada;

$\mathrm{P}_{\mathrm{p}_{\text {ap }}}$ - Potência perdida total do aproveitamento;

$\mathrm{P}_{\mathrm{p}_{\mathrm{g}}}$ - Perdas do gerador;

$\mathrm{P}_{\mathrm{p}_{\mathrm{i}}}$ - Perdas internas da turbina hidráulica;

$\mathrm{P}_{\mathrm{p}_{\mathrm{m}}}$ - Perdas de mecânicas;

$\mathrm{P}_{\mathrm{p}_{\text {sac }}}$ - Perdas do sistema de adução (canal); 
$\mathrm{P}_{\mathrm{p}_{\text {sat }}}$ - Perdas do sistema de adução (tubulação);

Q - Vazão de projeto;

$\mathrm{Q}_{1 / 1}$ - Vazão para o distribuidor todo aberto;

$\mathrm{Q}_{\mathrm{i}}$ - Vazão mínima;

RTD - Recomendação Técnica de Distribuição;

$\mathrm{T}$ - Tarifa de energia $(R \$ / k W h)$;

$\mathrm{t}$ - Tempo;

$t_{\text {horas }}$ - Tempo em horas;

V - Velocidade do escoamento da água;

VR - Valor anual de referência;

$\eta_{\mathrm{ap}}$ - Rendimento total do aproveitamento;

$\eta_{\mathrm{g}}$ - Rendimento do gerador;

$\eta_{i}$ - Rendimento interno da turbina hidráulica;

$\eta_{\mathrm{m}}$ - Rendimento mecânico;

$\eta_{\text {sac }}$ - Rendimento do sistema de adução (canal);

$\eta_{\text {sat }}$ - Rendimento do sistema de adução (tubulação);

$\rho$-Densidade da Água. 


\section{SUMÁRIO}

1 INTRODUÇÃO

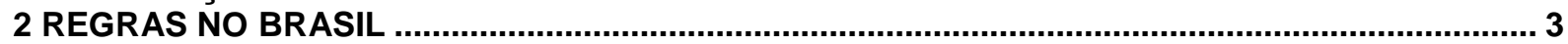

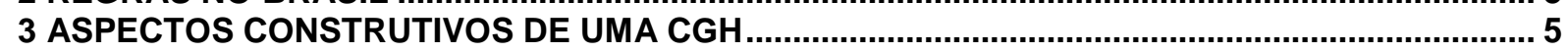

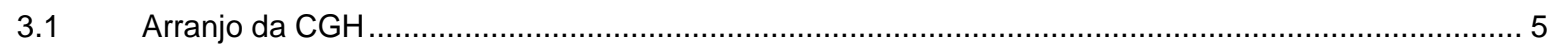

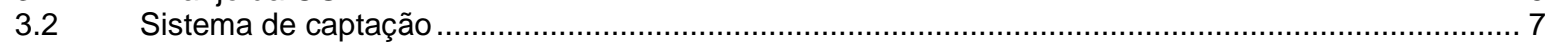

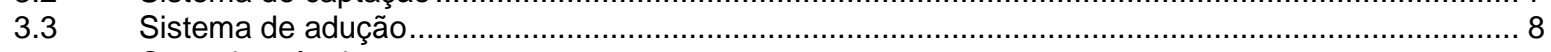

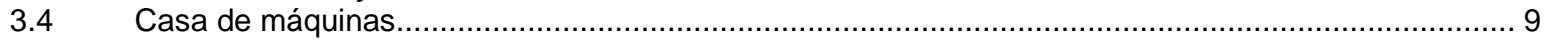

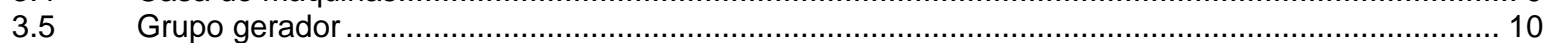

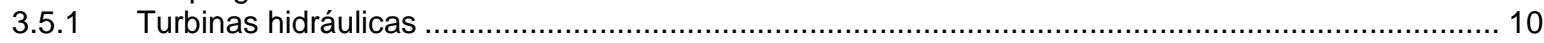

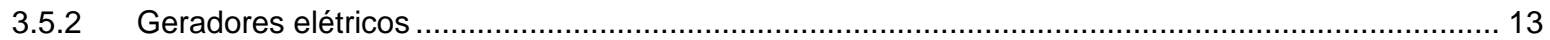

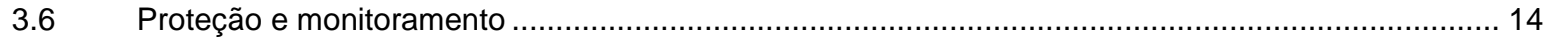

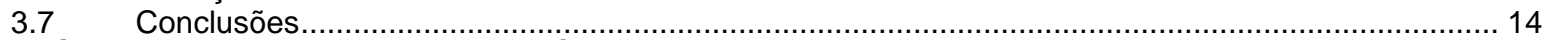

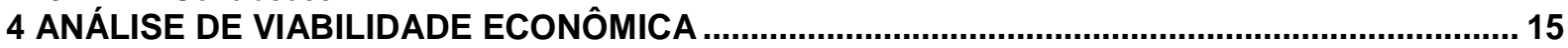

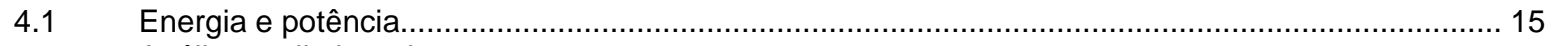

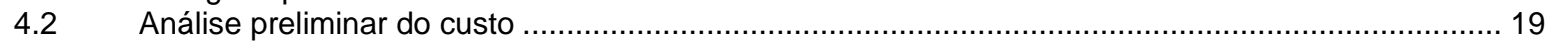

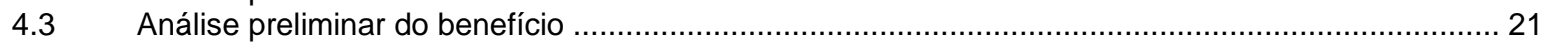

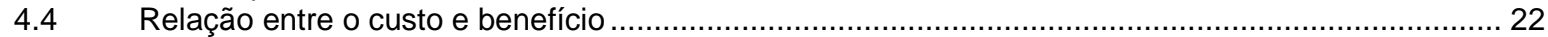

4.5 Desenvolvimentos de análise de viabilidade econômica de CGH.....................................................2 23

4.5.1 Dados necessários para realização dos desenvolvimentos de análise de viabilidade econômica...... 25

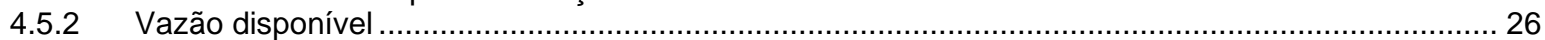

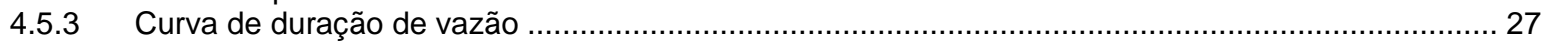

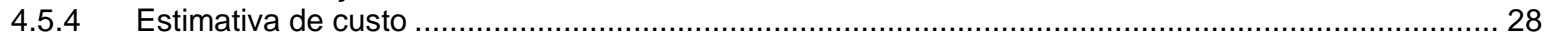

4.5.5 Análise de viabilidade econômica utilizando a curva de duração de vazões.................................... 28

4.5.6 Desenvolvimento da análise de viabilidade econômica utilizando as vazões médias mensais........... 32

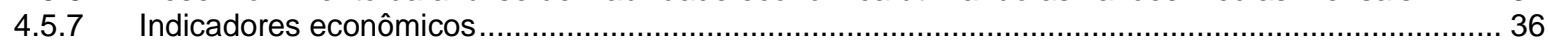

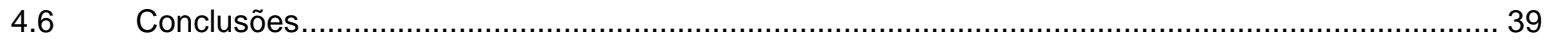

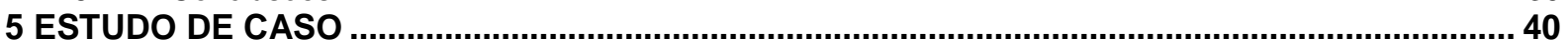

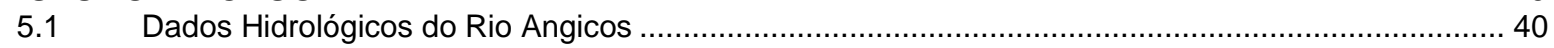

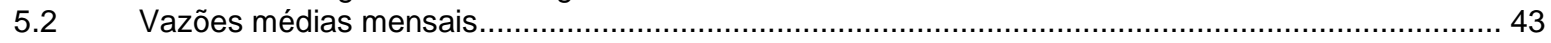

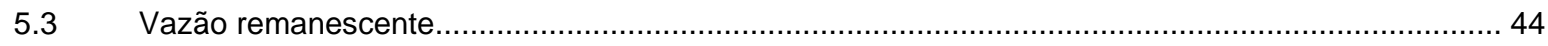

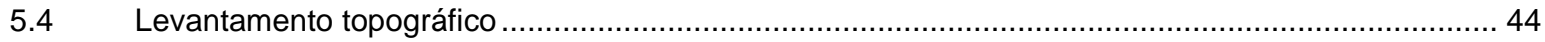

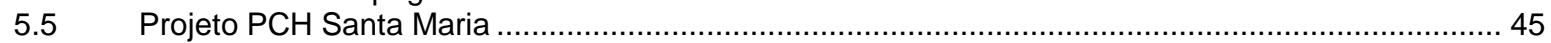

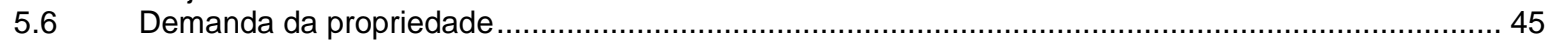

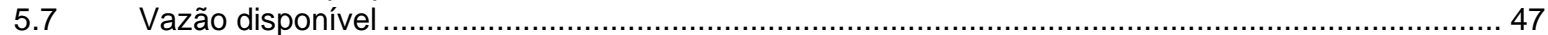

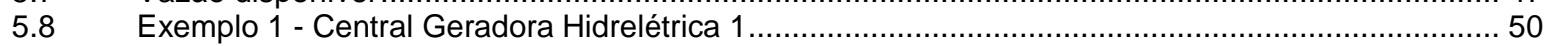

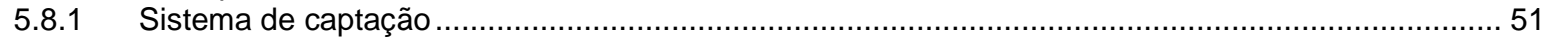

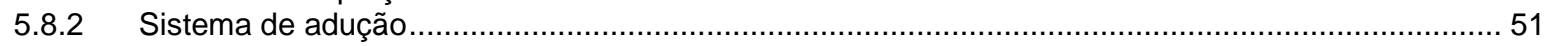

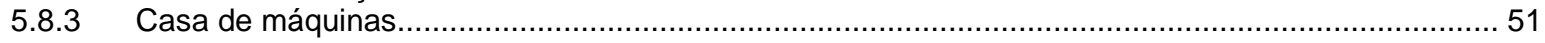

5.9 Exemplo 2 - Central Geradora Hidrelétrica 2 …….......................................................... 53

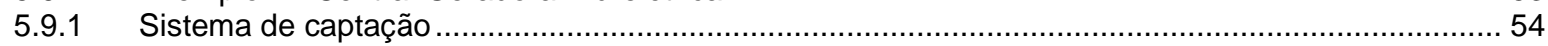

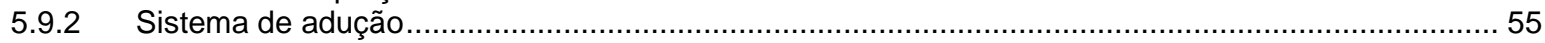

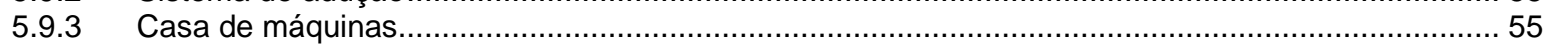

5.10 Exemplo 3 - Análise de viabilidade da CGH 3 …............................................................ 57

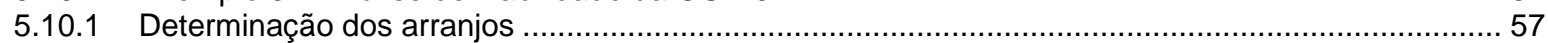

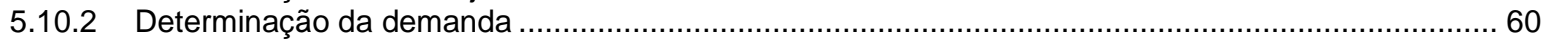

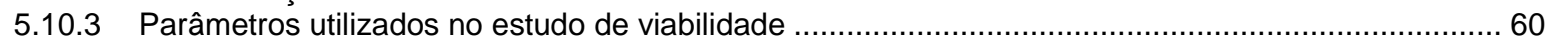

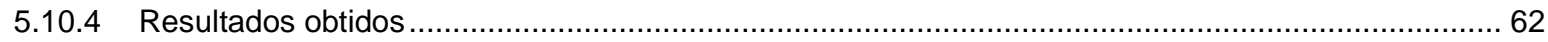

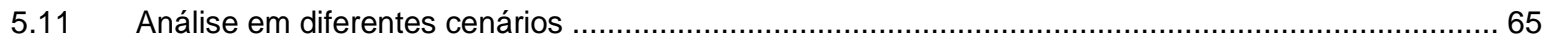

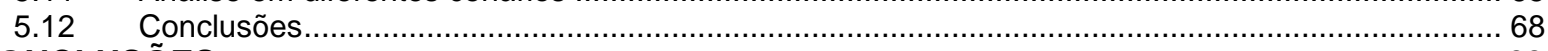

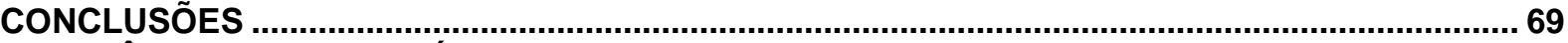

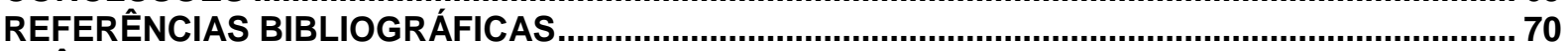

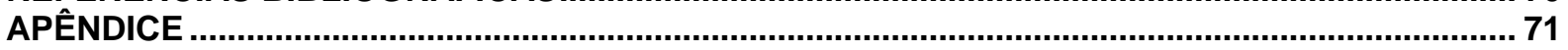

Apêndice I - Dados para realização da análise de viabilidade econômica................................... 72

Apêndice II - Função para determinação da curva de duração de vazões....................................74

Apêndice III - Função para determinação da estimativa de custo ……….................................... 75

Apêndice IV - Algoritmo para o cálculo dos indicadores econômicos .......................................... 77

Apêndice V - Outras funções ............................................................................................. 78

Apêndice VI - Desenvolvimento da análise de viabilidade econômica com a utilização da curva de duração de vazões ................................................................................................................. 79

Apêndice VII - Desenvolvimento da análise de viabilidade econômica com a utilização das

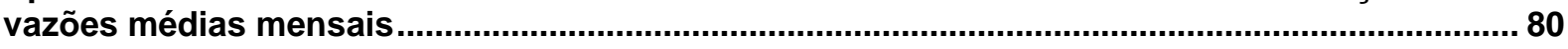

Apêndice VIII - Perfil longitudinal dos cortes mostrados na figura 5.20................................... 82 


\section{INTRODUÇÃO}

O aproveitamento de um potencial hidráulico para geração de energia, com potência instalada inferior a $1 M W$, é definido como Central Geradora Hidrelétrica - $\mathrm{CGH}$-, conforme mostrado no Guia do Empreendedor de Pequenas Centrais Hidrelétricas [1]. As CGHs independem de concessão ou autorização, devendo, apenas, ser realizado um registro na Agência Nacional de Energia Elétrica - ANEEL.

O principal benefício de uma CGH é a geração de energia. A utilização ou a comercialização dessa energia pode trazer um benefício financeiro. $\mathrm{O}$ valor desse benefício varia com uma série de fatores como a utilização da energia, a disponibilidade de outros recursos, o custo com a interligação com um sistema de distribuição, a tarifa de compra de energia e a tarifa de venda de energia.

Por outro lado, a construção de uma CGH envolve uma série de custos com estudos iniciais, desenvolvimento, projetos, equipamentos, estruturas, operação e manutenção. Atualmente, o custo de uma CGH encontra-se na faixa de $\mathrm{R} \$ 5.000,00$ por quilowatt instalado [13]. Entretanto esse valor desconsidera a variação de custo em função da escolha do arranjo, do dimensionamento dos equipamentos e das estruturas.

Fica evidente que, antes de iniciar o projeto de uma CGH, é necessária a realização de um estudo de viabilidade econômica e, para isso, deve-se estimar o custo e o benefício da CGH. É importante que essa análise permita a comparação entre as diversas possibilidades de arranjo e de dimensionamento dos componentes. Este trabalho aborda o estudo de viabilidade de uma CGH em um cenário de geração distribuída. O estudo se limita às CGHs fio d'água com um único grupo gerador.

No capítulo 2, é apresentada a definição do marco legal das CGHs no Brasil, as exigências para a realização do registro e as condições de comercialização da energia. $O$ capítulo 3 aborda os principais aspectos construtivos, os diferentes arranjos e as diversas possibilidades de escolha de cada componente.

O capítulo 4 aborda a variação da potência, da energia gerada, do custo e do benefício com a variação dos principais parâmetros de uma CGH. Nesse capítulo são apresentados dois desenvolvimentos de análise econômica que permitem a realização de uma análise considerando as diversas possibilidades de arranjo, a vazão disponível ao longo do ano e o dimensionamento do grupo gerador. O segundo desenvolvimento de análise econômica 
permite a realização da análise considerando a demanda da propriedade e as variações das tarifas.

O capítulo 5 apresenta um estudo de caso de uma propriedade rural onde, atualmente, estão instaladas duas CGHs operando isoladas da rede de distribuição. Os desenvolvimentos de análise apresentados no capítulo 4 são utilizados para a determinação do arranjo e da potência instalada de uma terceira CGH. Essa análise considera que as três CGHs irão compor um sistema interligado com a rede de distribuição local onde será possível a venda de todo o excedente de energia gerada. Por fim, é analisado o retorno financeiro das três CGHs considerando três cenários que se diferenciam pela utilização e comercialização da energia gerada. 


\section{REGRAS NO BRASIL}

Este capítulo aborda a definição do marco legal, as exigências para a realização do registro e as condições de comercialização da energia de uma $\mathrm{CGH}$.

O parágrafo quarto do art. 176 da Constituição Federal de 1988 determina que não dependerá de autorização ou concessão o aproveitamento do potencial de energia renovável de capacidade reduzida. $\mathrm{O}$ artigo $8^{\circ}$ da lei $\mathrm{n}^{\circ}$ 9.074, de 7 de julho de 1995, define que o aproveitamento de potenciais hidráulicos, iguais ou inferiores a $1.000 \mathrm{~kW}$ estão dispensados de concessão, permissão ou autorização, devendo apenas ser comunicados ao poder concedente.

Art. $5^{\circ}$ do decreto $\mathrm{n}^{\mathrm{o}} 2.003$, de 10 de setembro de 1996, define que o aproveitamento de potencial hidráulico igual ou inferior a $1.000 \mathrm{~kW}$ independe de concessão ou autorização, devendo, entretanto, ser comunicado ao órgão regulador e fiscalizador do poder concedente, para fins de registro.

Para a realização do registro com destinação da energia para fins de uso exclusivo é necessário apresentar os seguintes documentos devidamente autenticados: Formulário de registro de aproveitamento hidrelétrico com potência instalada igual ou inferior a $1.000 \mathrm{~kW}$, devidamente preenchido e assinado pelo responsável técnico; Cópia do Registro no CREA do responsável técnico; Prova de propriedade da área ou do direito de dispor livremente do terreno onde está implantada a central geradora e dos bens existentes na referida CGH; Planta de localização do empreendimento em carta planialtimétrica publicada por entidade oficial, em sua versão mais recente, contendo sistema de coordenadas geográficas, escala, legendas, datas da publicação e do trecho objeto do estudo pretendido; Planta em detalhe do empreendimento com indicação do reservatório, arranjo das estruturas, demarcação dos terrenos e pontos característicos de interesse. No caso do registro para fins de comercialização de energia elétrica, uso exclusivo com comercialização e serviço público, os interessados deverão apresentar uma documentação adicional a título de qualificação jurídica e a título de qualificação fiscal. [1]

O artigo 12 da lei $n^{\circ}$ 9.433, de 8 de janeiro de 1997, que Institui a Política Nacional de Recursos Hídricos, determina que estão sujeitos a outorga pelo Poder Público os direitos dos usos de recursos hídricos para aproveitamento dos potenciais hidrelétricos. A efetivação do registro do empreendimento não exime o interessado das responsabilidades quanto aos aspectos ambientais e de recursos hídricos [1]. 
A Lei $n^{\circ} 10.762$, de 11 de novembro de 2003 altera os artigos 17 e 26 da lei $n^{\circ} 9.427$, de 26 de dezembro de 1996, determinando que a ANEEL estipule um percentual de redução, aplicado também aos empreendimentos hidroelétricos com potência igual ou inferior a 1.000 $k W$, não inferior a cinqüenta por cento a ser aplicado às tarifas de uso dos sistemas elétricos de transmissão e de distribuição, incidindo na produção e no consumo da energia comercializada pelos aproveitamentos. Determina também que poderão comercializar energia elétrica com consumidor, ou conjunto de consumidores reunidos por comunhão de interesses de fato ou de direito cuja carga seja maior ou igual a $500 \mathrm{~kW}$, independentemente dos prazos de carência constante do art. 15 da Lei $\mathrm{n}^{\circ}$ 9.074, de 7 de julho de 1995, observada a regulamentação da ANEEL, podendo o fornecimento ser complementado por empreendimentos de geração associados às outras fontes definidas na mesma lei, visando a garantia de suas disponibilidades energéticas mas limitado a quarenta e nove por cento da energia média que produzirem.

A possibilidade de venda de energia para as concessionárias já eram previstas no decreto-lei $\mathrm{N}^{\mathrm{o}} 1.872$, de 21 de maio de 1981. Esse decreto-lei determina que os concessionários de serviço público de eletricidade ficam autorizados a adquirir de autoprodutores energia elétrica excedente por estes gerada com a utilização de fontes energéticas que não empreguem combustível derivado de petróleo. $\mathrm{O}$ artigo $2^{\circ}$ define que energia elétrica excedente é a diferença entre a geração elétrica que pode ser obtida pela plena utilização da capacidade instalada do autoprodutor e o seu consumo próprio.

Mesmo regulamentada a venda de energia desde essa época, desconhece-se se, até a presente data, já houve algum contrato de venda assinado, com alguma concessionária no país, principalmente com relação às CGHs [13]. A venda para a concessionária ainda não está garantida em lei. Esse tema vem sendo discutido no congresso no projeto de lei 630 de 2003. Esse projeto propõe que a partir do ano de 2011, as concessionárias, permissionárias e autorizadas do serviço público de distribuição de energia elétrica do SIN deverão realizar, pelo menos uma vez a cada ano, chamada pública para a aquisição de energia elétrica produzida a partir de fontes alternativas renováveis em plantas com capacidade de geração superior a $50 \mathrm{~kW}$ e igual ou inferior a $1.000 \mathrm{~kW}$. O projeto de lei propõe também que a produção de energia elétrica a partir de fontes alternativas renováveis será remunerada pelo Valor Anual de Referência do Mercado Regulado, acrescido de dez por cento, para o caso de pequenos aproveitamentos hidráulicos. 


\section{ASPECTOS CONSTRUTIVOS DE UMA CGH}

Este capítulo apresenta os componentes básicos de uma CGH e algumas considerações importantes para a escolha de cada componente. Os conceitos apresentados neste capitulo serão utilizados nos desenvolvimentos de estudo de viabilidade econômica apresentados nos capitulos seguintes.

\subsection{Arranjo da CGH}

A associação dos possíveis componentes de uma CGH caracteriza o seu arranjo. Normalmente, o arranjo de uma CGH é constituído por um sistema de captação, um sistema de adução, uma casa de máquinas, um grupo gerador, um sistema de restituição e um sistema de proteção e monitoramento. A escolha da estrutura de cada componente varia de acordo com as características da topografia, da hidrologia, do solo e dos materiais disponíveis. A figura 3.1 mostra exemplos de diferentes arranjos possíveis para uma CGH. É importante priorizar a utilização de materiais disponíveis na propriedade e buscar alternativas que possibilitará a redução dos custos, porém deve ser garantida a segurança e a eficiência do sistema.

Os arranjos das CGHs podem ser classificados como Central Hidrelétrica de Represamento - CHR -, figura 3.1 (a), Central Hidrelétrica de Desvio - CHD -, figura 3.1 (c), e Central Hidrelétrica de Derivação - CHV -, figura 3.1 (d) [12]. Entretanto, existem outros arranjos como, por exemplo, as CGHs com a utilização de turbina do tipo caixa aberta, figura 3.1 (b), e as CGHs com turbinas hidrocinéticas.

A principal diferença entre os arranjos abordados nesse estudo se refere à configuração da adução em baixa pressão. O arranjo CHR, figura 3.1 (a), não apresenta adução de baixa pressão. O arranjo CHD, figura 3.1 (c), apresenta adução em baixa pressão com utilização de tubulação e o arranjo CHV, figura 3.1 (d), apresenta adução em baixa pressão com utilização de um canal de escoamento livre. O sistema de adução pode também não apresentar tubulação em alta pressão para os arranjos que utilizem turbina do tipo caixa aberta, figura 3.1 (b). Nos sistemas de adução curtos pode ser utilizada a mesma tubulação para todos os trechos. 


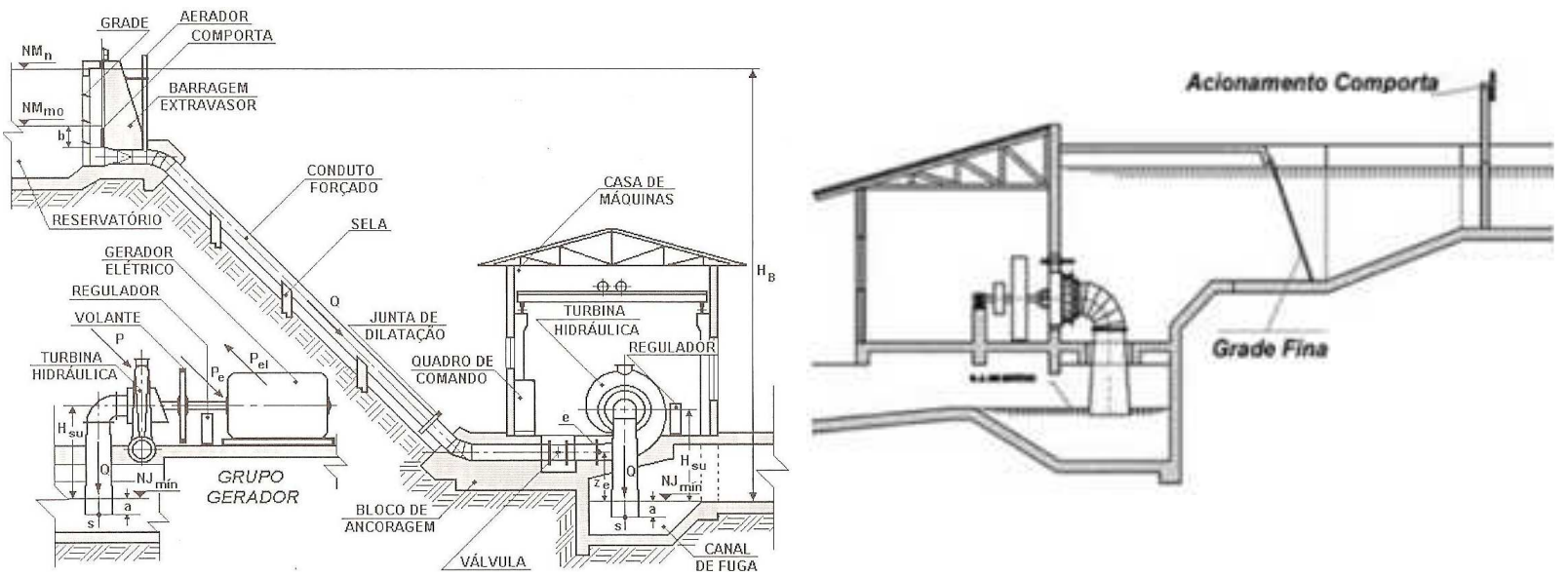

(a)

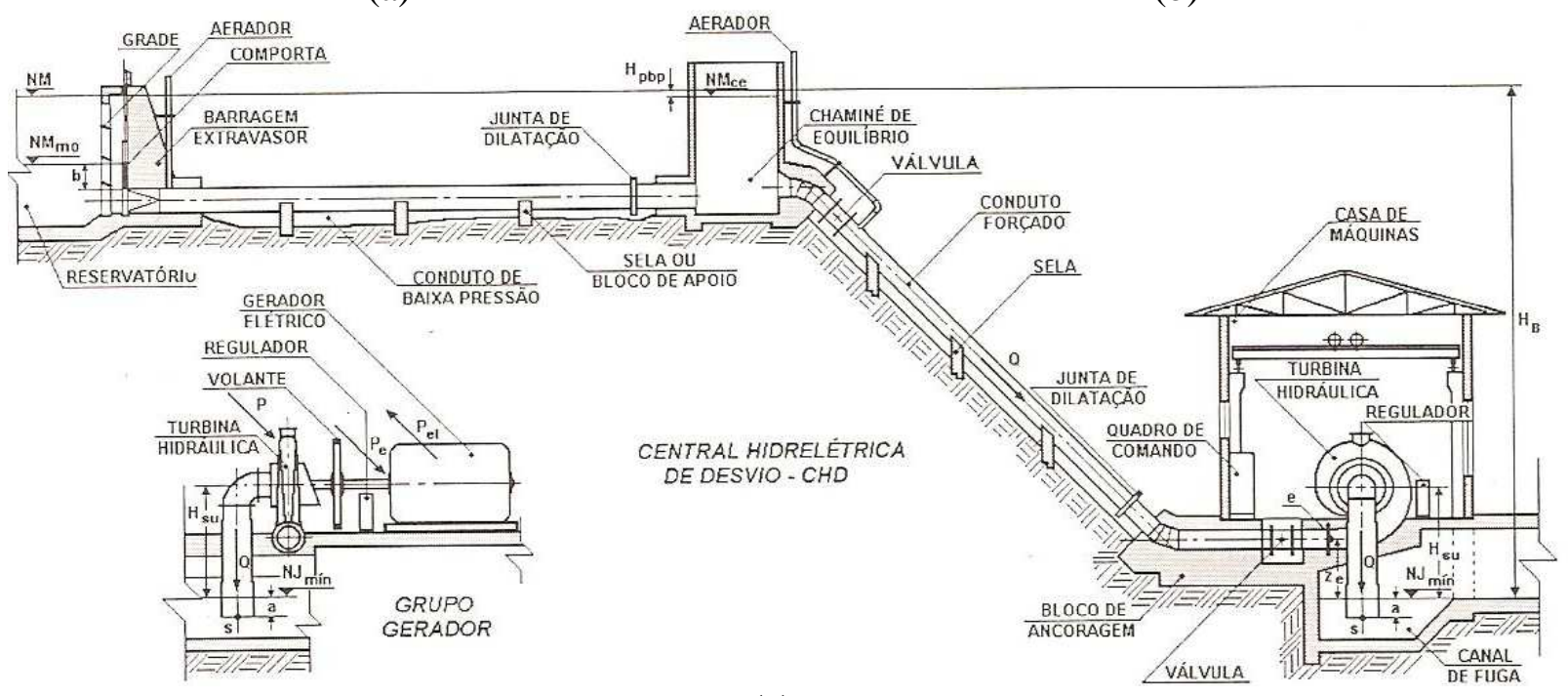

(c)

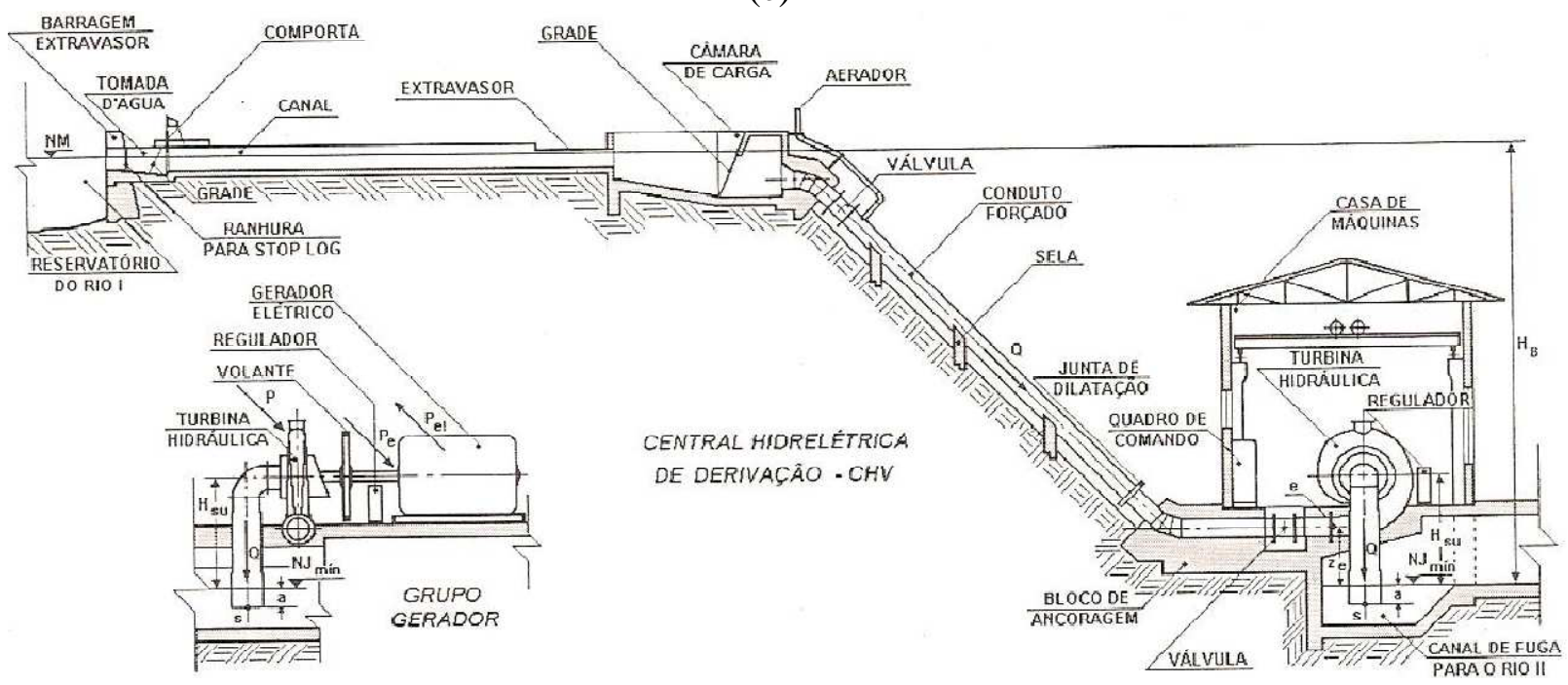

(d)

Figura 3.1 - Arranjos típicos de CGHs: (a) Central Hidrelétrica de Represamento - CHR; (b) Arranjo com turbina caixa aberta; (c) Central Hidrelétrica de Desvio - CHD; (d) Central Hidrelétrica de Derivação - CHV. Fonte: referência [12] e <http:// www.turbinaswirz.com.br/produtos.html $>$. 


\subsection{Sistema de captação}

As CGHs estudadas nesse trabalho são fio d'água, ou seja, não possuem a capacidade de armazenamento de água. A função da barragem, para esse caso, é garantir a operação da tomada d'água. Os tipos de barragens mais utilizados para essa aplicação são a barragem de terra, a barragem de concreto, a barragem de alvenaria de pedra e argamassa de cimento, a barragem Ambursen e a barragem de enrocamento.

A barragem deve ser construída em um local estreito do rio para possibilitar a economia de material. A escolha do tipo de barragem deve levar em consideração as condições da fundação, a disponibilidade de material, a disponibilidade de equipamentos e a disponibilidade de mão de obra.

A barragem de terra é apropriada para locais onde haja a disponibilidade de solo argiloso e a possibilidade de posicionar o vertedouro em uma das margens. Os outros tipos de barragens citados possibilitam que o vertedouro seja posicionado no corpo da barragem, mas exigem que as encostas sejam resistentes em rocha pouco fraturada. Se a fundação for coberta por uma camada espessa de matéria orgânica e inorgânica deixada pela água é preferível construir uma barragem de terra, caso contrário essa camada dever ser removida. [4]

A escolha entre a barragem de concreto ou de pedra com argamassa de cimento deve levar em consideração a velocidade de construção, a disponibilidade de material e o custo da obra. A barragem de concreto considerada neste trabalho é do tipo muro gravidade onde a pressão da água do reservatório e a pressão da infiltração da água é suportada pelo peso da barragem.

Pode ser utilizado concreto, a base cimento, brita e areia, ou o concreto ciclópico, que consiste na introdução de pedras de cerca de $25 \mathrm{~mm}$ de lado ou diâmetro. Em locais onde haja a disponibilidade de pedras de 15 a $30 \mathrm{~cm}$ de lado, pode-se optar pela construção da barragem de pedra e argamassa de cimento como alternativa para a redução da quantidade de concreto. [4]

A Barragem Ambursen, figura 3.2, é constituída de contrafortes de concreto, ou alvenaria de pedra e argamassa de cimento, e de pranchões de madeira ou concreto armado. Essa barragem é uma alternativa para a barragem de concreto e a barragem de alvenaria de pedra e argamassa de cimento. É ideal para locais onde tenha a disponibilidade de madeira. A escolha desse tipo de barragem possibilita a redução em até 5 vezes da quantidade de concreto e praticamente elimina a pressão proveniente da infiltração da água [4]. Outra vantagem é a facilidade de desvio do manancial durante a construção da barragem. A principal 
desvantagem é a vida útil dos pranchões de madeira e os vazamentos entre as frestas dos encaixes.

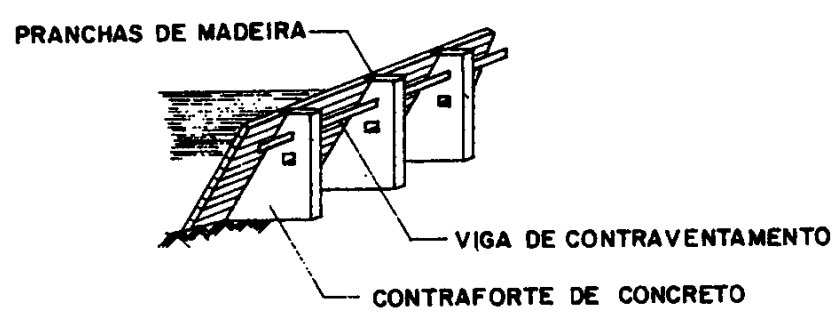

Figura 3.2 - Barragem Ambursen. Fonte: referência [4]

No sistema de captação deve ser previsto um vertedouro. A função do vertedouro é possibilitar a restituição do excedente de água sem comprometer a integridade das estruturas e do meio ambiente. O vertedouro pode ser localizado em um canal lateral ou no corpo da barragem. Pode ser previsto um canal lateral com a possibilidade de escoamento de água no corpo da barragem, exceto para as barragens de terra. Quando não for possível utilizar um canal lateral sem revestimento, pode-se estudar a utilização de um revestimento do canal. Dependendo da configuração do vertedouro, deve ser construída uma escada para a dissipação da energia do escoamento.

Para as barragens de concreto, de alvenaria de pedra e argamassa de cimento e Ambursen o vertedouro pode ser posicionado no corpo da barragem. Para barragens acima de dois metros deve ser construída uma bacia de dissipação a jusante da barragem [4].

A tomada d'água deve ser construída em um local onde haja um desnível suficiente e a menor distância possível em relação à casa de máquina. Deve-se equacionar o custo e a potência gerada e escolher a solução que apresentar a melhor relação custo-benefício. Deve ser construída em um trecho reto do manancial ou na margem côncava de um trecho em curvatura, para diminuir a entrada de sedimentos e objetos. Ela deve ser capaz de captar a vazão de projetos e a variação máxima e mínima do nível d'água, a fim de garantir o atendimento das cargas necessárias.

\subsection{Sistema de adução}

O sistema de adução pode ser composto de uma adução em baixa pressão e uma adução em alta pressão. A adução em baixa pressão pode ser em escoamento livre ou por meio de tubulação de PVC, de concreto ou de aço. No caso da adução em baixa pressão com utilização de tubulação é utilizada uma chaminé de equilíbrio entre a tubulação em baixa pressão e a adução em alta pressão. No caso da adução em baixa pressão com utilização de 
um canal de escoamento livre é utilizada uma câmara de carga entre o canal de escoamento livre e a adução em alta pressão. A adução em alta pressão deve ser, preferencialmente, de tubulação de concreto ou de aço. Pode-se utilizar tubulação de PVC, porém deve ser enterrada, o que dificulta a manutenção.

A chaminé de equilíbrio e a câmara de carga devem, em partida brusca, garantir que não entre ar no conduto forçado. Em parada brusca, a chaminé de equilíbrio deve garantir a sua própria estabilidade funcional e a do conduto de baixa pressão. Da mesma forma, a câmara de carga deve garantir a sua própria estabilidade funcional e a estabilidade do canal de adução. [12]

A declividade do fundo do canal deve ser constante e, no máximo, 0,0004 para que a perda no canal seja inferior a um por cento da queda bruta [12]. Se o solo não for muito permeável, esse canal pode ser construído sem revestimento. Para os outros casos pode-se estudar a utilização de algum revestimento. A inclinação do talude depende do tipo de solo e deve garantir a estabilidade do canal. A velocidade de escoamento deve ser compatível com a velocidade suportada pelo material do canal.

No final da adução em escoamento livre, deverá ser prevista uma estrutura onde o excedente de água seja escoado com segurança para o leito do manancial. Essa estrutura é chamada de extravasador.

A jusante da adução em baixa pressão, nos arranjos com canal de escoamento livre, ou na tomada d'água, para os demais arranjos, deve ser previsto um desarenador e uma grade de proteção contra objetos trazidos pela água. Essa grade deve ser instalada inclinada formando um ângulo de $75^{\circ}$ a $80^{\circ}$ com a horizontal [4]. A espessura da grade deve ser menor que a menor dimensão a ser atravessada pela água a jusante da grade.

A tubulação de aço deverá ser instalada sobre blocos de apoio. As tubulações de concreto armado poderão ser instaladas em valas, diretamente sobre o terreno. A tubulação de PVC ou de fibra deverá ser enterrada para evitar impactos e o contato com o sol. Nos trechos de curva da tubulação deverão ser instalados blocos de ancoragem para absorver os esforços longitudinais da tubulação.

\subsection{Casa de máquinas}

A casa de máquinas é o local onde será instalado o grupo gerador, o quadro de controle, o sistema de proteção, o transformador e outros componentes da CGH. Por isso, deve ser instalada em um local onde não ocorra risco de alagamento resultante das vazões 
máximas do manancial. Entretanto a escolha da cota da casa de máquinas refletirá na queda útil do projeto.

\subsection{Grupo gerador}

Os grupos geradores são constituídos basicamente de uma turbina, um gerador elétrico, um sistema de acoplamento, um volante de inércia, um sistema de controle e quadros elétricos. A turbina é o componente da CGH responsável em transformar a energia hidráulica em energia mecânica. O gerador é o componente responsável na transformação da energia mecânica em energia elétrica. O sistema de acoplamento transmite o torque entre o rotor da turbina e o rotor do gerador elétrico e, em alguns casos, ajusta, ou com engrenagens, ou com correias e polias, a velocidade de rotação nominal dos dois equipamentos. O volante de inércia proporciona o aumento da energia cinética do sistema aumentando a estabilidade durante os transitórios. O sistema de controle ajusta a potência hidráulica ou a carga para evitar a variação da velocidade de rotação do sistema.

\subsubsection{Turbinas hidráulicas}

Basicamente, as turbinas hidráulicas possuem um rotor acoplado a um eixo que permite a transferência de energia. Esse rotor é posicionado em uma estrutura que permite a orientação do fluxo d'água. O fluxo d'água pode ser orientado de forma distinta dependendo do tipo de turbina. A figura 3.3 mostra a geometria dos rotores das turbinas hidráulicas convencionais.

As turbinas hidráulicas, segundo a ABNT [11], são classificadas em dois grupos: turbinas hidráulicas de ação, quando o escoamento através do rotor ocorre sem variação de pressão; turbinas hidráulicas de reação, quando o escoamento através do rotor ocorre com variação de pressão [12].

A turbina Pelton é uma turbina de ação. O fluxo da água é orientado por um injetor e incide tangencialmente nas pás do rotor, figura 3.3 (a). Após incidir no rotor, o fluxo é dividido para as duas laterais e escoado para o sistema de restituição. O controle pode ser realizado por um sistema que controla a área da seção transversal do bico injetor ou uma válvula no sistema de adução forçada.

A turbina Michell-Banki pode operar como uma turbina de ação ou de reação. O rotor tem o formato de um cilindro com pás curvas apoiadas em dois discos laterais fixados no eixo. O fluxo d'água é direcionado por um injetor e controlado por uma pá diretriz. O fluxo 
incide nas pás do rotor e entra no interior do rotor. Posteriormente, o fluxo incide nas pás saindo do interior do rotor e é direcionado para o sistema de restituição, figura 3.3 (b).

A turbina Francis é uma turbina de reação. O fluxo da água é orientado por um tubo espiral, pelas pás fixas e por um distribuidor. O distribuidor possui um conjunto de pás móveis e o movimento das pás possibilita o controle da vazão. O fluxo entra no rotor na direção axial e sai na direção radial para um tubo de sucção, figura 3.3 (c).

A turbina Kaplan é uma turbina de reação. O fluxo da água é orientado por um tubo espiral. O fluxo entra no rotor na direção axial e sai também na direção axial para o tubo de sucção. O controle do fluxo d'água é realizado pela variação da inclinação das pás do rotor, variando ângulo de ataque, figura 3.3 (d).

Nas turbinas de caixa aberta o tubo espiral é eliminado. Nesse caso o distribuidor da turbina é posicionado no interior de um reservatório d'água.

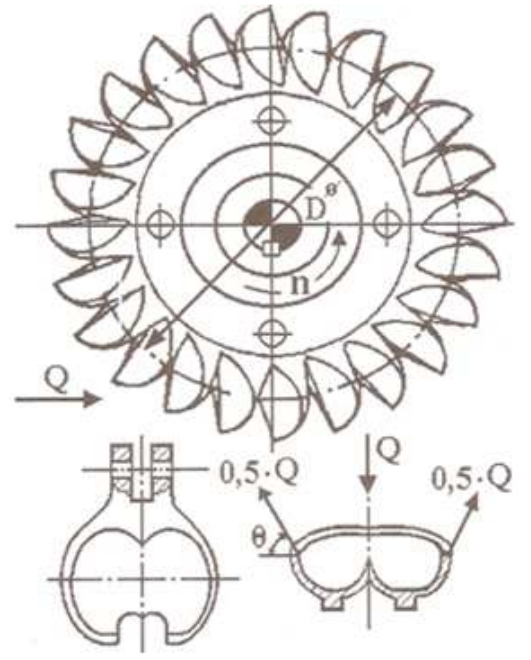

(a)

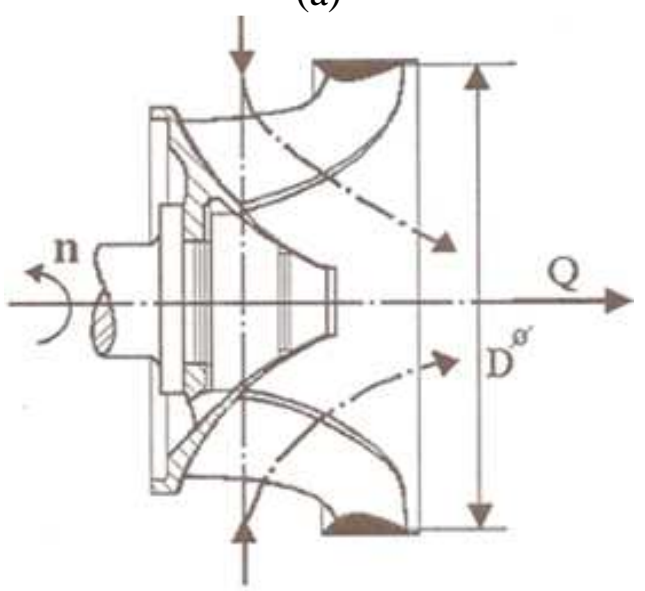

(c)

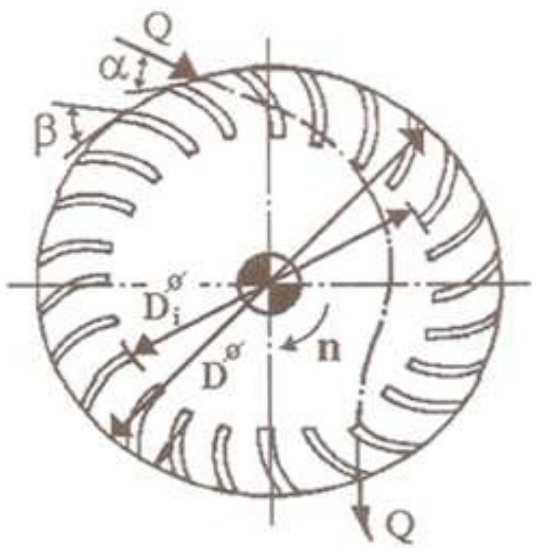

(b)

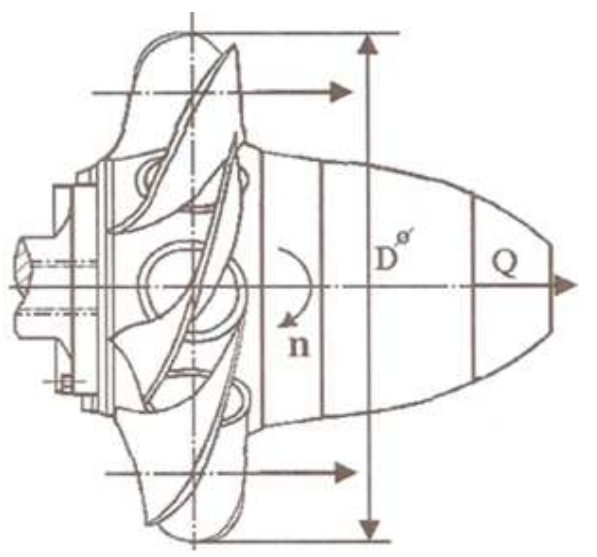

(d)

Figura 3.3 - Geometria dos rotores das turbinas hidráulicas: (a) turbina Pelton; (b) turbina MichelBanki; (c) turbina Francis; (d) turbina axial-hélice e Kaplan. Fonte: referência [12]. 
Além das turbinas apresentadas existem outros tipos de turbinas que, em geral, são variações das turbinas convencionais. Existem alternativas de turbinas de pequenos fabricantes da região amazônica como a turbina Turbo Silva, a turbina Idalma e a turbina com caixa espiral feita pelo processo "barro perdido", como mostrado na referência [13]. Existem também as rodas Pelton que apresentam o modelo da turbina Pelton, mas não apresentam a tecnologia empregada na sua fabricação.

Outra solução alternativa é a utilização de bomba centrífuga funcionando como turbinas. A principal vantagem é o fato de ser fabricada em série possibilitando a redução do custo. Não demanda mão de obra especializada para manutenção, a instalação é simples e apresentam robustez. Por outro lado possui rendimento um pouco inferior às turbinas tradicionais, não possui dispositivo de controle hidráulico e não permite variações de carga.

Uma alternativa para locais onde há grande vazão e baixa queda é a utilização de turbinas hidrocinéticas. A utilização dessa turbina elimina a necessidade de construção de barragem, de sistema de adução e de sistema de restituição. A figura 3.4 apresenta uma turbina hidrocinética desenvolvida pela Universidade de Brasília e possuí capacidade máxima de $2 \mathrm{~kW}$.

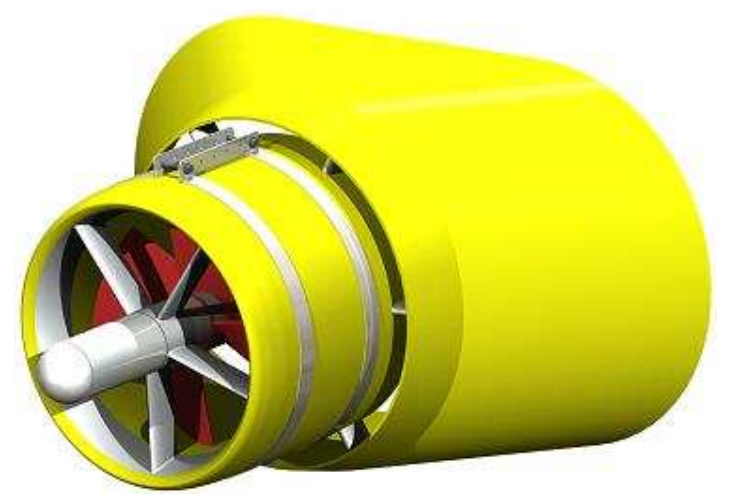

Figura 3.4 - Turbina hidrocinética desenvolvida pela UnB. Fonte: <http://www.noticiasdaamazonia.com.br/>

A figura 3.5 apresenta o campo de aplicação das turbinas hidráulicas utilizadas em CGHs com altura máxima de $200 \mathrm{~m}$ e vazão máxima de $7 \mathrm{~m} / \mathrm{s}$, tendo como base as informações apresentadas nas referências [4] e [5]. A partir do valor da altura bruta e da vazão de projeto é possível determinar uma turbina que apresente um campo de aplicação adequado ao aproveitamento em análise. A figura 3.5 também apresenta a relação entre a potência hidráulica disponível, a altura bruta e a vazão de projeto. 


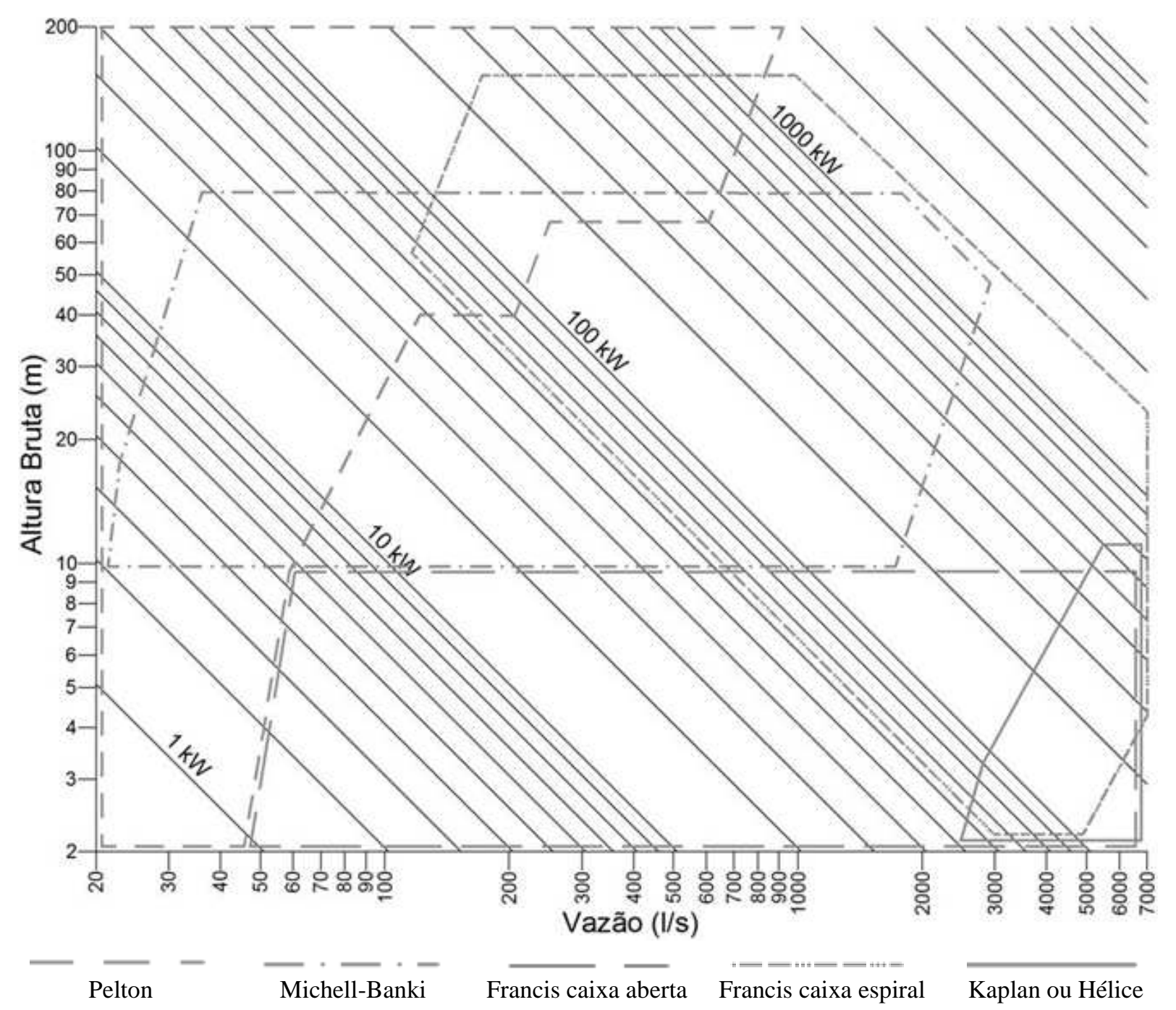

Figura 3.5 - Campo de aplicação das turbinas hidráulicas. Fonte: referências [4] e [5].

\subsubsection{Geradores elétricos}

Os geradores elétricos utilizados em CGHs podem ser síncronos ou de indução. A especificação básica de um gerador elétrico é a potência nominal. A potência elétrica ativa será determinada pela potência mecânica e pelo rendimento do gerador. A potência elétrica reativa é determinada pelo fator de potência da carga e é controlada, nos casos dos geradores síncronos, pela corrente de campo.

A máquina mais utilizada para essa aplicação é a máquina síncrona. A máquina de indução é a máquina mais robusta, mais utilizada na indústria e pode funcionar como motor e como gerador, porém é raramente usada como um gerador fornecendo energia elétrica para uma carga [10].

O fluxo de potência reativa não é invertido quando a máquina de indução opera como gerador. A potência reativa necessária para produzir o campo magnético não pode ser fornecida pela máquina primária, nem pelo rotor em gaiola de esquilo. A máquina de indução, 
dessa forma, somente pode operar fornecendo potência ativa se conectada a uma fonte externa de potência reativa. [3]

\subsection{Proteção e monitoramento}

Em uma CGH, deve ser previsto um sistema de proteção com a capacidade de retirar de operação o grupo gerador quando o sistema estiver em condições anormais de operação. A Eletrobrás [6] propõe, para a redução de custos, apenas a utilização das funções de proteção presentes na tabela 3.1 [12].

O sistema de monitoramento da CGH pode ser simplificado contendo apenas o mecanismo de desligamento automático e sinalização, visando à redução de custos [12]. Devem ser previstos medidores de tensão, corrente, potência e freqüência para facilitar a inspeção da CGH.

Tabela 3.1 - Função de proteção para CGHs. Fonte: referência [12].

\begin{tabular}{l|c|c|c}
\multicolumn{1}{c|}{ Proteção } & $\begin{array}{c}\text { Função } \\
\text { ANSI }\end{array}$ & $\begin{array}{c}<\mathbf{3 0 0} \\
(\boldsymbol{k W})\end{array}$ & $\begin{array}{c}\mathbf{3 0 0 - 1 0 0 0} \\
(\boldsymbol{k W})\end{array}$ \\
\hline Sobrecorrente & $51 \mathrm{~V}$ & & $\times$ \\
\hline Sobrecarga & 49 & $\times$ & $\times$ \\
\hline Seqüência negativa & 46 & & $\times$ \\
\hline Sobretensão & 59 & & $\times$ \\
\hline Diferencial em bloco & $87 \mathrm{GT}$ & & $\times$ \\
\hline Sobrecorrente de neutro & $51 \mathrm{G}$ & & $\times$ \\
\hline Disjuntor & 53 & $\times$ & $\times$
\end{tabular}

\subsection{Conclusões}

O capítulo 3 apresentou os principais aspectos construtivos e equipamentos das CGHs. Como mostrado nesse capítulo, existem diversas alternativas para a concepção de uma CGH. Essas alternativas variam de acordo com as condições físicas do terreno e do manancial analisado. A determinação dos componentes do arranjo também pode variar de acordo com a região, a disponibilidade de materiais, a utilização da energia gerada pela CGH e o perfil do empreendedor.

É importante considerar que a escolha de cada arranjo terá reflexo no custo e no benefício da CGH. Dessa forma deve ser realizada uma análise econômica para determinar a escolha do arranjo e da potência instalada que maximize o resultado econômico do empreendimento. 


\section{ANÁLISE DE VIABILIDADE ECONÔMICA}

Este capítulo apresenta a determinação do potencial hidráulico disponível, a estimativa do rendimento de cada componente, a estimativa de custo e a estimativa do benefício da CGH. Posteriormente serão apresentados dois desenvolvimentos para a realização do estudo de viabilidade econômica de uma CGH.

\subsection{Energia e potência}

A energia hidráulica disponível pode ser determinada pela energia potencial da água e, para as CGHs com utilização de turbinas hidrocinéticas, é determinada pela energia cinética da água. A energia hidráulica disponível $-E_{B}$ - é dada pela equação (4.1), sendo assim a potência hidráulica disponível pode ser determinada pela equação (4.2). Para a determinação da energia cinética, a energia hidráulica disponível é dada pela equação (4.3) e a potência disponível pode ser determinada pela equação (4.4). [12]

$$
\begin{gathered}
E_{B}=m(t) \cdot g \cdot H_{B} \\
P_{B}=\frac{d}{d t}(E)=\dot{m} \cdot g \cdot h \Leftrightarrow P_{B}=\rho \cdot Q \cdot g \cdot H_{B}
\end{gathered}
$$

$>\mathrm{E}_{\mathrm{B}}-$ Energia disponível;

$>\mathrm{g}$ - Aceleração da gravidade;

$>\mathrm{H}_{\mathrm{B}}-$ Altura bruta;

$>\mathrm{m}$ - Massa da água;

$>\mathrm{P}_{\mathrm{B}}-$ Potência disponível;

$>\mathrm{t}$ - Tempo;

$>\rho$-Densidade da Água.

$$
\begin{gathered}
E_{B}=\frac{m(t) \cdot v^{2}}{2} \\
P_{B}=\frac{d}{d t}(E)=\frac{d}{d t}(m) \cdot \frac{v^{2}}{2}=\frac{\rho \cdot v \cdot A \cdot v^{2}}{2} \Leftrightarrow P_{B}=\frac{\rho \cdot A \cdot v^{3}}{2}
\end{gathered}
$$

$>$ A - Área da sessão transversal atravessada pela água;

$>\mathrm{v}$ - Velocidade do escoamento da água.

Para as CGHs que utilizam turbinas de reação, a altura bruta é o desnível entre o nível d'água do sistema de adução e do sistema de restituição. Para as CGHs que utilizam turbinas de ação deve ser considerada a altura entre o sistema de adução e o injetor da turbina.

Entretanto, devem ser consideradas as perdas de energia em cada parte do arranjo estudado. Considerando a perda total do aproveitamento, equação (4.5), é possível determinar 
um valor para o rendimento total do aproveitamento que relaciona a potência hidráulica disponível e a potência elétrica gerada. Então a potência elétrica gerada é determinada pela equação (4.6).

$$
\begin{gathered}
P_{p_{a p}}=P_{B}-P_{e l} \\
P_{e l}=\eta_{a p} . P_{B}
\end{gathered}
$$

$>\mathrm{P}_{\mathrm{p}_{\mathrm{ap}}}$ - Potência perdida total do aproveitamento;

$>\mathrm{P}_{\mathrm{el}}$ - Potência elétrica gerada;

$>\eta_{\text {ap }}-$ Rendimento total do aproveitamento.

A potência perdida total do aproveitamento é a soma das perdas do sistema de adução, das perdas internas da turbina hidráulica, das perdas mecânicas e das perdas do gerador, conforme a equação (4.7). Dessa forma o rendimento total do aproveitamento pode ser determinado pela equação (4.8). [12]

$$
P_{p_{a p}}=P_{p_{s a}}+P_{p_{i}}+P_{p_{m}}+P_{p_{g}}
$$

$>\mathrm{P}_{\mathrm{p}_{\mathrm{ap}}}$ - Potência perdida total do aproveitamento;

$>\mathrm{P}_{\mathrm{p}_{\mathrm{sat}}}$ - Perdas do sistema de adução (tubulação);

$>\mathrm{P}_{\mathrm{p}_{\mathrm{sac}}}$ - Perdas do sistema de adução (canal);

$>\mathrm{P}_{\mathrm{p}_{\mathrm{i}}}-$ Perdas internas da turbina hidráulica;

$>\mathrm{P}_{\mathrm{p}_{\mathrm{m}}}$ - Perdas de mecânicas;

$>\mathrm{P}_{\mathrm{p}_{\mathrm{g}}}$ - Perdas do gerador.

$$
\eta_{a p}=\eta_{s a t} \cdot \eta_{s a c} \cdot \eta_{i} \cdot \eta_{m} \cdot \eta_{g}
$$

$>\eta_{\text {ap }}-$ Rendimento total do aproveitamento;

$>\eta_{\text {sat }}$ - Rendimento do sistema de adução (tubulação);

$>\eta_{\text {sac }}$ - Rendimento do sistema de adução (canal de escoamento livre);

$>\eta_{\mathrm{i}}$ - Rendimento interno da Turbina Hidráulica;

$>\eta_{\mathrm{m}}$ - Rendimento mecânico;

$>\eta_{\mathrm{g}}-$ Rendimento do gerador.

Para a determinação da energia gerada em uma CGH deve ser considerado que, ao longo do período analisado, a CGH pode gerar uma potência elétrica inferior à potência elétrica nominal. O fator de capacidade de uma CGH relaciona a potência instalada e a potência média gerada, como mostra a equação (4.9).

$$
f_{c}=\frac{P_{m}}{P_{i}}
$$


$>\mathrm{P}_{\mathrm{i}}-$ Potência instalada;

$>\mathrm{P}_{\mathrm{m}}$ - Potência média gerada;

$>\mathrm{f}_{\mathrm{c}}-$ Fator de capacidade;

Considerando a equação (4.2), e que a densidade da água é, aproximadamente, 1.000 $\mathrm{kg} / \mathrm{m}^{3}$, a potência elétrica gerada em uma CGH, em $k W$, pode ser definida pela equação (4.10). Para $\mathrm{t}$ em horas e considerando o fator de capacidade da CGH, equação (4.9), a equação (4.11) mostra a energia elétrica gerada por uma CGH em $k W h$.

$$
\begin{aligned}
& P_{e l(k W)}=\eta_{a p} \cdot Q \cdot g \cdot H_{B}(k W) \\
& E_{e l(k W h)}=P_{e l(k W)} \cdot t \cdot f_{c}(k W h)
\end{aligned}
$$

$>\mathrm{t}_{\text {(horas) }}-$ Tempo em horas.

$>\mathrm{P}_{\mathrm{el}(k W)}$ - Potência elétrica gerada $(k W)$;

$>\mathrm{E}_{\mathrm{el}(k W h)}$ - Energia elétrica gerada $(k W h)$.

Como mostrado na equação (4.8) o rendimento total do aproveitamento depende do rendimento de cada componente do arranjo da CGH. A estimativa inicial do valor do rendimento de cada componente do arranjo de uma $\mathrm{CGH}$ pode ser determinada pelos valores de rendimento mostrados na tabela 4.1 .

Tabela 4.1 - Valores típicos de rendimento. Fonte: referência [12].

\begin{tabular}{c|c}
$\boldsymbol{\eta}_{\text {sat }}-$ Rendimento do sistema de adução (tubulação) \\
\hline $\mathrm{L} \leq 80$ & $0,98<\eta_{\text {sat }} \leq 1,00$ \\
\hline $80<\mathrm{L} \leq 300$ & $0,97<\eta_{\text {sat }} \leq 0,98$ \\
\hline $300<\mathrm{L} \leq 800$ & $0,96<\eta_{\text {sat }} \leq 0,97$ \\
\hline $800<\mathrm{L}$ & $\eta_{\text {sat }}=0,95$ \\
\hline$\eta_{\text {sac }}-$ Rendimento do sistema de adução (canal de escoamento livre) \\
\hline \multicolumn{2}{c}{$0,99 \leq \eta_{\text {sac }} \leq 1,00$} \\
\hline$\eta_{\mathbf{i}}-$ Rendimento interno da Turbina Hidráulica \\
\hline Hidrocinética & $0,30<\eta_{\mathbf{i}} \leq 0,60$ \\
\hline Michell - Banki e Turgo & $0,50<\eta_{i} \leq 0,85$ \\
\hline Pelton Francis Kaplan & $0,75<\eta_{i} \leq 0,97$ \\
\hline \multicolumn{2}{c}{$0,90<\eta_{\mathrm{m}} \leq 0,98$} \\
\hline
\end{tabular}

L - Comprimento da tubulação $(m)$; 
Como pode ser observado na figura 4.1 (a), o rendimento da turbina varia de acordo com a variação da altura e da potência elétrica gerada. A variação da potência gerada também altera o rendimento do gerador, conforme a figura 4.1 (b). Dessa forma, a figura 4.1 mostra a variação do rendimento da turbina e do gerador em função do ponto de operação do sistema. As expressões apresentadas na tabela 4.2, determinam o limite inferior de operação em virtude da queda do rendimento, em função da vazão com o distribuidor completamente aberto, para cada tipo de turbina.

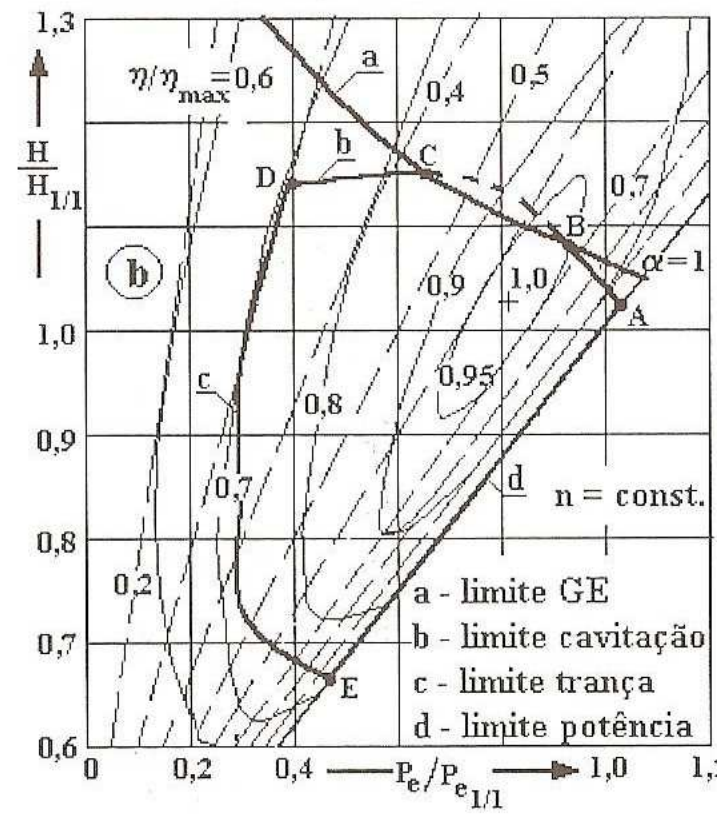

(a)

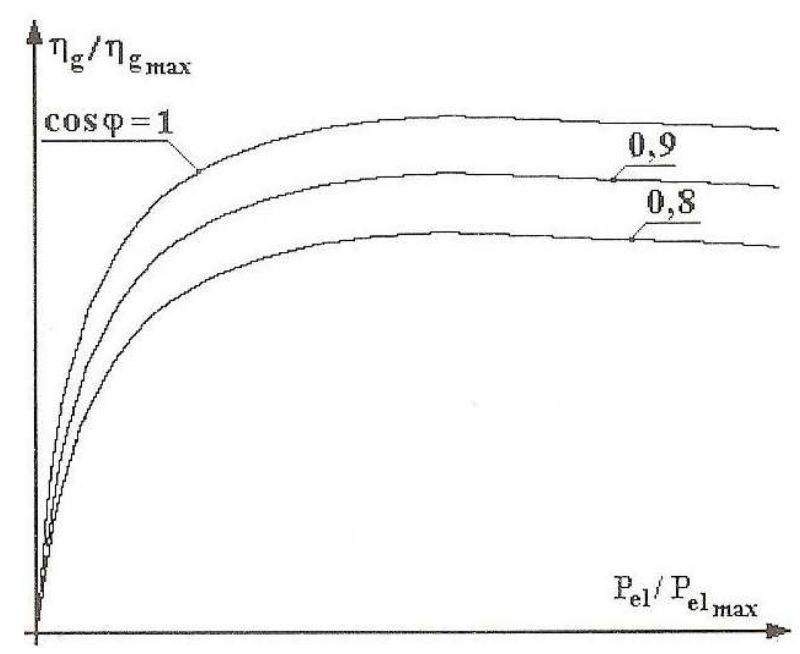

(b)

Figura 4.1 - Variação do rendimento do grupo gerador: (a) rendimento da turbina; (b) rendimento do gerador. Fonte: referência [12].

Tabela 4.2 - Limite inferior de operação. Fonte: referência [12].

\begin{tabular}{l|c}
\multicolumn{1}{c|}{ Turbina } & Expressão para a determinação da vazão mínima \\
\hline Pelton & $Q_{i}=0,25 \times Q_{1 / 1}$ \\
\hline Michell-Banki & $Q_{i}=0,45 \times Q_{1 / 1}$ \\
\hline Francis & $Q_{i}=\left(0,248+2,714.10^{-3} \times n_{q A}-3,403.10^{-6} \times n_{q A}^{2}\right) \times Q_{1 / 1}$ \\
\hline $\begin{array}{l}\text { Axial hélice com distribuidor } \\
\text { fixo }\end{array}$ & $Q_{i}=0,88 \times Q_{1 / 1}$ \\
\hline $\begin{array}{l}\text { Axial hélice com distribuidor } \\
\text { móvel }\end{array}$ & $Q_{i}=0,81 \times Q_{1 / 1}$ \\
\hline $\begin{array}{l}\text { Axial Kaplan com } \\
\text { distribuidor fixo }\end{array}$ & $Q_{i}=0,71 \times Q_{1 / 1}$ \\
\hline $\begin{array}{l}\text { Axial Kaplan com } \\
\text { distribuidor móvel }\end{array}$ & $Q_{i}=0,25 \times Q_{1 / 1}$
\end{tabular}


$n_{q A}=10^{3} \times n \times \frac{\mathrm{Q}_{1 / 1}{ }^{0,5}}{9,81 \times H_{b}{ }^{0,75}} ;$

$>n$ - Rotação (rpm);

$>\mathrm{n}_{\mathrm{qA}}-$ Rotação específica da turbina no sistema internacional de unidades;

$>\mathrm{Q}_{\mathrm{i}}$ - Vazão mínima;

$>\mathrm{Q}_{1 / 1}$ - Vazão para o distribuidor todo aberto;

Nas análises de viabilidade econômica apresentadas nesse trabalho, é considerado o limite inferior de operação da turbina, porém, para simplificação da análise, é desconsiderada a redução do rendimento do grupo gerador em função do ponto de operação.

\subsection{Análise preliminar do custo}

A maior parcela do custo de uma CGH é o investimento inicial. O investimento inicial engloba o custo dos estudos iniciais, do desenvolvimento, de engenharia, da aquisição de equipamentos, da aquisição de materiais e da execução das obras. Após a entrada em operação, o custo é basicamente a manutenção dos equipamentos e a operação da CGH. A estimativa de custo utilizada nesse trabalho engloba o investimento inicial e o total gasto com a manutenção e a operação.

Para estudos preliminares, pode-se determinar a estimativa do custo da aquisição de equipamentos, da aquisição de materiais e da execução das obras conforme as equações mostradas na tabela 4.3, que utiliza as dimensões do arranjo básico da CGH. É importante ressaltar que essa tabela é uma estimativa de custo para Pequena Central Hidrelétrica - PCH e é utilizada nesse trabalho como uma indicação de preço.

As estimativas de custo presentes na tabela 4.3 são referentes a janeiro de 1998. Nesse trabalho, para corrigir esses valores, é utilizado o Índice Nacional de Custo da Construção INCC - disponível na referência [14]. Esse índice é elaborado pela Fundação Getúlio Vargas e apura a evolução dos custos no setor da construção civil. De acordo com o INCC o custo da construção civil em junho de 2010 é $273 \%$ do custo referente a janeiro de 1998.

Atualmente, o custo de construção de CGHs encontra-se na faixa de R \$ 5.000,00 por quilowatt instalado. Com base nos custos de diversas CGHs é possível definir um custo médio percentual para cada componente ou, pelo menos, para cada categoria de atividades e equipamentos. [13] 
Tabela 4.3 - Estimativa de custo para PCH. Fonte: referência [12]

\begin{tabular}{|c|c|c|c|}
\hline Item & Variáveis & Custo $(R \$)-01 / 98$ & Custo $(R \$)-06 / 10$ \\
\hline \multicolumn{4}{|c|}{ Sistema de captação } \\
\hline Desvio do rio & he, Le & $39,85 \times h_{e} \times L_{e}$ & $108,85 \times h e \times L e$ \\
\hline Barragem de concreto & $\mathrm{hb}, \mathrm{Lb}$ & $196,23 \times h_{b} \times L_{b}$ & $536,03 \times h b \times L b$ \\
\hline Tomada d'água & Q & $4.428,54 \times Q$ & $12096,96 \times Q$ \\
\hline Comporta e grade & Q & $9,70 \times Q^{2}+167,90 \times Q+700$ & $\begin{aligned} & 26,50 \times Q^{2}+458,63 \times Q \\
&+1912,11 \\
&\end{aligned}$ \\
\hline \multicolumn{4}{|c|}{ Sistema de adução } \\
\hline Canal de adução & $\mathrm{Q}, \mathrm{L}_{\mathrm{c}}$ & $33,92 \times Q \times L_{c}$ & $92,67 \times Q \times L_{c}$ \\
\hline Câmara de carga & $Q$ & $5.146,17 \times Q$ & $14.057,22 \times Q$ \\
\hline $\begin{array}{l}\text { Tubulação da adução em baixa } \\
\text { pressão }\end{array}$ & $\mathrm{Q}, \mathrm{L}_{\mathrm{bp}}$ & $161,15 \times Q \times L_{b p}$ & $440,18 \times Q \times L_{b p}$ \\
\hline $\begin{array}{l}\text { Bloco de concreto para tubulação } \\
\text { da adução em baixa pressão }\end{array}$ & $\mathrm{L}_{\mathrm{bp}}$ & $3,45 \times L_{b p}$ & $9,45 \times L_{b p}$ \\
\hline Chaminé de Equilíbrio & $Q$ & $1.679,93 \times Q$ & $4.588,88 \times Q$ \\
\hline $\begin{array}{l}\text { Tubulação da adução em alta } \\
\text { pressão }\end{array}$ & $\mathrm{Q}, \mathrm{L}_{\mathrm{ap}}$ & $170,09 \times Q \times L_{a p}$ & $464,62 \times Q \times L_{a p}$ \\
\hline $\begin{array}{l}\text { Blocos de concreto para tubulação } \\
\text { da adução em alta pressão }\end{array}$ & $\mathrm{Q}, \mathrm{L}_{\mathrm{ap}}$ & $56,35 \times Q \times L_{a p}$ & $153,93 \times Q \times L_{a p}$ \\
\hline \multicolumn{4}{|c|}{ Grupo gerador } \\
\hline Turbina hidráulica e volante & $\mathrm{P}_{\mathrm{el}(k W)}$ & $116,87 \times P_{e l(k W)}$ & $319,24 \times P_{e l(k W)}$ \\
\hline Regulador de velocidade & $\mathrm{P}_{\mathrm{el}(k W)}$ & $59,29 \times P_{e l(k W)}$ & $161,97 \times P_{e l(k W)}$ \\
\hline Válvula & $\mathrm{P}_{\mathrm{el}(k W)}$ & $17,52 \times P_{e l(k W)}$ & $47,87 \times P_{e l(k W)}$ \\
\hline Gerador elétrico & $\mathrm{P}_{\mathrm{el}(k W)}$ & $168,58 \times P_{e l(k W)}$ & $460,50 \times P_{e l(k W)}$ \\
\hline Quadro de comando & $\mathrm{P}_{\mathrm{el}(k W)}$ & $36,59 \times P_{e l(k W)}$ & $99,93 \times P_{e l(k W)}$ \\
\hline \multicolumn{4}{|c|}{ Sistema elétrico } \\
\hline Sistema de Proteção & $\mathrm{P}_{\mathrm{el}(k W)}$ & $12,65 \times P_{e l(k W)}$ & $34,55 \times P_{e l(k W)}$ \\
\hline Subestação & $\mathrm{P}_{\mathrm{el}(k W)}$ & $71,58 \times P_{e l(k W)}$ & $195,53 \times P_{e l(k W)}$ \\
\hline Linha de transmissão & $\mathrm{L}_{\mathrm{lt}}, \mathrm{P}_{\mathrm{el}}$ & $0,0073 \times L_{l t} \times P_{e l(k W)}$ & $0,0199 \times L_{l t} \times P_{e l(k W)}$ \\
\hline \multicolumn{4}{|c|}{ Outras estruturas } \\
\hline Casa de maquina & $\mathrm{P}_{\mathrm{el}(k W)}$ & $40,44 \times P_{e l(k W)}$ & $110,48 \times P_{e l(k W)}$ \\
\hline Canal de fuga & $\mathrm{Q}, \mathrm{L}_{\mathrm{cf}}$ & $34,17 \times Q \times L_{\text {caf }}$ & $93,33 \times Q \times L_{c a f}$ \\
\hline \multicolumn{4}{|c|}{ Outros } \\
\hline Terreno & CUT, $A_{\text {te }}$ & $C U T \times A_{t e}$ & CUT $\times$ Ate \\
\hline Operação e Manutenção & $\mathrm{P}_{\mathrm{el}(\mathrm{kW})}, \mathrm{C}_{\mathrm{ch}}$ & $\begin{aligned} 24.414+1,73 \times & P_{e l(k W)} \\
& +0,00793 \\
& \times C_{c h}\end{aligned}$ & $\begin{aligned} 66.652+4,73 \times & P_{e l(k W)} \\
& +0,0216 \\
& \times C_{c h}\end{aligned}$ \\
\hline
\end{tabular}

$>\mathrm{h}_{\mathrm{e}}-$ Altura da ensecadeira $(m)$;

$>\mathrm{L}_{\mathrm{e}}$ - Comprimento da ensecadeira $(m)$;

$>\mathrm{h}_{\mathrm{b}}$ - Altura da barragem $(m)$;

$>\mathrm{L}_{\mathrm{b}}$ - Comprimento da barragem $(m)$;

$>\mathrm{L}_{\mathrm{c}}-$ Comprimento da adução em alta pressão $(m)$;

$>\mathrm{L}_{\mathrm{bp}}$ - Comprimento do conduto em baixa pressão $(m)$;

$>\mathrm{L}_{\mathrm{ap}}$ - Comprimento do conduto em alta pressão $(m)$;

$>\mathrm{L}_{\mathrm{lt}}$ - Comprimento da linha de transmissão $(m)$;

$>\mathrm{A}_{\mathrm{te}}$ - Área do terreno utilizado $(h a)$;

$>$ CUT - Custo por unidade de terreno $(R \$ / h a)$;

$>\mathrm{C}_{\mathrm{ch}}-$ Custo total da $\mathrm{CGH}(R \$)$. 
Esse valor corrigido com o INCC para junho de 2010 é de $\mathrm{R} \$ 5.500,00$ e é utilizado como uma referência de preço por unidade de potência instalada nesse trabalho. A tabela 4.4 apresenta os custos percentuais médios de cada item das CGHs. A partir dos dados disponíveis na tabela 4.4 é possível determinar que os custos referentes aos estudos iniciais, ao desenvolvimento, à engenharia e aos outros é $33 \%$ do custo total da CGH. O custo referente a esses itens é considerado na determinação da estimativa de custo. A inserção referente a esse custo será efetuada dividindo a estimativa de custo calculada na tabela 4.3 por um índice de 0,67 , que é equivalente a somar esses itens ao custo total.

Tabela 4.4 - Custos percentuais médios das CGHs. Fonte: referência [13].

\begin{tabular}{|c|c|c|c|}
\hline DESCRIÇÃO & $\begin{array}{c}\text { CUSTO } \\
(\%)\end{array}$ & DESCRIÇÃO & $\begin{array}{c}\text { CUSTO } \\
(\%)\end{array}$ \\
\hline \multicolumn{2}{|l|}{ ESTUDOS INICIAIS } & \multicolumn{2}{|l|}{ EQUIPAMENTO DE GERAÇÃO } \\
\hline Investigação do local & $1,00 \%$ & Turbinas, geradores, reguladores, painéis & $22,00 \%$ \\
\hline Estudo hidrológico & $0,50 \%$ & Instalação dos equipamentos & $3,00 \%$ \\
\hline Avaliação ambiental & $1,00 \%$ & Transporte & $2,00 \%$ \\
\hline Projeto básico & $1,00 \%$ & Subtotal 4 & $27 \%$ \\
\hline Estimativa de custos & $0,30 \%$ & \multicolumn{2}{|l|}{ ESTRUTURAS DIVERSAS } \\
\hline Preparação de relatórios & $0,20 \%$ & Estrada de acesso & $5,00 \%$ \\
\hline Gerenciamento do projeto & $1,00 \%$ & Barragem & $9,00 \%$ \\
\hline Passagens e diárias & $0,60 \%$ & Canal de adução & $4,00 \%$ \\
\hline Subtotal 1 & $5,60 \%$ & Tomada d'água & $2,00 \%$ \\
\hline \multicolumn{2}{|c|}{ DESENVOLVIMENTO } & Tubulação & $5,00 \%$ \\
\hline Negociação do PPA & $0,50 \%$ & Casa de máquinas & $3,00 \%$ \\
\hline Licenças & $0,50 \%$ & Subestação e linha de transmissão & $10,00 \%$ \\
\hline Levantamentos geológicos & $0,60 \%$ & Transporte & $2,00 \%$ \\
\hline Gerenciamento do projeto & $0,70 \%$ & Subtotal 5 & $40,00 \%$ \\
\hline Passagens e diárias & $0,60 \%$ & \multicolumn{2}{|l|}{ OUTROS } \\
\hline Subtotal 2 & $2,90 \%$ & "Overhead" do contratante & $5,00 \%$ \\
\hline \multicolumn{2}{|l|}{ ENGENHARIA } & Treinamento & $0,50 \%$ \\
\hline Projeto executivo & $3,00 \%$ & Contingências & $12,00 \%$ \\
\hline Contratação & $1,00 \%$ & Subtotal 6 & $17,50 \%$ \\
\hline Supervisão da construção & $3,00 \%$ & & \\
\hline Subtotal 3 & $7,00 \%$ & Total Geral & $100,00 \%$ \\
\hline
\end{tabular}

\subsection{Análise preliminar do benefício}

O principal benefício da implantação de uma CGH é a geração de energia. Aplicando a equação (4.10) na equação (4.11), determinando um período de tempo e uma tarifa de energia para o período considerado é possível determinar o benefício econômico da CGH analisada, no período correspondente, como mostra a equação (4.12) 


$$
B=\eta_{a p} \cdot Q \cdot g \cdot H_{B} \cdot t \cdot f_{c} \cdot T(R \$)
$$

T - Tarifa de energia $(R \$ / k W h)$;

$>\mathrm{B}$ - Benefício da CGH $(R \$)$.

Ao realizar a análise do benefício deve-se determinar a utilização dessa energia, pois a remuneração do benefício da geração de energia varia de acordo com a tarifa considerada. As diferenças entre a tarifa paga às concessionárias e a tarifa paga pela concessionária podem alterar, de forma significativa, o valor do benefício. A utilização da energia também reflete no fator de capacidade, alterando o valor do benefício.

\subsection{Relação entre o custo e benefício}

Em um sistema de geração isolado, a determinação da potência instalada deve levar em consideração a potência disponível, a energia disponível, a demanda, o crescimento da demanda e a possibilidade de utilização de outras fontes de energia. Em sistemas de geração interligados a rede e com a possibilidade de venda do excedente de energia gerada, a escolha deve levar em consideração a viabilidade econômica da geração de energia considerando as tarifas de mercado.

Analisando a equação (4.12), o aumento do rendimento, da vazão, da altura, do fator de capacidade e da tarifa resulta no aumento do benefício no período de tempo determinado, porém o aumento desses parâmetros pode resultar no aumento do investimento inicial. $\mathrm{O}$ aumento da vazão e da altura resulta diretamente no aumento da potência instalada, o que implica o aumento do custo. O aumento do rendimento, em geral, resulta no aumento do valor dos componentes do arranjo. O aumento da altura é limitado pelas características do terreno e pode resultar no aumento do comprimento do sistema de adução, provocando o aumento do custo.

O aumento da vazão de projeto pode ser limitado pelas características hidrológicas do manancial e pode acarretar a diminuição do fator de capacidade. Isso ocorre devido à diminuição da probabilidade dessa vazão ser igualada ou superada à vazão do limite mínimo de operação da turbina, resultando na retirada de operação do grupo gerador nos períodos correspondentes. Além disso, no período em que o sistema estiver operando com a vazão abaixo da vazão nominal e acima da vazão mínima exigida, o rendimento do grupo gerador será reduzido gradativamente.

Fica evidente que a escolha do arranjo e da potência instalada deve ser feita após uma análise do custo, do benefício e do perfil do empreendedor. Deve-se levar em conta a variação 
do custo e do benefício para cada arranjo e para cada potência instalada e, posteriormente, utilizar indicadores econômicos que possibilitem a análise do empreendimento.

\subsection{Desenvolvimentos de análise de viabilidade econômica de CGH}

Nesse tópico são apresentados dois desenvolvimentos de análise de viabilidade econômica de CGHs. Primeiramente, é apresentado um desenvolvimento de análise com a utilização da curva de duração de vazões. Posteriormente, é apresentado outro desenvolvimento de análise que utiliza a série de vazões médias em um período hidrológico completo. Nesse desenvolvimento de análise as tarifas poderão variar ao longo do ano e com a utilização da energia. Os dois desenvolvimentos consideram que a CGH opera a fio d'água e possuí apenas um grupo gerador. São apresentadas funções e algoritmos no ambiente MATLAB para a realização do desenvolvimento proposto.

Para facilitar a apresentação dos desenvolvimentos de análise, é apresentado um exemplo de um aproveitamento fictício. Os três arranjos estão apresentados na figura 4.2, os dados referentes a cada arranjo estão apresentados na tabela 4.5 e a série de vazões médias mensais disponíveis estão apresentados na figura 4.3. Nessa análise, a tarifa da energia comprada é de $0,20 R \$ / k W h$ e a tarifa da energia vendida é de $0,16 R \$ / k W h$. Os valores das tarifas, para simplificação, são considerados constantes e são valores próximos aos valores das tarifas de mercado apresentados no capítulo 5.

Conforme apresentado na figura 4.2, os três arranjos estão localizados no mesmo trecho do manancial e apresentam a mesma altura bruta. As cotas a montante e a jusante são as mesmas para os três arranjos. O arranjo 1, figura 4.2 (a), é uma central hidrelétrica de represamento, o arranjo 2, figura 4.2 (b), é uma central hidrelétrica de desvio e o arranjo 3, figura 4.2 (c), é uma central hidrelétrica de derivação. Considerando a altura bruta do aproveitamento, as vazões características do manancial e os campos de aplicação das turbinas hidráulicas apresentados da figura 3.5, o grupo gerador escolhido possui uma turbina tipo Michell-Banki para os três arranjos. 


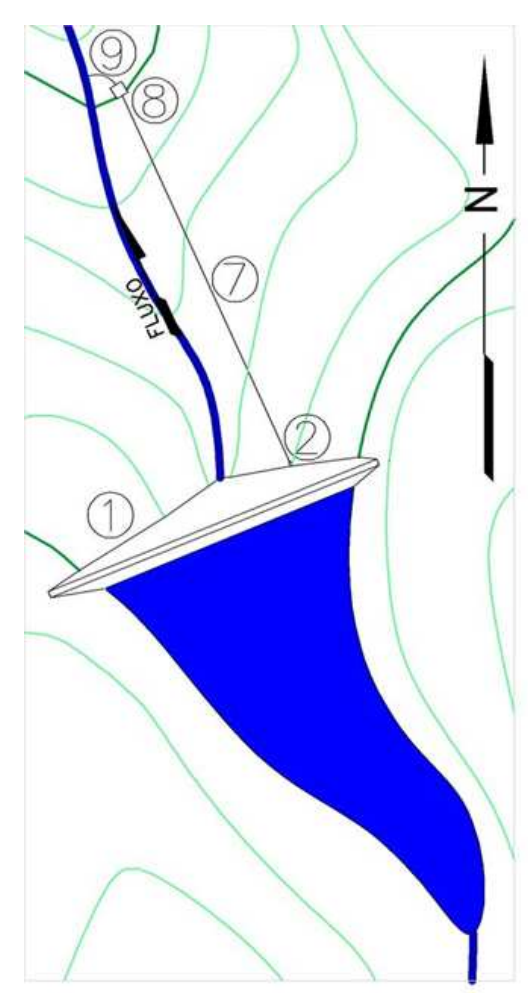

(a)

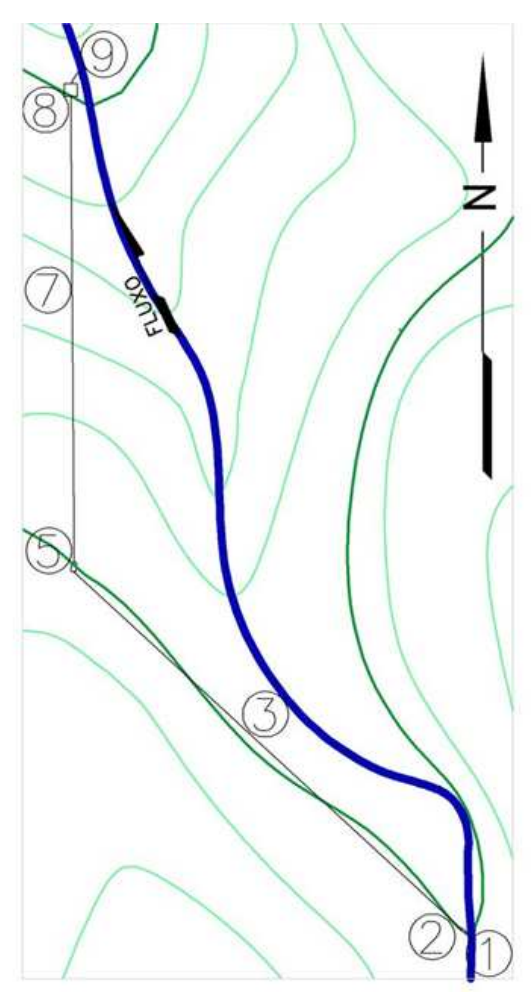

(b)

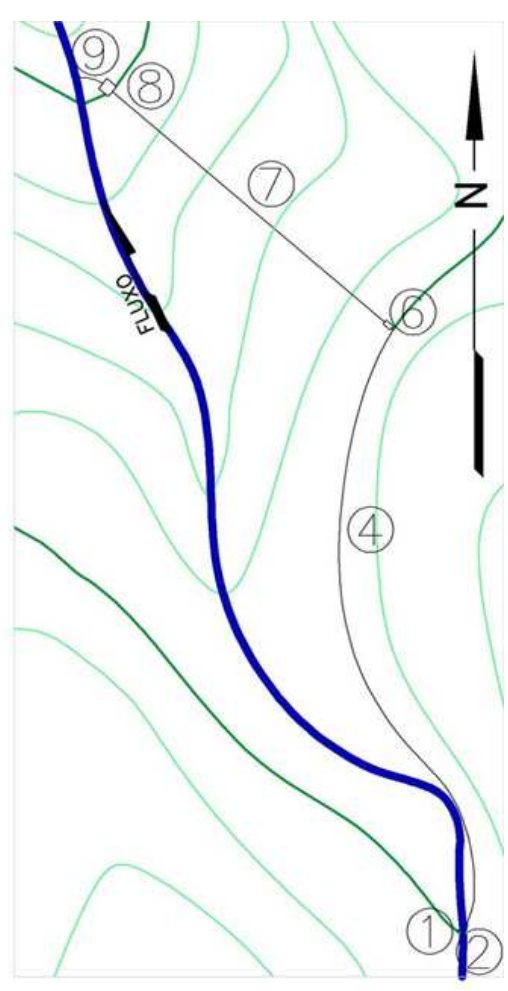

(c)

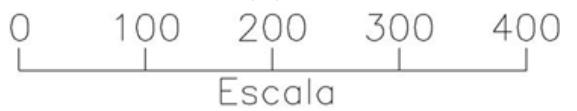

Legenda: 1 - represa; 2 - sistema de captação; 3 - tubulação de baixa pressão; 4 - canal de escoamento livre; 5 - chaminé de equilíbrio; 6 - câmara de carga; 7 - tubulação de alta pressão; 8 casa de máquina; 9 - sistema de restituição.

Figura 4.2 - Exemplo para apresentação dos desenvolvimentos de análise de viabilidade econômica de CGH: (a) Arranjo CHR; (b) Arranjo CHD; (c) Arranjo CHV.

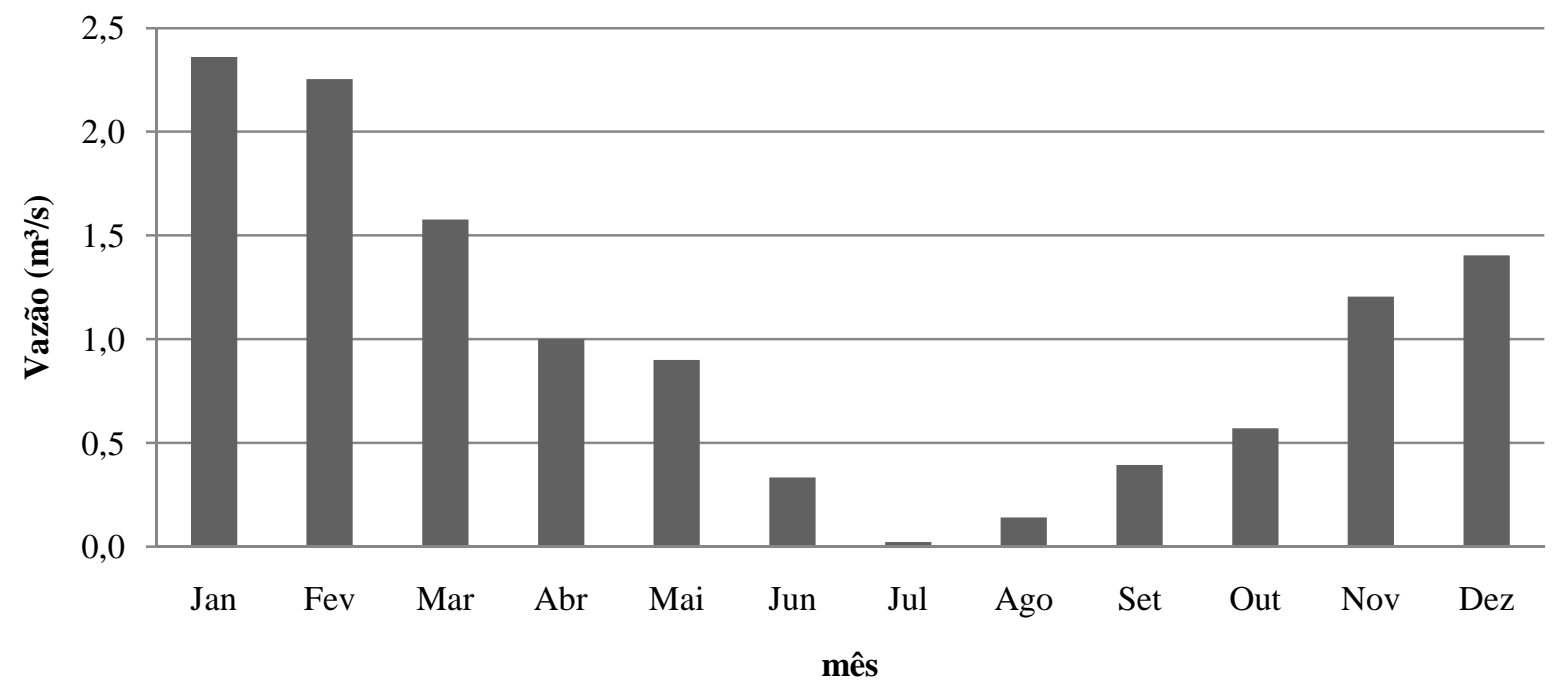

Figura 4.3 - Série de vazões médias mensais disponíveis do manancial do exemplo apresentado. 


\subsubsection{Dados necessários para realização dos desenvolvimentos de análise de viabilidade econômica}

Os dados necessários para a realização dos desenvolvimentos de análise econômica estão listados abaixo. A tabela 4.5 apresenta os dados utilizados para a realização da análise do exemplo apresentado. O apêndice I apresenta o arquivo Dados.m com as variáveis criadas para a utilização dos algoritmos utilizados.

Dados gerais:

- Número de arranjos;

- Tarifa de energia constante;

- Taxa de juros $(a a)$

- Horizonte da análise econômica (anos);

- Custo unitário do terreno $(R \$ / h a)$.

Dados variáveis para cada arranjo considerado. Os dados devem ser inseridos em um vetor linha onde cada coluna será correspondente a um determinado arranjo:

- Área utilizada do terreno $(h a)$;

- Cota a montante $(m)$;

- Cota a jusante $(m)$

- Tipo de arranjo (1 - CHR, 2 - CHD, 3 - CHV);

- Comprimento da adução em alta pressão;

- Comprimento da adução em baixa pressão;

- Rendimento da adução em alta pressão;

- Rendimento da adução em baixa pressão;

- Tipo de turbina (1 - Pelton, 2 - Michell-Banki, 3 - Francis, 4 - Axial hélice com distribuidor fixo, 5 - Axial hélice com distribuidor móvel, 6 - Axial Kaplan com distribuidor fixo, 7 - Axial Kaplan com distribuidor móvel);

- Rotação da turbina Francis (rpm);

- Rendimento da turbina;

- Rendimento do gerador;

- Tipo de barragem (1 - terra, 2 - concreto);

- Altura da ensecadeira $(m)$;

- Comprimento da ensecadeira $(m)$;

- Altura da barragem $(m)$;

- Comprimento da barragem $(m)$;

- Comprimento do canal de fuga $(m)$;

- Comprimento da linha de transmissão $(m)$.

Dados variáveis em cada período. Os dados devem ser inseridos em um vetor linha onde cada coluna será correspondente a um determinado período:

- Série das vazões médias disponíveis em um ciclo hidrológico completo $\left(\mathrm{m}^{3} / \mathrm{s}\right)$;

- Tarifa da energia comprada para cada mês;

- Tarifa da energia vendida para cada mês. 
Dados variáveis a cada hora. Os dados devem ser inseridos em um vetor linha. Cada coluna será correspondente a uma determinada hora do período hidrológico completo.

- Demanda.

Tabela 4.5 - Dados do exemplo apresentado.

\begin{tabular}{|c|c|c|c|}
\hline Descrição & \multicolumn{3}{|c|}{ Valor } \\
\hline Número de arranjos & \multicolumn{3}{|c|}{3} \\
\hline Tarifa de energia constante $(R \$ / k W h)$ & \multicolumn{3}{|c|}{0,16} \\
\hline $\begin{array}{l}\text { Tarifa de energia comprada para cada mês } \\
(R \$ / k W h)\end{array}$ & \multicolumn{3}{|c|}{0,20 (constante ao longo do ano) } \\
\hline $\begin{array}{l}\text { Tarifa de energia vendida para cada mês } \\
(R \$ / k W h)\end{array}$ & \multicolumn{3}{|c|}{0,16 (constante ao longo do ano) } \\
\hline Taxa de juros $(a a)$ & \multicolumn{3}{|c|}{0,12} \\
\hline Horizonte da análise econômica (anos) & \multicolumn{3}{|c|}{20} \\
\hline Custo unitário do terreno $(R \$ / h a)$ & \multicolumn{3}{|c|}{3000} \\
\hline Demanda da propriedade rural & \multicolumn{3}{|c|}{$100 \mathrm{~kW}$ (constante ao longo do ano) } \\
\hline Arranjo & Arranjo 1 & Arranjo 2 & Arranjo 3 \\
\hline Cota a montante $(\mathrm{m})$ & 925 & 925 & 925 \\
\hline Cota a jusante $(m)$ & 900 & 900 & 900 \\
\hline Tipo de Arranjo (CHR, CHD, CHV) & CHR & CHD & $\mathrm{CHV}$ \\
\hline Comprimento da adução em alta pressão $(m)$ & 347,58 & 367,8 & 282,37 \\
\hline Comprimento da adução em baixa pressão $(m)$ & - & 415 & 507,32 \\
\hline Rendimento da adução em alta pressão & 0,96 & 0,96 & 0,97 \\
\hline Rendimento da adução em baixa pressão & - & 0,96 & 0,99 \\
\hline Tipo de turbina & M.-Banki & M.-Banki & M.-Banki \\
\hline Rendimento da turbina & 0,70 & 0,70 & 0,70 \\
\hline Rendimento do gerador & 0,90 & 0,90 & 0,90 \\
\hline Altura da ensecadeira $(m)$ & 5 & 2 & 2 \\
\hline Comprimento da ensecadeira $(\mathrm{m})$ & 9 & 4 & 4 \\
\hline Tipo da barragem (Terra ou concreto) & Terra & Concreto & Concreto \\
\hline Altura da barragem $(\mathrm{m})$ & 13,00 & 3,00 & 3,00 \\
\hline Comprimento da barragem $(m)$ & 280,00 & 7,00 & 7,00 \\
\hline Comprimento do canal de fuga $(m)$ & 27,64 & 14,01 & 22,18 \\
\hline Área da barragem $(h a)$ & 4 & - & - \\
\hline Comprimento da linha de transmissão $(m)$ & 100 & 100 & 100 \\
\hline
\end{tabular}

\subsubsection{Vazão disponível}

Há algumas considerações importantes para a determinação da vazão disponível. Deve-se verificar se existe alguma captação de água a montante do sistema de captação da CGH. Além disso, deve ser considera a vazão remanescente, que é vazão mínima que deve ser vertida. A vazão disponível para o exemplo apresentado está mostrada na figura 4.3. 


\subsubsection{Curva de duração de vazão}

A curva de duração de vazão indica a probabilidade ou o tempo por unidade (pu) do período hidrológico completo no qual a vazão é mantida igual ou superior a uma determinada vazão. Nesse estudo é utilizado um período de um ano.

O apêndice II mostra uma função desenvolvida que calcula a curva de duração de vazões. A figura 4.4 mostra o gráfico obtido com a utilização dessa função tendo como entrada os dados presentes na figura 4.3. A função está apresentada abaixo.

Função:

- function [puCrescente, VazaoSuperada, $\mathrm{x}$, CurvaVazaoSuperada $]=$ Duracao(Vazao, grau) Entrada:

- Vazao - Série de vazões médias. Devem ser em períodos igualmente espaçados e durante um ciclo hidrológico completo.

- grau - Grau do polinômio utilizado na interpolação.

Etapas:

1. Calcula o número de períodos da série de vazões considerada.

2. Calcula a probabilidade de a vazão ser igualada ou superada e armazena esse dado no vetor pu.

3. Ordena os valores de pu em ordem crescente e cada respectivo valor de vazão.

4. Realiza uma interpolação para a determinação da curva.

Saída:

- $\mathrm{pu}$ - Valores por unidade do período hidrológico completo;

- VazaoSuperada - valores da vazão correspondente a cada valor de pu;

- $\quad \mathrm{x}$ - vetor com os valores de 0 a 1 com a resolução da curva de duração de vazão;

- CurvaDuracaoVazao - Curva de duração de vazão;

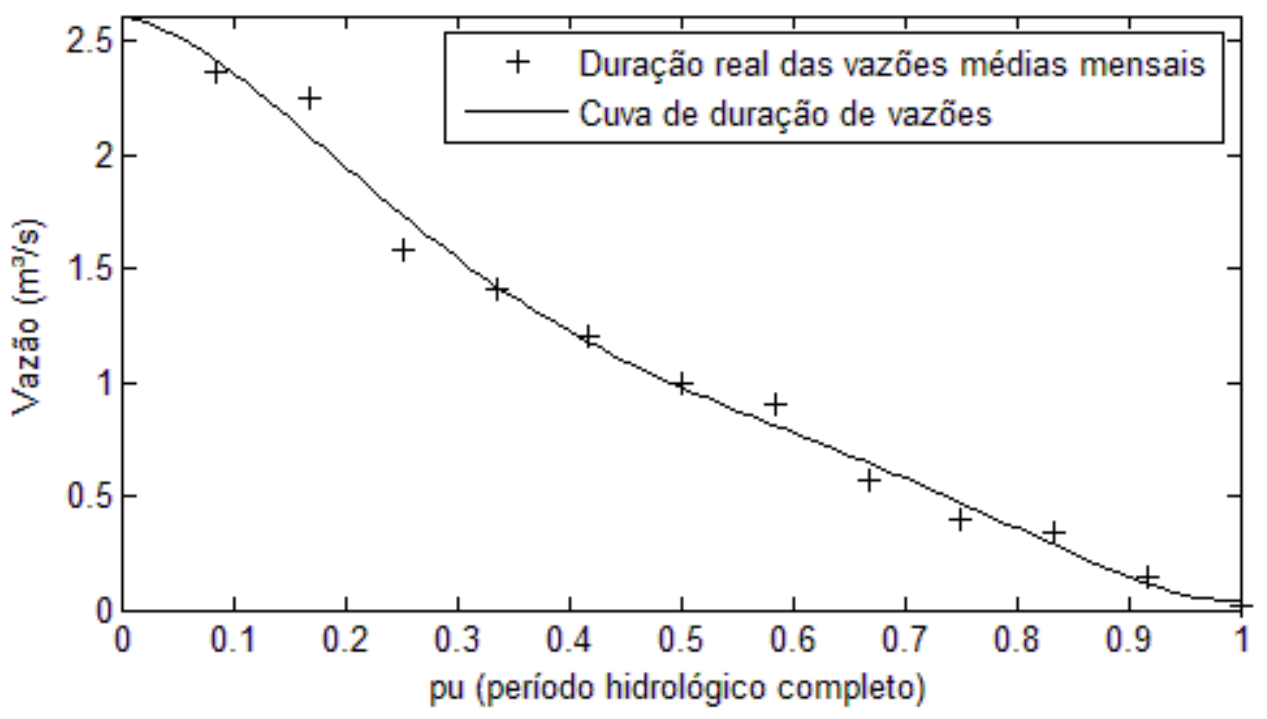

Figura 4.4 - Curva de duração de vazões do exemplo apresentado. 


\subsubsection{Estimativa de custo}

Os dois desenvolvimentos de análise utilizam a estimativa de custo conforme discutido no item 4.2. O apêndice III mostra uma função que realiza essa estimativa de custo, conforme apresentado abaixo.

Função:

function [EstimativaCusto] = EstimativaCusto(Q,Barragem,he,Le,hb,Lb,Arranjo, Lap, Lbp, Lcf, Pel,Llt,CUT,Ate)

Entradas:

- $\quad \mathrm{Q}$ - Vazão da $\mathrm{CH}\left(\mathrm{m}^{3} / \mathrm{s}\right)$;

- Barragem - Tipo de barragem (1 - terra, 2 - concreto)

- he - Altura da ensecadeira $(m)$;

- Le - Comprimento da ensecadeira $(m)$;

- hb - Altura da barragem $(m)$;

- $\quad$ Lb - Comprimento da barragem $(m)$;

- Arranjo - Tipo de arranjo (1 - CHR, 2 - CHD, 3 - CHV);

- Lap - Comprimento da adução em alta pressão;

- Lbp - Comprimento da adução em baixa pressão;

- Lcf - Comprimento do canal de fuga;

- Pel - Potência elétrica da CGH $(k W)$;

- $\mathrm{Lt}$ - Comprimento da linha de transmissão $(m)$;

- CUT - Custo por unidade de área $(R \$ / h a)$;

- Ate - Área utilizada $(h a)$.

Etapas:

- Calcula o custo do sistema de captação de acordo com o tipo de barragem;

- Calcula o custo do sistema de adução de acordo com o tipo de arranjo;

- Calcula o valor dos demais itens da tabela 4.3 exceto o custo com a operação e manutenção;

- Calcula o custo total considerando o custo com manutenção, os custos referentes aos estudos iniciais, ao desenvolvimento, a engenharia e a outros.

Saída:

- EstimativaCusto - Estimativa de custo da CGH.

\subsubsection{Análise de viabilidade econômica utilizando a curva de duração de vazões.}

A partir da curva de duração de vazões, figura 4.4, pode-se utilizar a equação (4.10) para estabelecer uma curva de duração de potência. Os valores de rendimento e altura bruta presentes na equação (4.10) podem variar para cada arranjo, portanto é conveniente determinar a curva de duração de potência para cada caso. As curvas de duração de potência, 
para o exemplo apresentado, estão mostradas na figura 4.5, porém essas curvas não consideram os limites operacionais do grupo gerador.

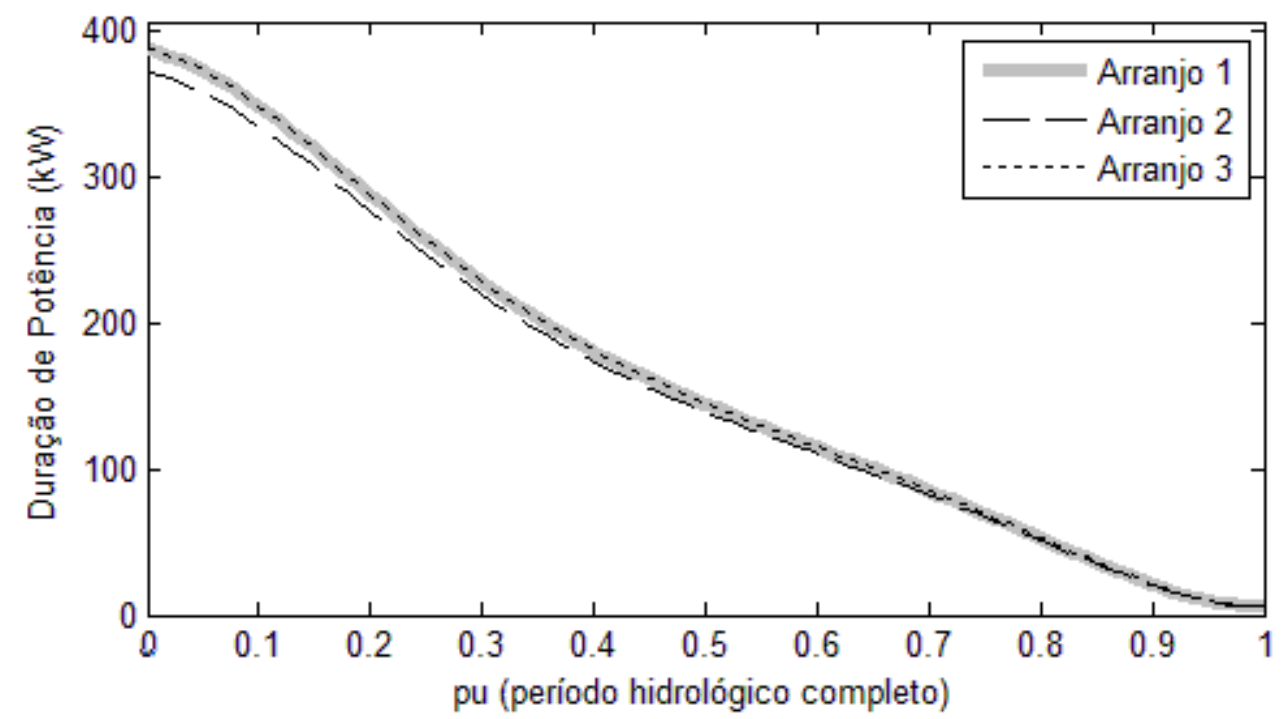

Figura 4.5 - Curvas de duração de potência do exemplo apresentado desconsiderando os limites operacionais do grupo gerador.

O limite inferior de operação da turbina Michell-Banki é 45\% da vazão nominal, conforme apresentado na tabela 4.2. Portanto é possível determinar a curva de duração de potência da CGH do exemplo apresentado para cada arranjo e cada valor de potência instalada considerando os limites de operação do grupo gerador. A figura 4.6 mostra a curva de duração de potência do arranjo 3 para a potência instalada de $50 \mathrm{~kW}$, de $100 \mathrm{~kW}$ e de $370 \mathrm{~kW}$.

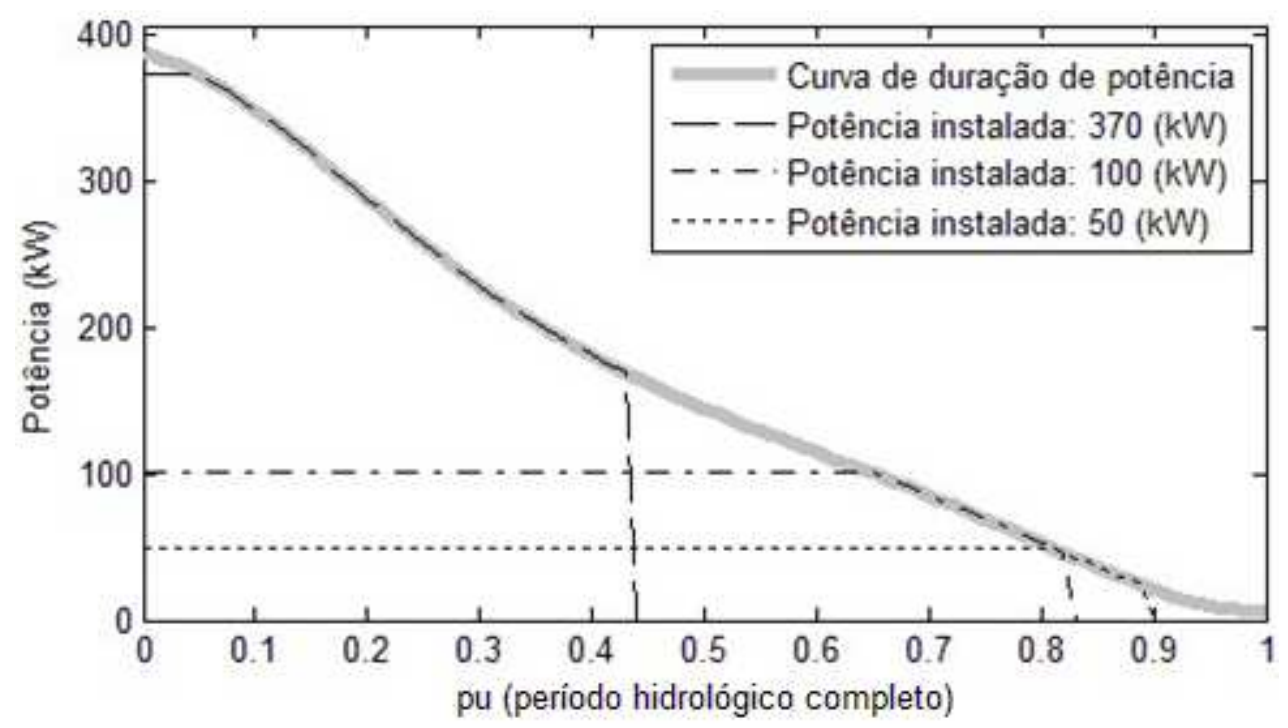

Figura 4.6 - Curva de duração de potência do arranjo 3, do exemplo apresentado, para a potência instalada de $50 \mathrm{~kW}$, de $100 \mathrm{~kW}$ e de $370 \mathrm{~kW}$.

A energia gerada pela CGH pode ser determinada a partir das curvas de duração de potência em função do arranjo e da potência instalada. A energia gerada é a integral da curva de duração de potência, considerando os limites operacionais do grupo gerador, multiplicada 
pelo número de horas do período hidrológico completo. A figura 4.7 mostra a energia gerada em função da vazão de projeto, para os três arranjos do exemplo apresentado.

Nessa análise, toda a energia gerada será consumida ou vendida. Dessa forma, o benefício anual, considerando uma tarifa única, é a energia gerada multiplicada pela tarifa constante, com mostra a figura 4.8. Como apresentado na figura 4.7 o aumento da vazão de projeto e, por conseguinte, da potência instalada resulta no aumento da energia gerada até determinado limite. A partir desse limite, o aumento da vazão de projeto provocará a redução da energia gerada, em virtude do limite operacional da turbina, provocando a redução do fator de capacidade.

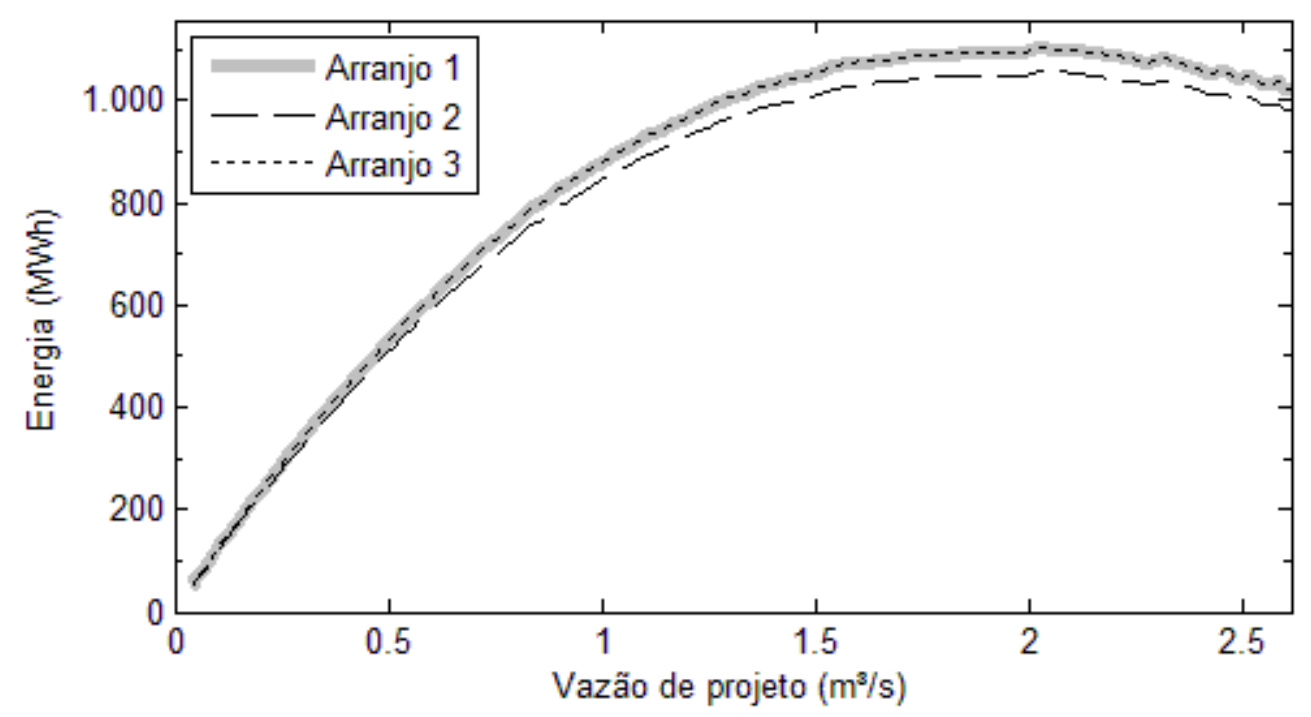

Figura 4.7 - Energia gerada em função da potência instalada do exemplo apresentado.

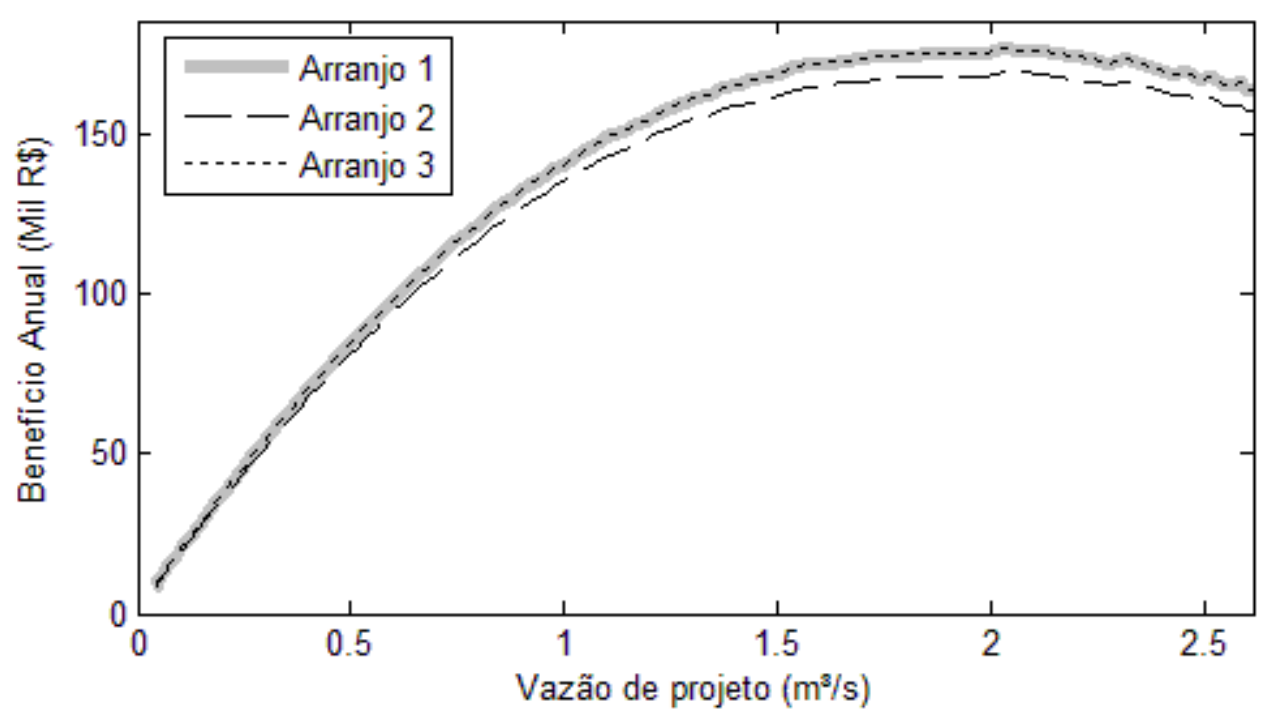

Figura 4.8 - Benefício anual em função da potência instalada do exemplo apresentado.

A estimativa de custo é calculada conforme o item 4.5.4. Para cada arranjo e cada valor de vazão de projeto, são verificados os valores dos parâmetros necessários para o cálculo. A vazão de projeto e a potência instalada apresentam uma relação direta como mostra 
a figura 4.9. Portanto é possível determinar o custo de cada arranjo em função da vazão de projeto, como mostra a figura 4.10 .

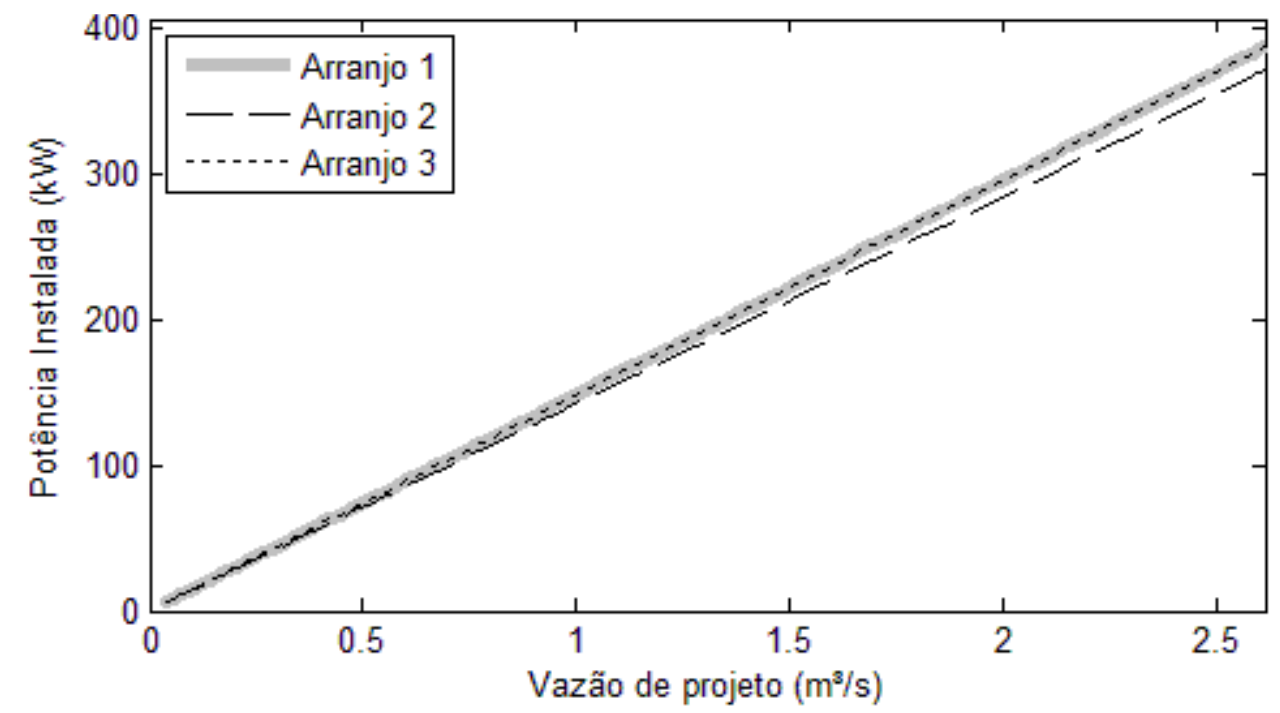

Figura 4.9 - Relação entre a potência instalada e a vazão de projeto do exemplo apresentado.

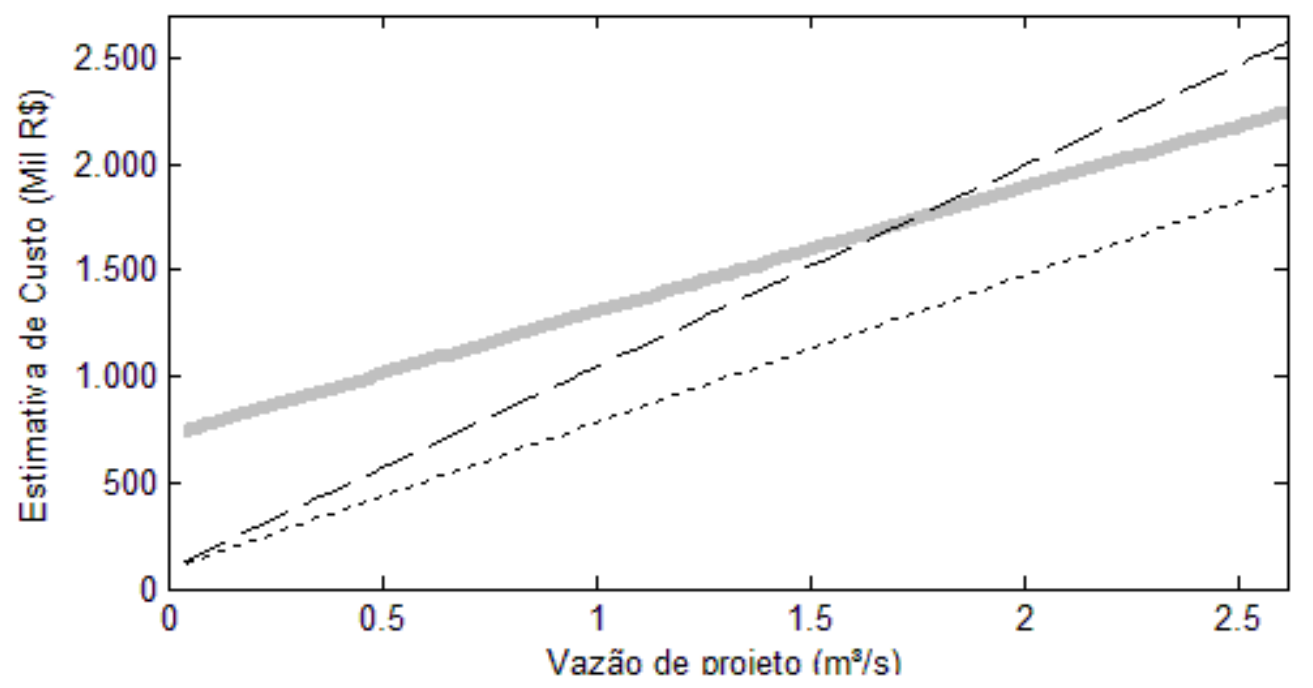

Figura 4.10 - Estimativa e de custo em função da potência instalada do exemplo apresentado.

O apêndice VI apresenta um algoritmo para a realização da análise de viabilidade econômica utilizando a curva de duração de vazões. Esse algoritmo pode ser dividido em etapas conforme apresentado abaixo.

1. Calcula a curva de duração de vazões;

2. Calcula a curva de duração de potência para cada arranjo desconsiderando os limites operacionais da turbina;

3. Calcula a curva de duração de potência para cada arranjo considerando os limites operacionais da turbina;

4. Calcula a energia gerada para cada valor de potência instalada e para cada arranjo;

5. Calcula o benefício anual para cada arranjo e cada valor de potência instalada;

6. Calcula a estimativa de custo com a função EstimativaCusto para cada arranjo e cada valor de potência instalada;

7. Calcula os indicadores financeiros para cada arranjo e cada valor de potência instalada; 
8. Calcula os indicadores para a análise do investimento.

A utilização desse desenvolvimento de análise permite a verificação imediata da variação da energia em função da vazão de projeto, o que ajuda na determinação do arranjo e da potência instalada mais apropriada para o caso estudado. Por outro lado, esse desenvolvimento de análise não fornece os subsídios para a análise considerando as variações das tarifas. O desenvolvimento de análise que será apresentado a seguir permitirá a realização desse tipo de análise.

\subsubsection{Desenvolvimento da análise de viabilidade econômica utilizando as vazões médias mensais}

Para realização de uma análise de viabilidade de uma CGH em um ambiente de geração distribuída deve ser considerada a diferença entre a tarifa paga pela concessionária e a tarifa paga para concessionária. Além disso, as tarifas consideradas e a demanda da propriedade podem variar ao longo do ano. Tendo em vista esse cenário é natural a necessidade de incorporar, na análise de viabilidade, as variações das tarifas e da demanda. $\mathrm{O}$ desenvolvimento da análise de viabilidade econômica utilizando as vazões médias mensais é uma análise no domínio do tempo. Dessa forma, é possível realizar o cálculo do benefício considerando a utilização da energia e as variações das tarifas ao longo do ano.

A equação (4.10) é utilizada para calcular a potência disponível para cada arranjo e em cada mês. A figura 4.11 mostra a potência disponível média mensal, para cada arranjo do exemplo estudado nesse capítulo. A potência disponível é calculada de acordo com os dados hidrológicos disponíveis na figura 4.3 e com os dados de cada respectivo arranjo, disponíveis na tabela 4.5 .

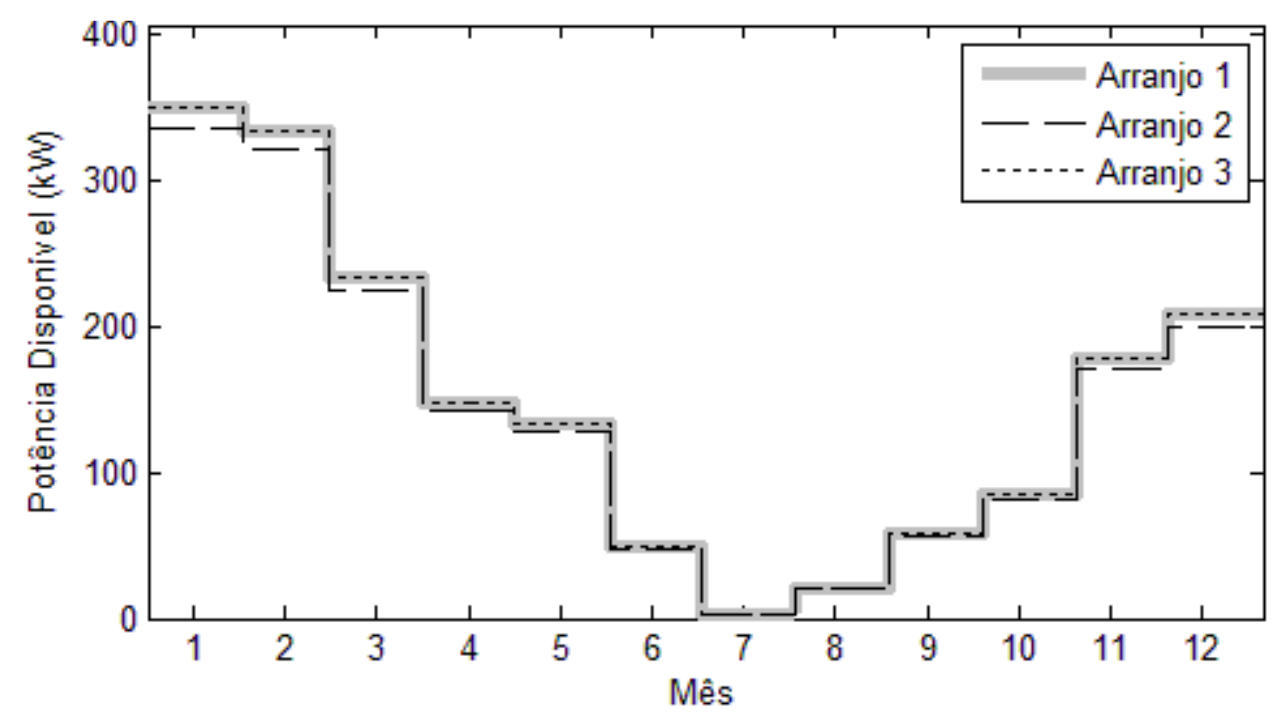

Figura 4.11 - Potência disponível média mensal para carda arranjo do exemplo apresentado. 
É considerado que a demanda da propriedade pode ser suprida pela concessionária local e que todo o excedente de potência é absorvido pela rede de distribuição. A energia gerada e consumida pela propriedade é remunerada pela tarifa de compra de energia da concessionária. $\mathrm{O}$ excedente de energia gerada é remunerado a uma tarifa de venda. Para simplificação da análise do exemplo apresentado nesse capítulo, a tarifa de compra e a tarifa de venda são constantes ao longo do ano. Os valores das tarifas são apresentados na tabela 4.5 .

Para a determinação do benefício anual, é necessário determinar a energia consumida pela propriedade e a energia excedente. A análise proposta calcula o fluxo de potência, em cada hora, para cada possível valor de potência instalada. A potência máxima disponível nesse exemplo é $370 \mathrm{~kW}$. É analisado o fluxo de potência, para cada arranjo, com a potência instalada variando de 1 a $370 \mathrm{~kW}$. Para simplificar a visualização, São apresentados apenas os gráficos de fluxo de potência do arranjo 3. Os gráficos mostram o fluxo de potência para a potência instalada de $50 \mathrm{~kW}$, de $100 \mathrm{~kW}$ e de $370 \mathrm{~kW}$.

A figura 4.12 (a) mostra a potência disponível levando em consideração os limites operacionais da turbina. Considerando que a demanda de potência da propriedade é de 100 $k W$ ao longo do ano, é possível determinar a potência excedente, as figura 4.12 (b), e a potência fornecida para a propriedade, figura 4.12 (c), ao longo do ano. A figura 4.12 (d) mostra a demanda de potência da concessionária para cada caso.

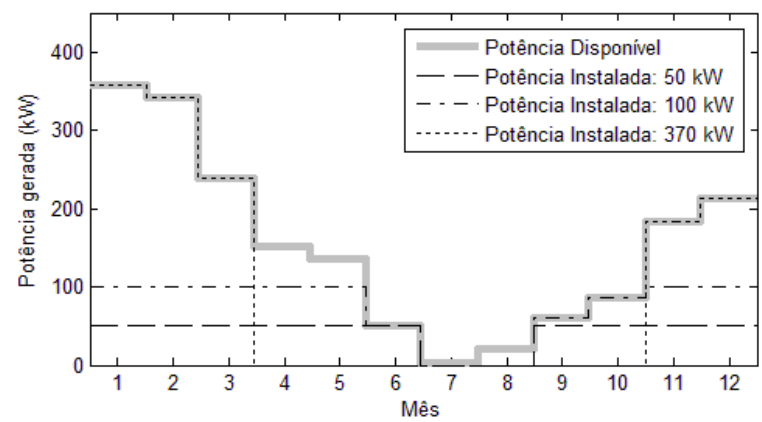

(a)

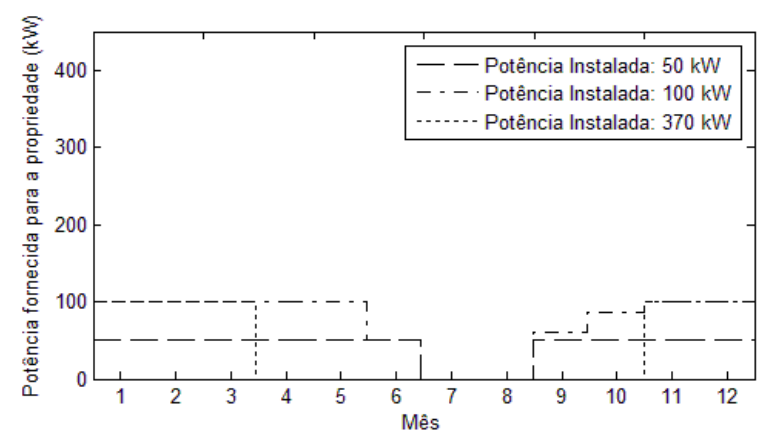

(c)

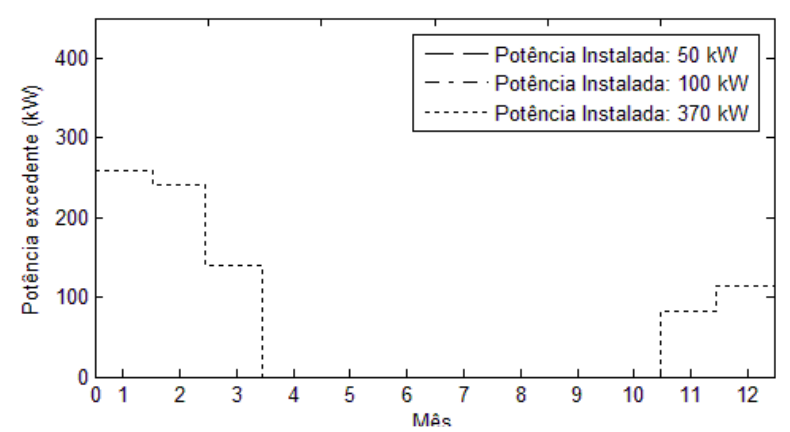

(b)

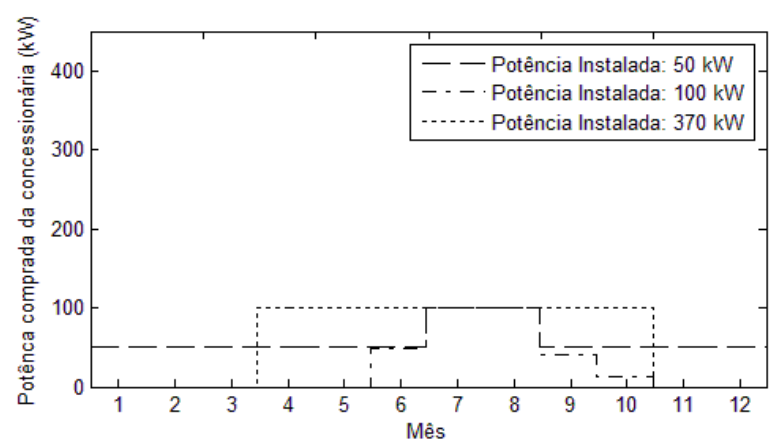

(d)

Figura 4.12 - Fluxo de potência do arranjo 3, do exemplo apresentado, para potência instalada de 50 $k W$, de $100 k W$ e de $370 k W$. 
A quantidade de energia gerada em um período é a integral da potência correspondente definida nesse período. Portanto é possível calcular a energia excedente, a energia fornecida para a concessionária e a energia comprada da concessionária em um ano. Figura 4.13 mostra o fluxo de energia do arranjo 3 do exemplo mostrado nesse capítulo em função da potência instalada.

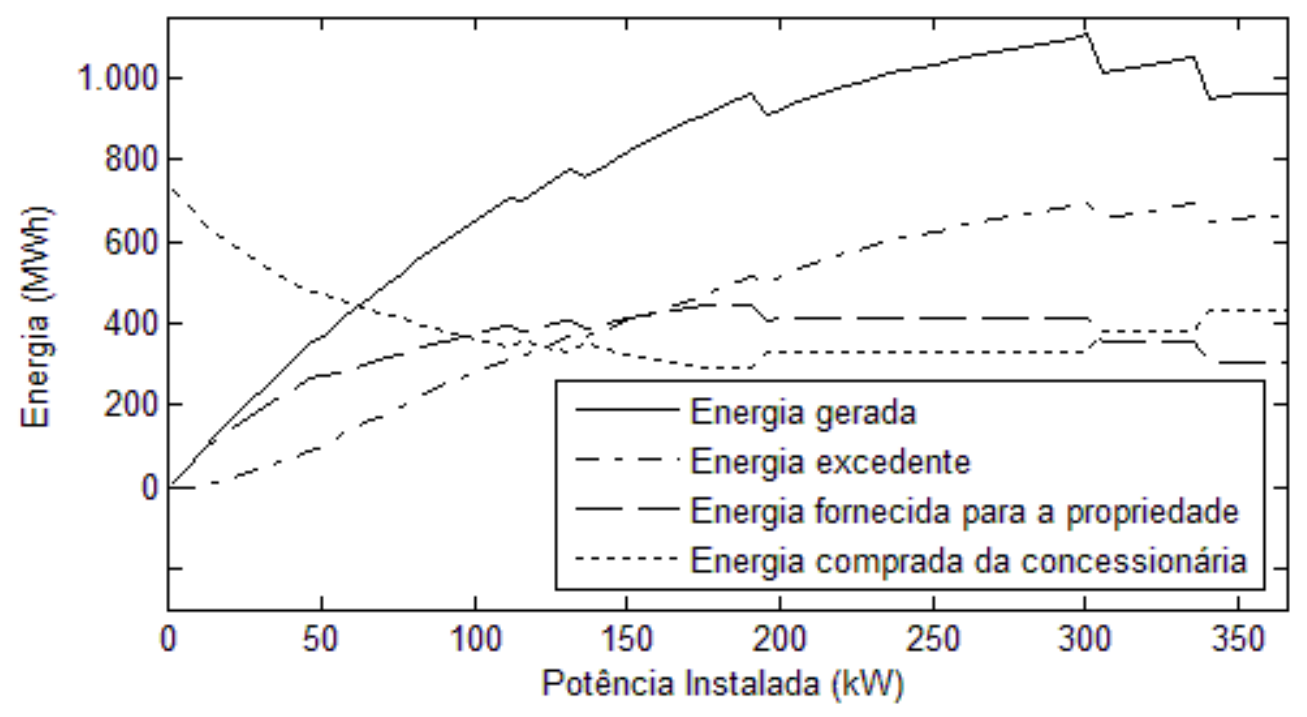

Figura 4.13 - Energia excedente, energia fornecida para a concessionária e energia comprada da concessionária em um ano em função da potência instalada. Energia referente ao arranjo 3 do exemplo proposto.

O benefício, em cada mês, da energia excedente é a energia excedente gerada no mês multiplicada pela tarifa de venda correspondente. O benefício, em cada mês, da energia fornecida para a propriedade é a energia fornecida para a propriedade no mês multiplicada a tarifa de compra correspondente.

O benefício anual da CGH é a soma do benefício anual da energia excedente e da energia fornecida para a propriedade. Como mostra a figura 4.13 e a figura 4.14 , o aumento da potência instalada resulta no aumento da energia gerada até determinado limite. A partir desse limite, o aumento da vazão de projeto provoca a redução da energia gerada, em virtude do limite operacional da turbina, reduzindo o fator de capacidade.

A estimativa de custo é calculada conforme o item 4.5.4. Para cada arranjo e para cada valor de potência instalada, são verificados os valores dos parâmetros necessários para o cálculo do custo. A vazão de projeto é calculada a partir da potência instalada e das características de cada arranjo. Portando é possível determinar o custo de cada arranjo em função da potência instalada como mostra a figura 4.15 . 


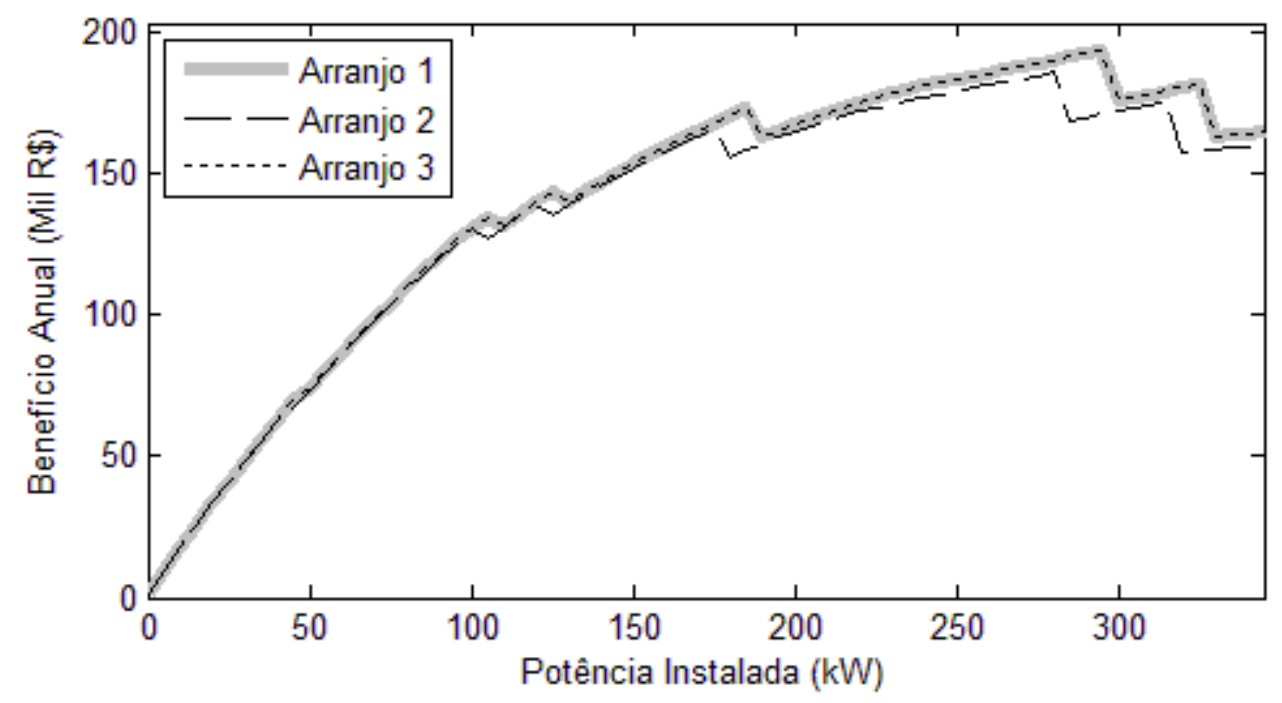

Figura 4.14 - Benefício anual para cada arranjo, do exemplo proposto, em função da potência instalada.

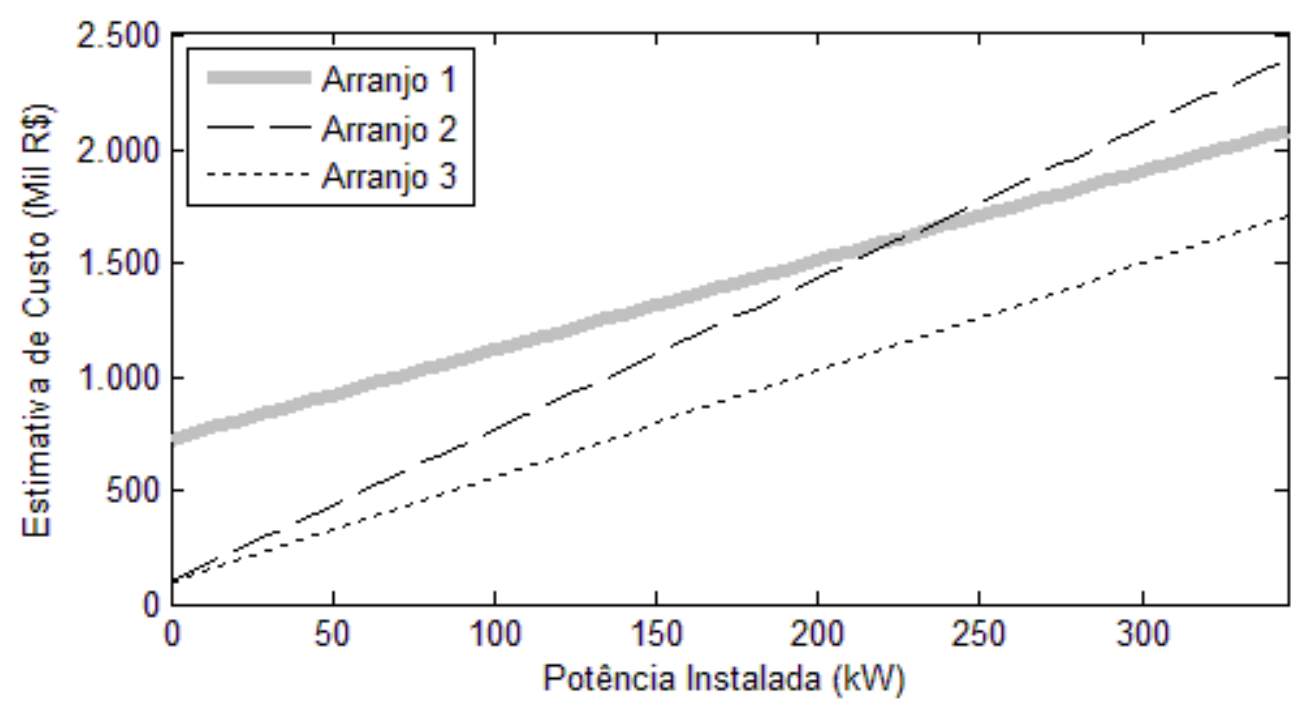

Figura 4.15 - Estimativa de custo para cada arranjo, do exemplo proposto, em função da potência instalada.

O apêndice VII mostra um algoritmo desenvolvido para realizar o desenvolvimento descrito nesse item. As etapas desse algoritmo estão descritas abaixo.

1. Recebe a série de vazões médias mensais disponíveis;

2. Calcula a série de vazões médias mensais disponíveis;

3. Recebe um vetor com a demanda para cada hora do ano;

4. Determina a potência máxima;

5. Inicia um loop que analisa o sistema para cada potência instalada e incrementa essa potência até a potência máxima instalada;

6. Determina a potência média gerada no mês levando em consideração a vazão disponível, para cada arranjo;

7. Determina a potência média gerada no mês levando em consideração os limites operacionais da turbina;

8. Determina o fluxo de potência em cada arranjo e em cada hora de acordo com a potência gerada, a demanda em cada hora e para cada arranjo; 
9. Calcula o fluxo de potência médio $(k W)$ e o fluxo de energia gerada em cada mês $(k W h)$, para cada arranjo;

10. Calcula o fluxo de energia no ano e o benefício anual, para cada arranjo e cada valor de potência instalada;

11. Calcula a vazão correspondente à potência predeterminada e determina o investimento inicial para cada arranjo e cada valor de potência instalada;

12. Loop se repete até que a potência seja igual à máxima potência disponível;

13. Calcula os indicadores para a análise do investimento;

\subsubsection{Indicadores econômicos}

Os desenvolvimentos de análise econômica apresentados possibilitaram a realização da estimativa do benefício anual e da estimativa de custo da CGH para cada arranjo e cada valor de potência instalada. A partir desses valores é possível calcular indicadores financeiros para possibilitar a análise de viabilidade econômica do empreendimento. Nesse trabalho serão utilizados 4 indicadores financeiros para a realização da análise do investimento: valor presente líquido, índice de lucratividade, período de payback descontado e taxa interna de retorno.

O valor presente líquido é o valor presente dos benefícios subtraído o valor presente dos custos. O índice de lucratividade é o valor presente dos benefícios dividido pelo valor presente dos custos. O período de Payback é o número de períodos necessários para a recuperação do investimento considerando o valor presente do fluxo de caixa. A taxa interna de retorno é a taxa que iguala o valor presente dos benefícios com o valor presente dos custos. A figura 4.16 mostra os indicadores econômicos encontrados com a análise utilizando a curva de duração de vazões e a figura 4.17 mostra os indicadores econômicos encontrados com a análise da série de vazões médias mensais.

Especialistas do setor acreditam que seja mais atraente avaliar investimentos em taxas percentuais ao invés dos valores monetários do valor presente líquido. Contudo, deve-se preferencialmente utilizar mais do que uma ferramenta de análise de investimento, e todas as alternativas devem ser consideradas em uma análise, pois qualquer alternativa pode parecer viável se for comparada com as alternativas suficientemente ruins. [13]

A figura 4.16 e a figura 4.17 apresentam os resultados dos dois desenvolvimentos de análise econômica. Os indicadores foram calculados com o algoritmo mostrado no apêndice IV. É possível observar nas duas figuras que o aumento gradual da potência instalada, e conseqüentemente, da vazão de projeto resulta no aumento do resultado econômico até determinado limite a partir do qual o aumento da potência instalada provoca a redução do resultado econômico. Isso ocorre porque o custo cresce diretamente com o aumento da 
potência instalada e o benefício anual apresenta um limite de crescimento. Dessa forma é possível observar que cada indicador apresenta uma vazão de projeto e uma potência instalada que maximiza o resultado econômico levando em consideração esse indicador.

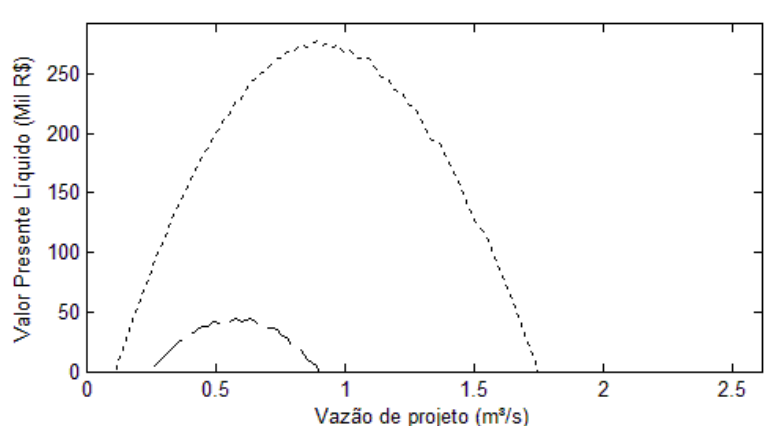

(a)

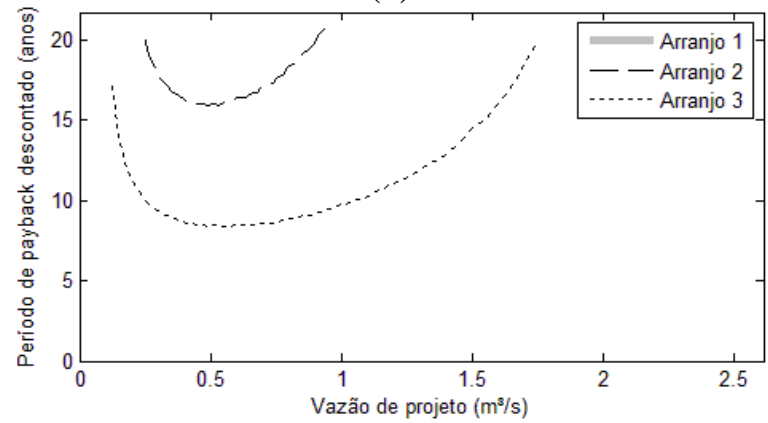

(c)

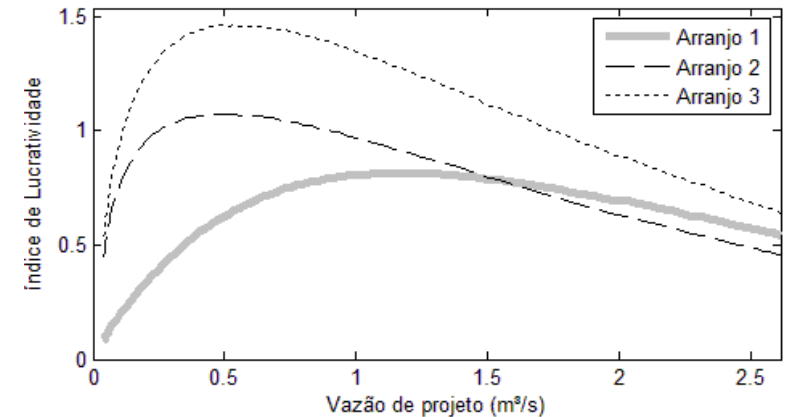

(b)

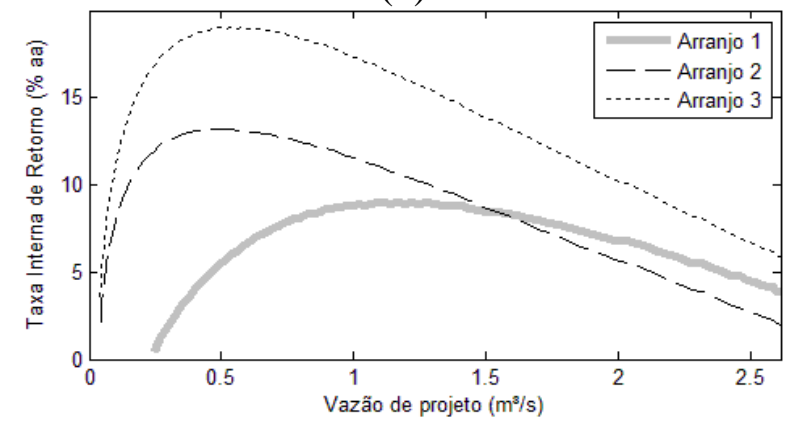

(d)

Figura 4.16 - Indicadores econômicos do desenvolvimento de análise econômica utilizando a curva de duração de vazão: (a) Valor presente líquido (Mil R\$); (b) Índice de lucratividade; (c) Período de payback descontado (anos); (d) Taxa interna de retorno (\% aa).

Tabela 4.6 - Arranjo e a potência instalada que otimiza cada indicador da análise de viabilidade econômica utilizando a curva de duração de vazões.

\begin{tabular}{l|r|r|r|r|r|r}
\multicolumn{1}{c|}{ Indicador } & Valor & Arranjo & $\begin{array}{c}\text { Potência } \\
\text { instalada } \\
(\boldsymbol{k} \boldsymbol{W})\end{array}$ & $\begin{array}{c}\text { Investimento } \\
\text { inicial } \\
(\boldsymbol{R} \boldsymbol{\$})\end{array}$ & $\begin{array}{c}\text { Benefício } \\
\text { anual } \\
(\boldsymbol{R} \boldsymbol{\$})\end{array}$ & $\begin{array}{c}\text { Custo } \\
(\boldsymbol{R} \boldsymbol{\$} / \boldsymbol{k} \boldsymbol{W})\end{array}$ \\
\hline $\begin{array}{l}\text { Valor presente } \\
\text { líquido }\end{array}$ & $\mathrm{R} \$ 277.684,91$ & 3 & 132,36 & $707.459,50$ & $131.889,93$ & $5.345,12$ \\
\hline $\begin{array}{l}\text { Indice de } \\
\text { Lucratividade }\end{array}$ & 1,46 & 3 & 79,19 & $458.337,32$ & $89.809,96$ & $5.787,98$ \\
\hline $\begin{array}{l}\text { Período de } \\
\text { Payback }\end{array}$ & $8,38($ anos) & 3 & 79,19 & $458.337,32$ & $89.809,96$ & $5.787,98$ \\
\hline $\begin{array}{l}\text { Taxa interna de } \\
\text { retorno }\end{array}$ & $19(\% a a)$ & 3 & 79,19 & $458.337,32$ & $89.809,96$ & $5.787,98$ \\
\hline
\end{tabular}




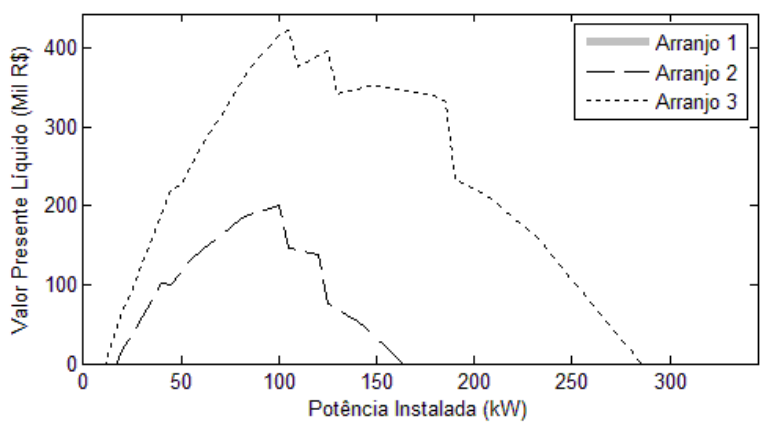

(a)

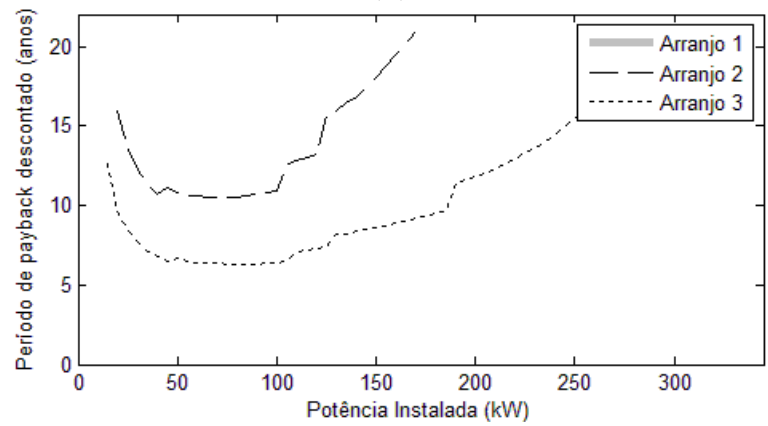

(c)

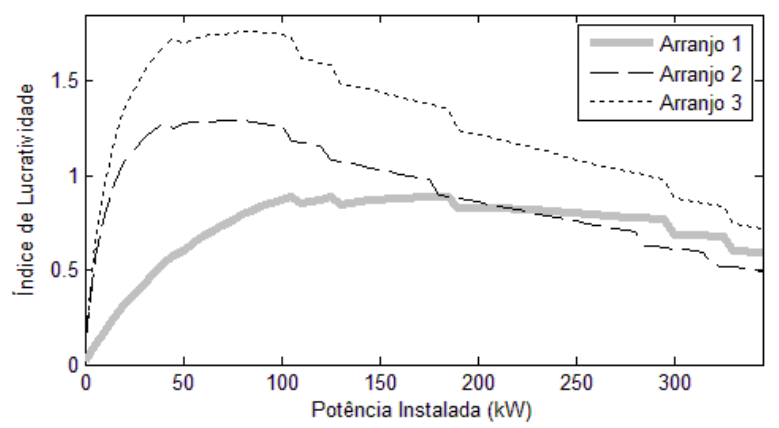

(b)

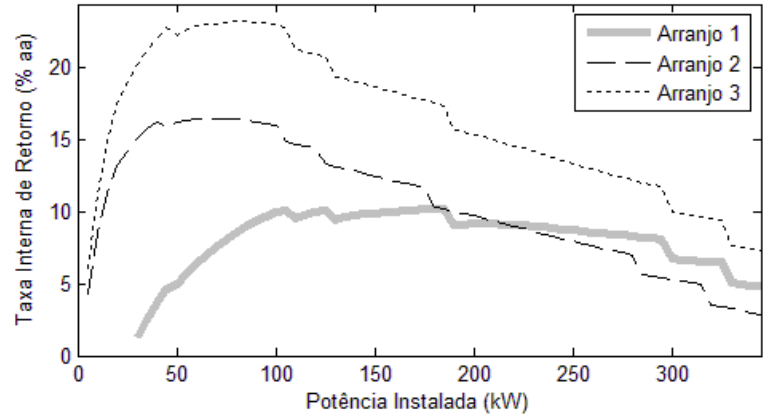

(d)

Figura 4.17 - Indicadores econômicos do desenvolvimento de análise econômica utilizando vazões médias mensais: (a) Valor presente líquido (Mil R\$); (b) Índice de lucratividade; (c) Período de payback descontado (anos); (d) Taxa interna de retorno (\% aa).

Tabela 4.7- Arranjo e potência instalada que otimiza cada indicador do estudo de viabilidade econômica utilizando a série de vazões médias mensais.

\begin{tabular}{|c|c|c|c|c|c|c|}
\hline Indicador & Valor & Arranjo & $\begin{array}{c}\text { Potência } \\
\text { instalada } \\
(k W)\end{array}$ & $\begin{array}{l}\text { Investimento } \\
\text { inicial } \\
(\boldsymbol{R} \$)\end{array}$ & $\begin{array}{c}\text { Benefício } \\
\text { anual } \\
(\boldsymbol{R} \$)\end{array}$ & $\begin{array}{c}\text { Custo } \\
(R \$ / k W)\end{array}$ \\
\hline $\begin{array}{l}\text { Valor presente } \\
\text { líquido }\end{array}$ & $\mathrm{R} \$ 422.421,87$ & 3 & 105,00 & $583.965,49$ & $134.733,91$ & $5.561,58$ \\
\hline $\begin{array}{l}\text { Índice de } \\
\text { Lucratividade }\end{array}$ & 1,76 & 3 & 85,00 & $490.255,69$ & $115.603,03$ & $5.767,71$ \\
\hline $\begin{array}{l}\text { Período de } \\
\text { Payback }\end{array}$ & 6,29 (anos) & 3 & 85,00 & $490.255,69$ & $115.603,03$ & $5.767,71$ \\
\hline $\begin{array}{l}\text { Taxa interna de } \\
\text { retorno }\end{array}$ & $23(\% a a)$ & 3 & 85,00 & $490.255,69$ & $115.603,03$ & $5.767,71$ \\
\hline
\end{tabular}

A tabela 4.6 e a tabela 4.7 apresentam o arranjo e a potência instalada que maximizam o resultado econômico levando em consideração cada indicador. Essa tabela também apresenta o investimento inicial, o benefício anual e o custo por unidade de potência para cada respectivo arranjo e potência instalada.

O custo por unidade de potência está próximo do valor de referência considerado nesse trabalho, $\mathrm{R} \$ 5.500,00$. Todas as análises apontaram o arranjo 3 como sendo o mais viável economicamente. $\mathrm{O}$ valor da potência instalada que maximiza o resultado econômico 
está entre 79 e $132 \mathrm{~kW}$ para a análise com uma única tarifa, e entre 85 e $105 \mathrm{~kW}$ para análise considerando uma tarifa de venda e uma tarifa de compra.

Conforme apresentado nas tabelas 4.6 e 4.7 o arranjo 3 é economicamente viável para uma faixa de potência instalada, pois o valor presente líquido é maior do que zero, o índice de lucratividade é maior do que um, o período de payback está dentro do horizonte de análise considerado e a taxa interna de retorno é maior do que o custo do capital considerado, $12 \%$. Pode ser observado nas figuras 4.16 e 4.17 que uma escolha errada de um determinado arranjo e de uma determinada potência instalada pode tornar um empreendimento economicamente viável em um empreendimento que não trará retorno financeiro ao empreendedor.

\subsection{Conclusões}

O capítulo 4 apresentou dois desenvolvimentos para realização da análise de viabilidade econômica de CGHs. O desenvolvimento de análise de viabilidade econômica utilizando a curva de duração de vazões apresenta uma melhor compreensão gráfica, mas apresenta a limitação referente à variação da tarifa.

A análise de viabilidade econômica utilizando a série de vazões médias mensais possibilita a análise de uma CGH em um cenário de geração distribuída com a variação entre a tarifa de compra de energia, a tarifa de venda de energia e das tarifas ao longo do ano. Entretanto não são consideradas, no cálculo do fluxo de potência, as variações da vazão ao longo do mês.

Vale ressaltar que a determinação do custo utilizada apresenta limitações e deve ser usada apenas como uma estimativa de custo. Essa estimativa desconsidera as possibilidades de redução de custo com a utilização das alternativas econômicas apresentadas no capítulo 3.

Apesar das limitações apresentadas, os desenvolvimentos de análise de viabilidade econômica apresentados permitem a avaliação da viabilidade do empreendimento considerando uma série de parâmetros relativos à hidrografia, ao arranjo, à potência instalada e às tarifas de energia. 


\section{ESTUDO DE CASO}

Este capítulo apresenta um estudo de caso de uma propriedade rural onde existem duas CGHs instaladas. Será estudada a possibilidade de aumento da capacidade de geração. Para a realização do estudo de viabilidade econômica, serão aplicados os desenvolvimentos de análise de viabilidade econômica apresentados no capítulo 4.

Neste capítulo, são apresentados três aproveitamentos hidrelétricos. Os aproveitamentos estão localizados na fazenda Santa Maria, propriedade do senhor Carlos Roberto Ferrari de Carvalho. A fazenda Santa Maria está localizada no município de Padre Bernardo GO, está a $25 \mathrm{~km}$ da cidade de Padre Bernardo e a $65 \mathrm{~km}$ de Brazlândia - DF. A propriedade está localizada na latitude sul $15^{\circ} 18^{\prime} 44^{\prime \prime}$ e na longitude oeste $48^{\circ} 18^{\prime} 14^{\prime}$ ' e o acesso à propriedade é a BR 080.

Atualmente existem duas CGHs instaladas na propriedade e será estudada a possibilidade de instalar mais uma CGH. São aproveitamentos hidrelétricos do Rio Angicos, cuja nascente se localiza nos domínios da fazenda Santa Maria. Todos os locais de interesse estão localizados no interior da propriedade.

As principais atividades econômicas desenvolvidas na fazenda Santa Maria são o cultivo de capim para a produção de semente, a produção agrícola e a produção de gelo. A produção de gelo é realizada em uma fábrica localizada na propriedade com água extraída em um poço artesiano e energia elétrica proveniente da CGH 1, com potência instalada de 180 $k W$.

A CGH 1 entrou em operação do dia 24 de janeiro de 1981 e era propriedade do senhor Alceu Barroso, pai do atual proprietário. Essa CGH foi implantada para alimentar uma fábrica de beneficiamento de arroz, já desativada. O projeto e implantação foram realizados pelo Joaquim Barbosa e Geraldo Maia. Dez anos depois entrou em operação a CGH 2, com potência instalada de $40 \mathrm{~kW}$, para suprir as residências localizadas no platô superior da propriedade.

\subsection{Dados Hidrológicos do Rio Angicos}

O Rio Angicos está integralmente no estado de Goiás. É afluente da margem esquerda do rio Maranhão, que por sua vez, nasce no Distrito Federal e forma o Rio Tocantins ao se juntar com o Rio das Almas. O Rio Angicos está na bacia do Rio Maranhão que é a sub-bacia 20 da bacia do Rio Tocantins. Essa classificação é utilizada pela ANEEL. A figura 5.1 mostra 
a bacia do Rio Tocantins e indica a bacia do rio Maranhão. A figura 5.2 mostra a bacia do Rio Angicos.

Os dados hidrológicos do Rio Angicos, utilizados nesse trabalho, foram retirados do estudo hidrológico disponível no inventário hidrelétrico simplificado do Rio Angicos [8] realizado em novembro de 2000 pelo engenheiro hidrólogo Joanir Mongin, especialista em hidrologia superficial, e a geóloga Renata Machado, especialista em Geotécnica. Esse inventário foi realizado para a seleção do aproveitamento mais favorável para a construção da PCH Santa Maria. Essa alternativa, apesar de ser viável, está, temporariamente, descartada pelo proprietário.

Os parâmetros físicos do Rio Angicos foram levantados em uma inspeção ao local. Uma equipe percorreu o trajeto da nascente à foz do rio e levantaram os dados que possibilitaram a construção do perfil longitudinal mostrado na figura 5.3.

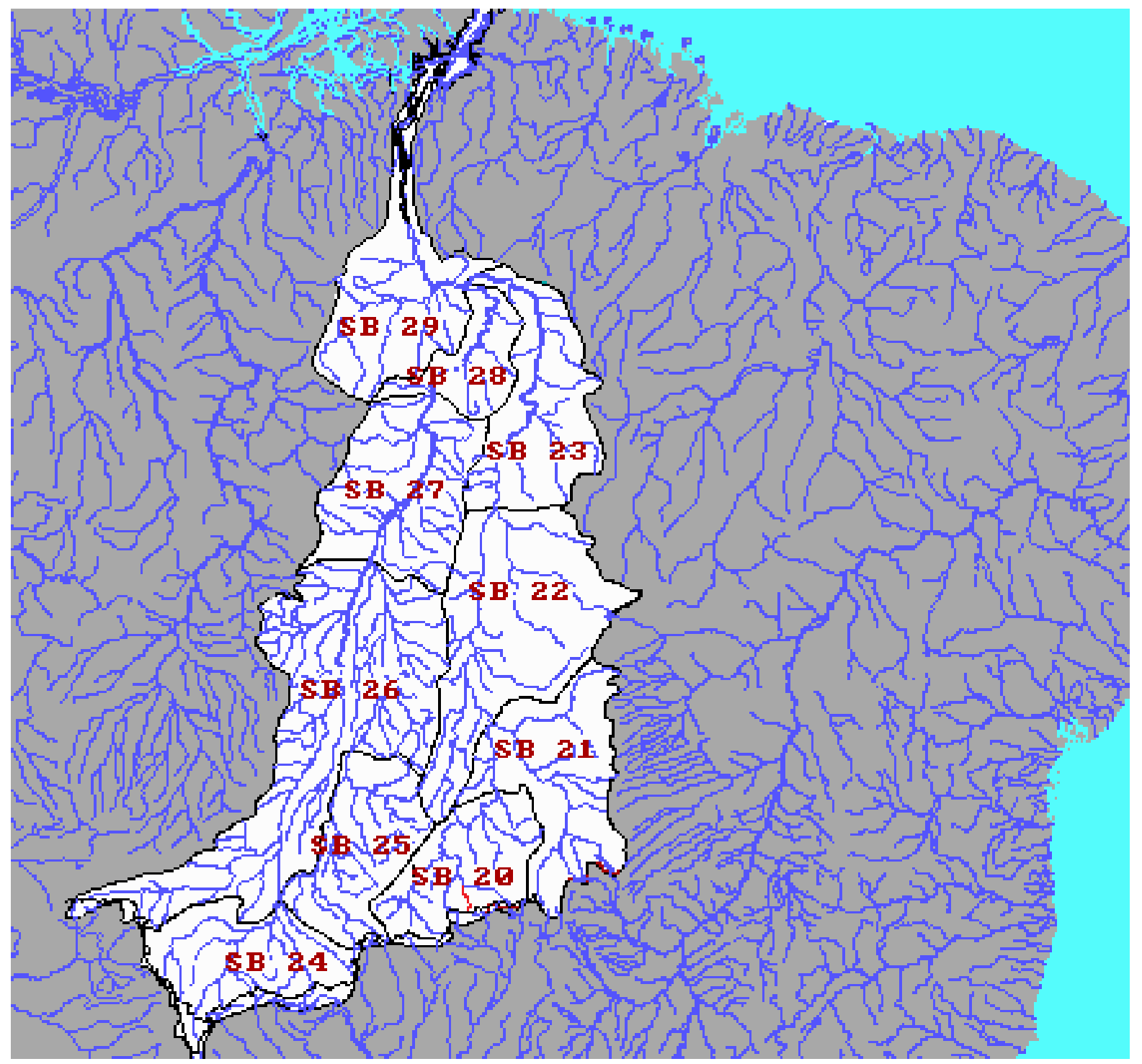

Figura 5.1 - Bacia do Tocantins. Sub-Bacia 20 - Bacia do Rio Maranhão. Fonte: referência [15]. 


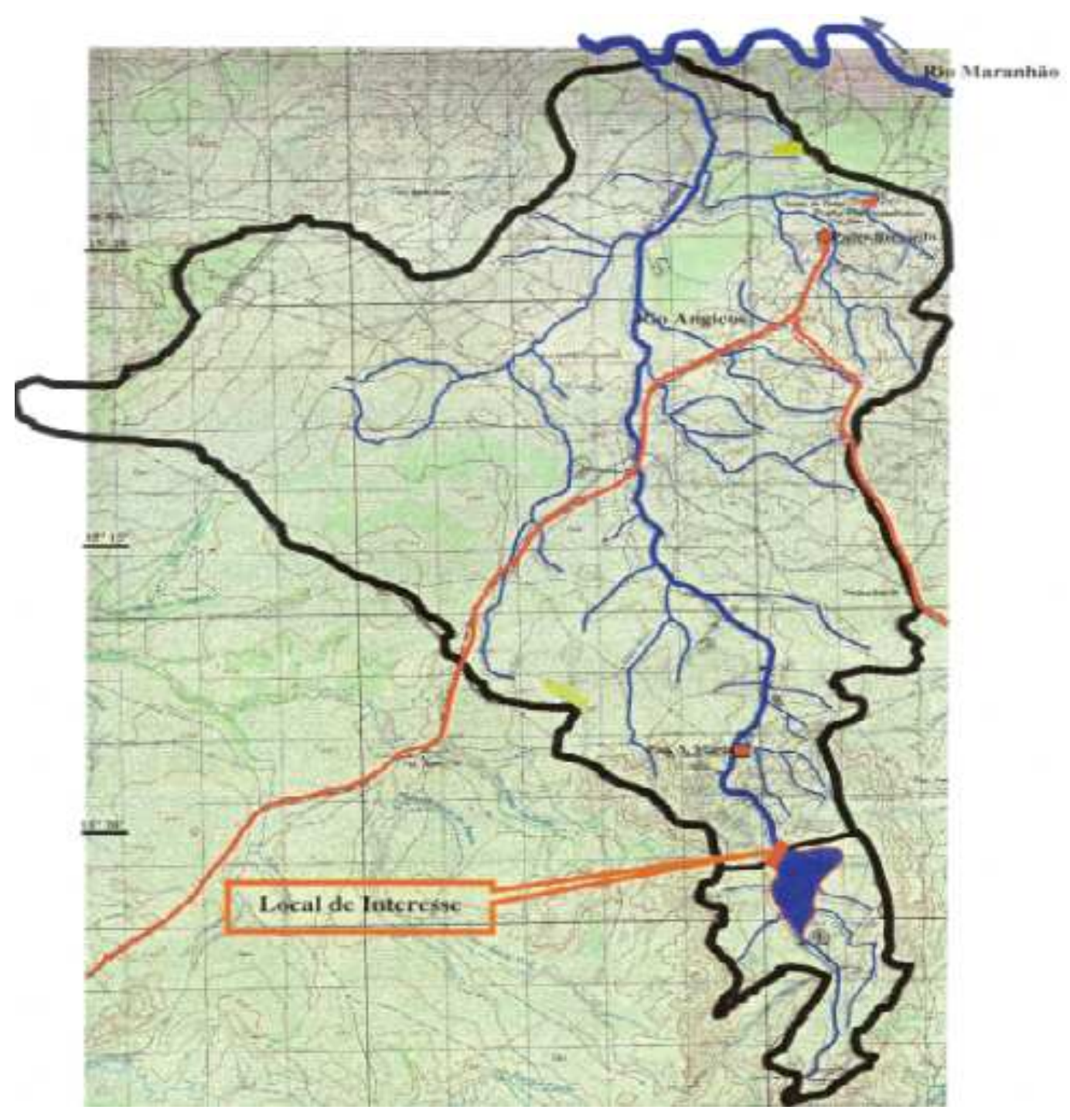

Figura 5.2 - Bacia do Rio Angicos. Fonte: referência [8].

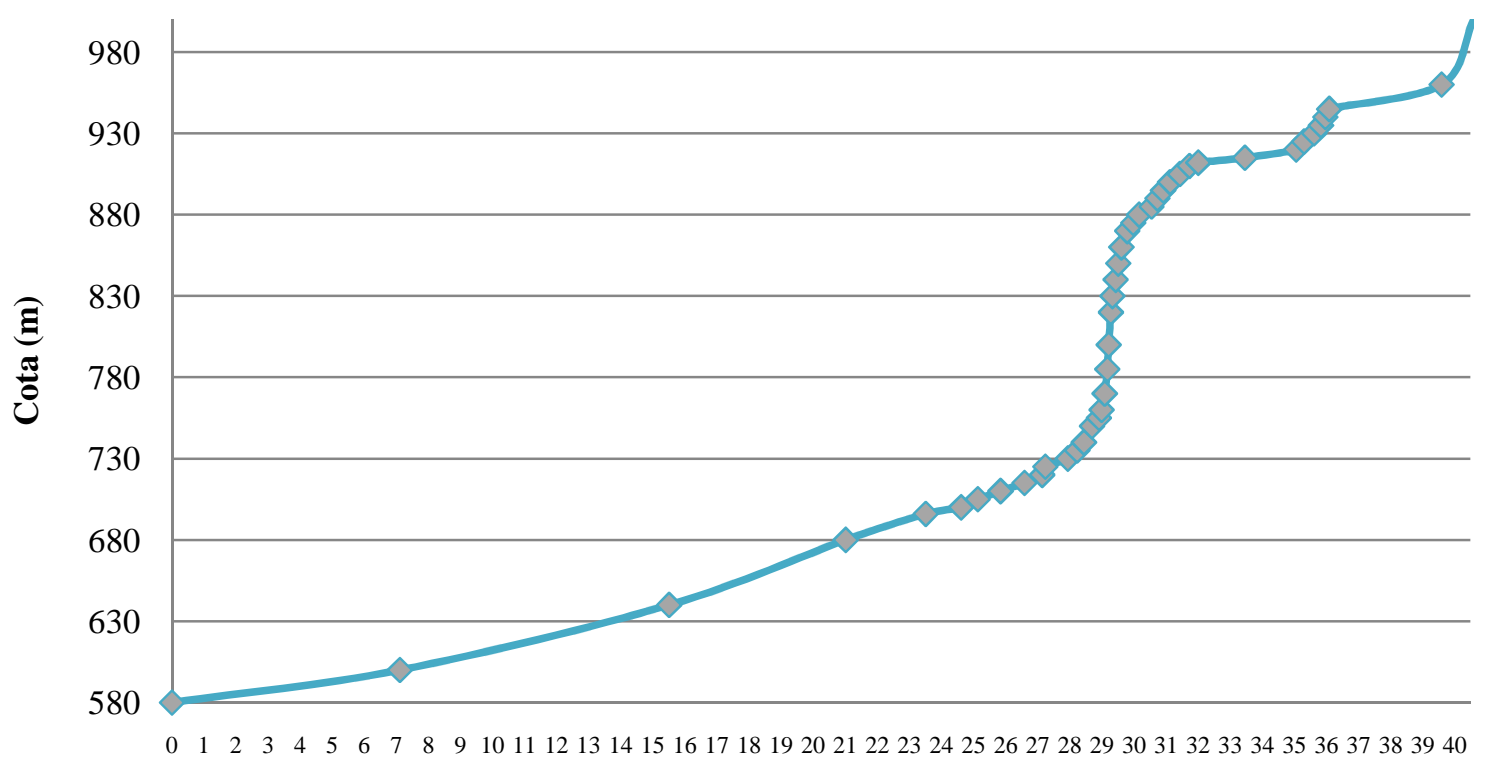

Comprimento do Tavelgue (km)

Figura 5.3 - Perfil longitudinal do Rio Angicos. Fonte: dados presentes na referência [8]. 


\subsection{Vazões médias mensais}

Devido à inexistência de postos pluviométricos na bacia do Rio Angicos, a vazão foi calculada de forma indireta usando como base as séries de alturas pluviométricas diárias. Os dados utilizados são retirados dos postos pluviométricos mostrados na tabela 5.1. A obtenção da vazão, tomando como base a altura pluviométrica, foi realizada calculando os coeficientes de deflúvios mensais, calculados para uma bacia no Rio Descoberto semelhante à bacia do Rio Angicos [8]. O resultado do estudo hidrológico está mostrado na figura 5.4 e na tabela 5.2. Observa-se uma queda severa das médias mensais nos períodos de estiagem, característica comum dos mananciais da região.

Tabela 5.1 - Postos hidro-metereológico utilizados nos estudos. Fonte: referência [8].

\begin{tabular}{l|l|c|c|c|c}
\multirow{2}{*}{$\begin{array}{c}\text { Código } \\
\text { (ANEEL) }\end{array}$} & \multicolumn{2}{|c|}{ Posto } & \multirow{2}{*}{$\begin{array}{c}c \\
\boldsymbol{A} \\
\end{array}$} & & \multicolumn{2}{c|}{ Coordenadas } & \multirow{2}{*}{ Período } \\
\cline { 4 - 5 } & & & Latitude S & Longitude W & \\
\hline 01548001 & Mimoso & & $15^{\circ} 03^{\prime}$ & $48^{\circ} 09^{\prime}$ & $1973-1997$ \\
\hline 01548002 & Padre Bernardo & & $15^{\circ} 42^{\prime}$ & $48^{\circ} 16^{\prime}$ & $1986-1997$ \\
\hline 60435000 & S. Antônio do descoberto & & $48^{\circ} 14^{\prime}$ & $1978-1983$ \\
\hline 01548007 & Brazlândia & 11500 & $15^{\circ} 41^{\prime}$ & $48^{\circ} 13^{\prime}$ & $1971-1990$
\end{tabular}

$\mathrm{A}_{\mathrm{D}}$ - Área de drenagem $(h a)$

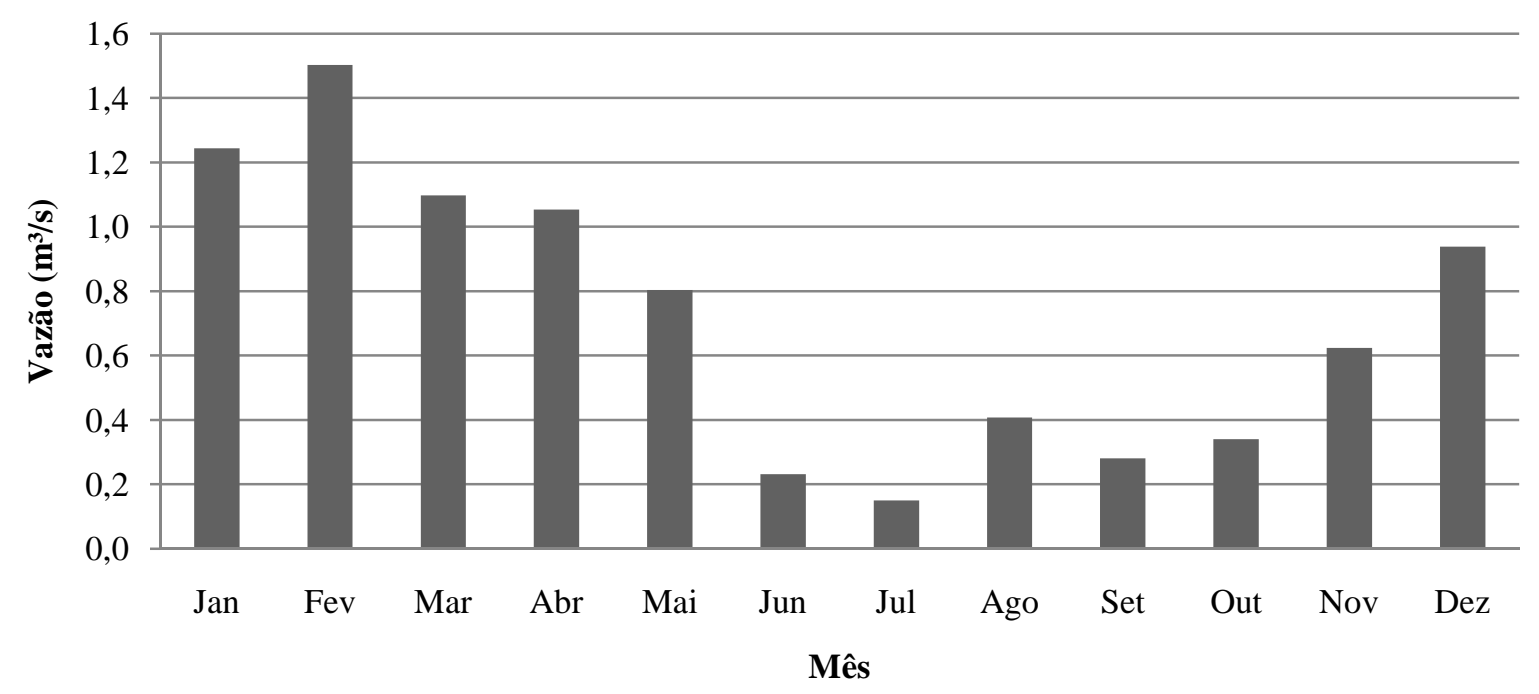

Figura 5.4 - Vazões médias mensais de longo período do Rio Angicos no local de interesse. Fonte: referência [8].

Tabela 5.2 - Vazões médias mensais de longo período no local de interesse. Fonte: referência [8].

\begin{tabular}{c|c|c|c|c|c|c|c|c|c|c|c|c} 
Mês & Jan & Fev & Mar & Abr & Mai & Jun & Jul & Ago & Set & Out & Nov & Dez \\
\hline Vazão $\left(m^{3} / s\right)$ & 1,244 & 1,503 & 1,097 & 1,053 & 0,803 & 0,232 & 0,150 & 0,408 & 0,281 & 0,340 & 0,624 & 0,938
\end{tabular}




\subsection{Vazão remanescente}

A vazão remanescente, ou seja, a vazão do Rio Angicos compreendida entre o barramento e a casa de força, de acordo com a norma $\mathrm{N}^{0} 3$ da ANEEL, deve ser $80 \%$ da descarga mínima média mensal para uma série de, no mínimo, dez anos de observações. Como o cálculo das vazões médias foi feito de forma indireta, não se dispondo, no local de interesse, de uma série de vazões mínimas médias mensais, de forma a permitir a aplicar a norma da ANEEL na sua plenitude, adotou-se o valor do período do mês de junho como referência. Portanto, em atendimento às normas da ANEEL, a vazão remanescente no local de interesse considerada é $0,120 \mathrm{~m}^{3} / \mathrm{s}$ [8].

No trecho considerado existe uma cachoeira de $120 \mathrm{~m}$ de altura que forma uma barreira natural entre os ecossistemas do platô inferior e superior da propriedade. Outro fato que deve ser ressaltado é que o trecho do rio considerado está inteiramente nos domínios da propriedade do empreendedor, não prejudicando nenhum proprietário vizinho.

\subsection{Levantamento topográfico}

O levantamento topográfico utilizado nesse estudo é o mesmo utilizado no projeto básico da PCH Santa Maria e possuí curvas de nível a cada cinco metros de altitude. Esse detalhamento é suficiente para a execução dos estudos propostos. A figura 5.5 mostra curvas de nível do levantamento topográfico e a localização do leito do Rio Angicos.

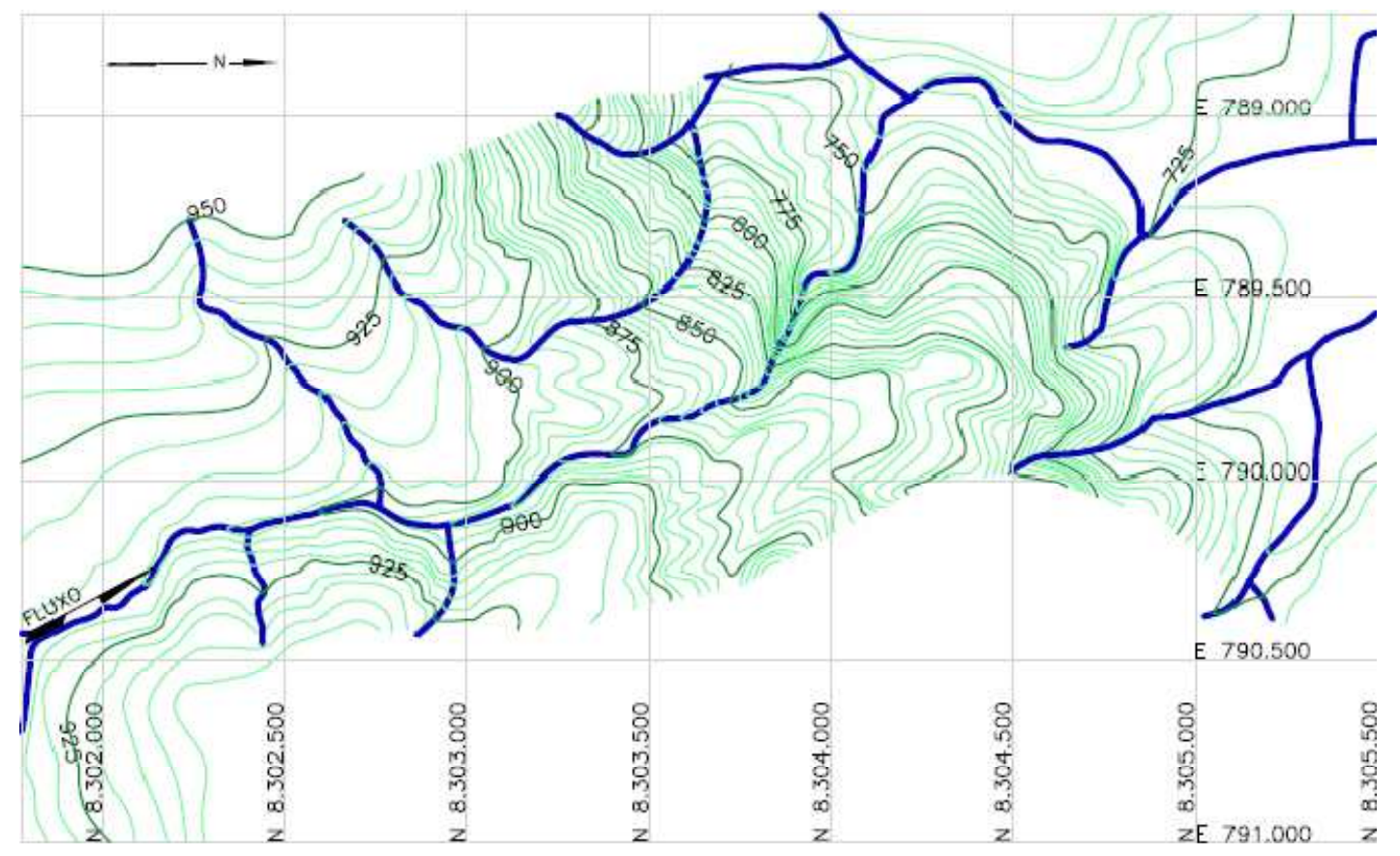

Figura 5.5 - Levantamento topográfico utilizado no projeto básico da PCH Santa Maria. Fonte: referência [7]. 


\subsection{Projeto PCH Santa Maria}

O projeto básico da PCH Santa Maria prevê a construção de uma barragem com o volume útil de, no mínimo, 19.844.600 $\mathrm{m}^{3}$, para a regularização de uma descarga firme de projeto de 1,00 $\mathrm{m}^{3} / \mathrm{s}$. Esse volume foi calculado para garantir o volume necessário para a regularização com o acréscimo das perdas por evaporação durante o período crítico considerado de sete meses. O projeto básico apresenta uma barragem com um espelho d'água de 289 ha e um volume total de $22.500 .000 \mathrm{~m}^{3}$.

A PCH Santa Maria teria vazão de projeto de $1,00 \mathrm{~m}^{3} / \mathrm{s}$ e uma queda útil de $120 \mathrm{~m}$. É uma central hidrelétrica de represamento com uma barragem de terra, uma tubulação forçada e uma casa de máquinas com duas unidades Pelton de 0,85 $\mathrm{MW}$ cada. A figura 5.6 mostra o arranjo desse projeto. Essa alternativa, apesar de ser viável, está, temporariamente, descartada pelo proprietário.

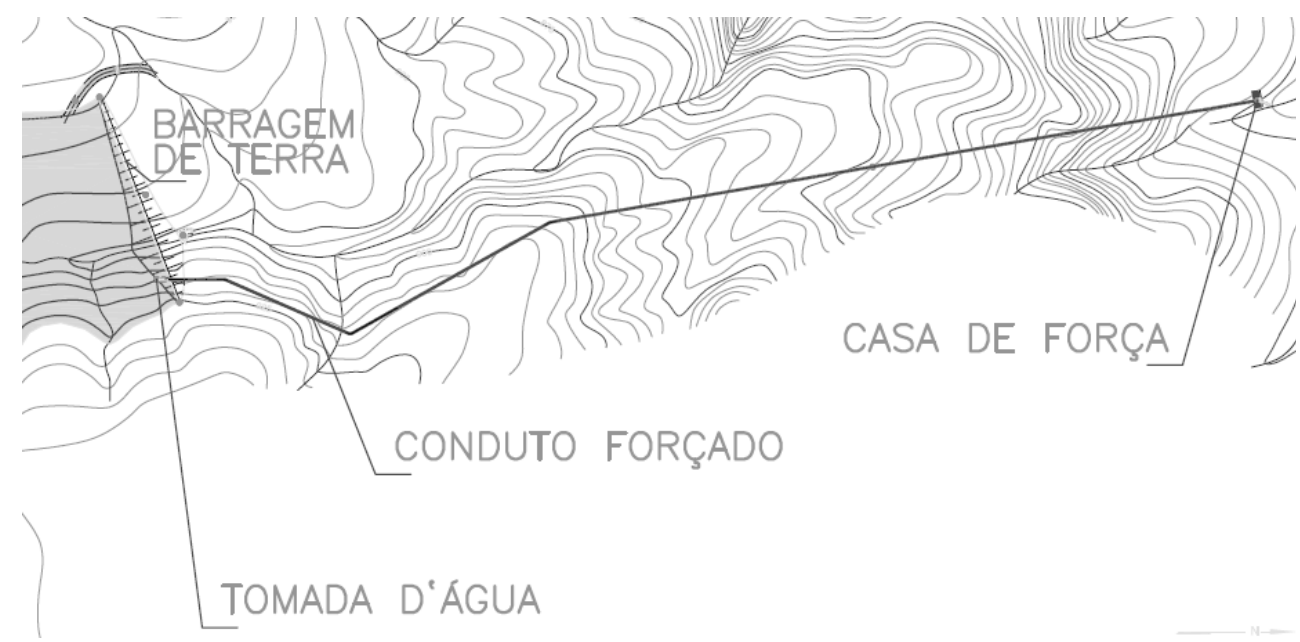

Figura 5.6 - Projeto PCH Santa Maria. Fonte: referência [7].

\subsection{Demanda da propriedade}

Para determinar a demanda das residências da propriedade, é utilizado o método conforme a Recomendação Técnica de Distribuição - RTD - 27, "Critério para Cálculo de Demanda em Edifícios Residenciais de Uso Coletivo", do Comitê de Distribuição - CODI. O conjunto de residências 1 possui nove residências de, aproximadamente $100 \mathrm{~m}^{2}$, resultando em uma demanda de 20,344 $\mathrm{kW}$. O conjunto de residências 2 possui três residências de, aproximadamente $100 \mathrm{~m}^{2}$, resultando em uma demanda de $6,876 \mathrm{~kW}$.

A fábrica de gelo opera oito horas por dia e suas cargas são basicamente os motores e a iluminação. Existem hoje instalados um motor de $75 \mathrm{hp}$, um motor de $55 \mathrm{hp}$, quatro motores de $10 h p$, dez motores de $2 h p$ e a iluminação. A demanda da fábrica de Gelo, utilizado a Norma Técnica de Distribuição - NTD - 6.01/1997, "Fornecimento em Tensão Secundaria de 
Distribuição", da Companhia Energética de Brasília - CEB -, é de, aproximadamente, 140 $k W$. Um fator limitante para o crescimento da fábrica é a disponibilidade de energia. Há o interesse em duplicar a produção da fábrica. Dessa forma, é considerado um crescimento de $100 \%$ da demanda da fábrica.

O proprietário da fazenda Santa Maria informou que existe um projeto para a instalação de oito sistemas de irrigação de pivô central, seis no platô superior, a montante das CGHs, e dois no platô inferior, a jusante das CGHs. O bombeamento da água para os sistemas do platô superior, área 1, será realizado por um conjunto moto-bomba com um motor de 100 $k W$. Nos dois pivôs do platô inferior, área 2, não haverá bombeamento de água, pois será utilizado o desnível natural do terreno.

O deslocamento da estrutura metálica será realizado por um conjunto de motores. São considerados dez motores de $2 c v$ para cada estrutura com fator de demanda de 0,55, totalizando oitenta motores. Entretanto, não há a necessidade de acionar mais de um pivô, simultaneamente, no platô superior e é considerada a possibilidade de acionamento de um pivô do platô superior e um pivô inferior, simultaneamente. O aumento da demanda, em virtude da execução do projeto de irrigação, é de $157 \mathrm{~kW}$. É mostrado adiante que o sistema de irrigação será utilizado apenas nos meses de maio a setembro.

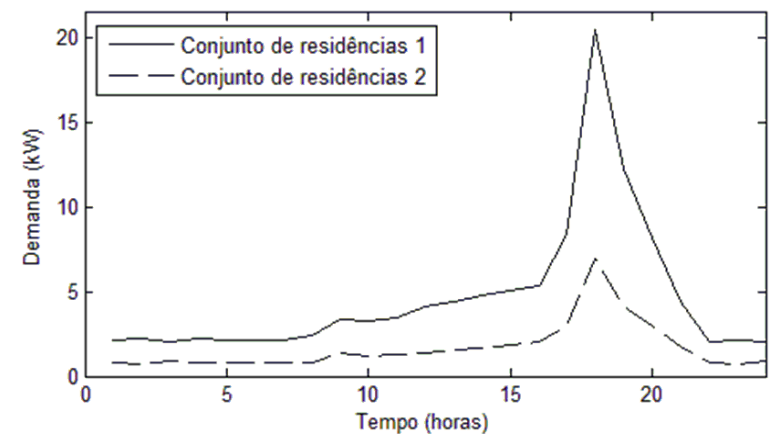

(a)

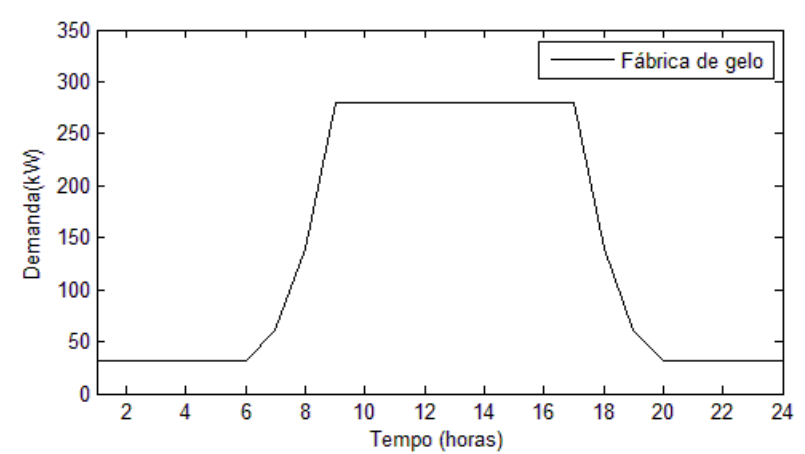

(b)

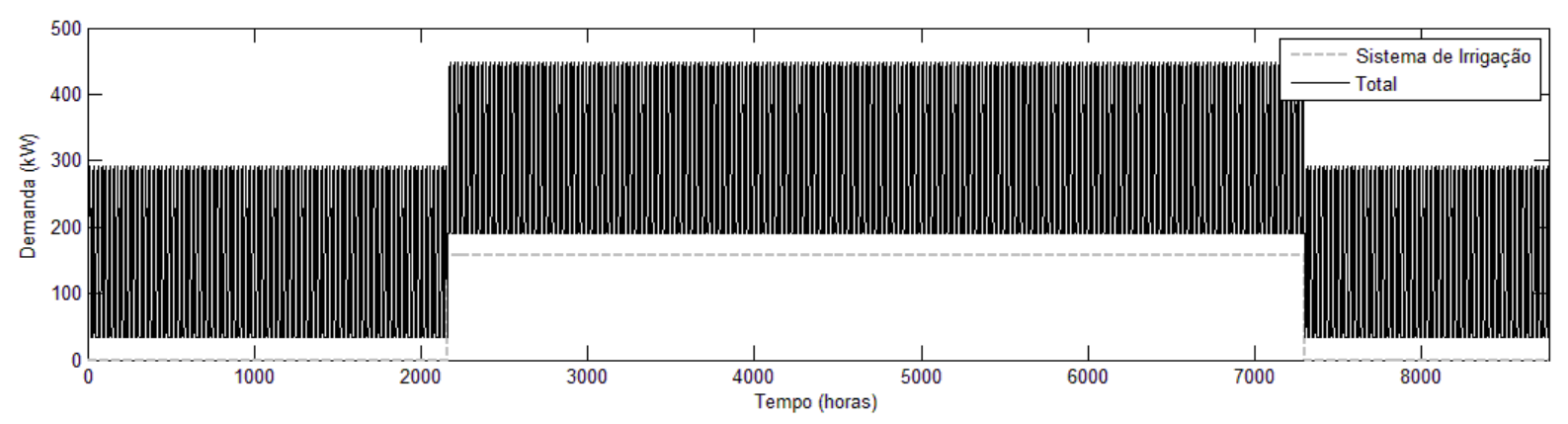

(c)

Figura 5.7 - Demanda futura da propriedade: (a) demanda do conjunto de residências 1 e do conjunto de residências 2; (b) Demanda da fábrica de gelo; (c) demanda do sistema de irrigação e demanda total. 
A figura 5.7 (a) e (b) mostra uma estimativa da demanda futura dos conjuntos de residências e da fábrica de gelo ao longo do dia. A figura 5.7 (c) mostra a demanda do sistema de irrigação e a demanda total da propriedade ao longo do ano.

\subsection{Vazão disponível}

Como a captação de água para seis dos oito pivôs estará à montante das CGHs, a vazão captada para o sistema de irrigação do platô superior é considerada no cálculo da vazão disponível. A tabela 5.3 mostra a precipitação média em cada mês do posto Padre Bernardo nos anos de 1986 a 1997, conforme mostrado na referência [8]. É considerado que uma planta necessita, em média, de $150 \mathrm{~mm}$ de precipitação em um mês de 30 dias. A área 1 possui cerca de $480 h a$ e a área 2 possui cerca de 160 ha. Com essas informações é possível determinar a vazão necessária para a irrigação de cada área, como mostra a tabela 5.3. A captação de água da área 2 não influencia na determinação da vazão disponível, pois está a jusante de todas as CGHs consideradas.

Tabela 5.3 - Cálculo da vazão necessária para irrigação.

\begin{tabular}{l|c|c|c|c|c}
\multicolumn{1}{c|}{ Mês } & $\begin{array}{c}\text { Precipitação } \\
\text { média no } \\
\text { mês }(\mathbf{m m})\end{array}$ & $\begin{array}{c}\text { Altura } \\
\text { requerida no } \\
\text { mês }(\boldsymbol{m})\end{array}$ & $\begin{array}{c}\text { Irrigação } \\
\text { Necessária } \\
\text { no mês }(\boldsymbol{m})\end{array}$ & $\begin{array}{c}\text { Vazão para } \\
\text { irrigação da } \\
\text { área } \mathbf{1}\left(\boldsymbol{m}^{\mathbf{3} / \boldsymbol{s}}\right)\end{array}$ & $\begin{array}{c}\text { Vazão para } \\
\text { irrigação da } \\
\text { área 2 }(\boldsymbol{m} \mathbf{3} \boldsymbol{s})\end{array}$ \\
\hline Janeiro & 167,00 & 0,150 & 0 & 0,000 & 0,000 \\
\hline Fevereiro & 189,20 & 0,140 & 0 & 0,000 & 0,000 \\
\hline Março & 162,80 & 0,155 & 0 & 0,000 & 0,000 \\
\hline Abril & 78,50 & 0,150 & 0,072 & 0,132 & 0,044 \\
\hline Maio & 33,10 & 0,155 & 0,122 & 0,209 & 0,070 \\
\hline Junho & 0,08 & 0,150 & 0,149 & 0,278 & 0,093 \\
\hline Julho & 5,30 & 0,155 & 0,149 & 0,259 & 0,086 \\
\hline Agosto & 15,20 & 0,155 & 0,139 & 0,242 & 0,081 \\
\hline Setembro & 32,70 & 0,150 & 0,117 & 0,217 & 0,072 \\
\hline Outubro & 111,20 & 0,155 & 0,044 & 0,070 & 0,023 \\
\hline Novembro & 177,60 & 0,150 & 0 & 0,000 & 0,000 \\
\hline Dezembro & 206,30 & 0,155 & 0 & 0,000 & 0,000
\end{tabular}

A vazão disponível para geração de energia é as vazões médias mensais descontadas as vazões necessárias para a irrigação e a vazão remanescente. A figura 5.8 apresenta a série de vazões médias mensais disponíveis atualmente e a figura 5.9 mostra a série de vazões médias mensais disponíveis após a conclusão do projeto de irrigação. A figura 5.10 apresenta a curva de duração de vazões disponíveis atualmente e a figura 5.11 mostra a curva de duração de vazões disponíveis após a conclusão do projeto de irrigação. 


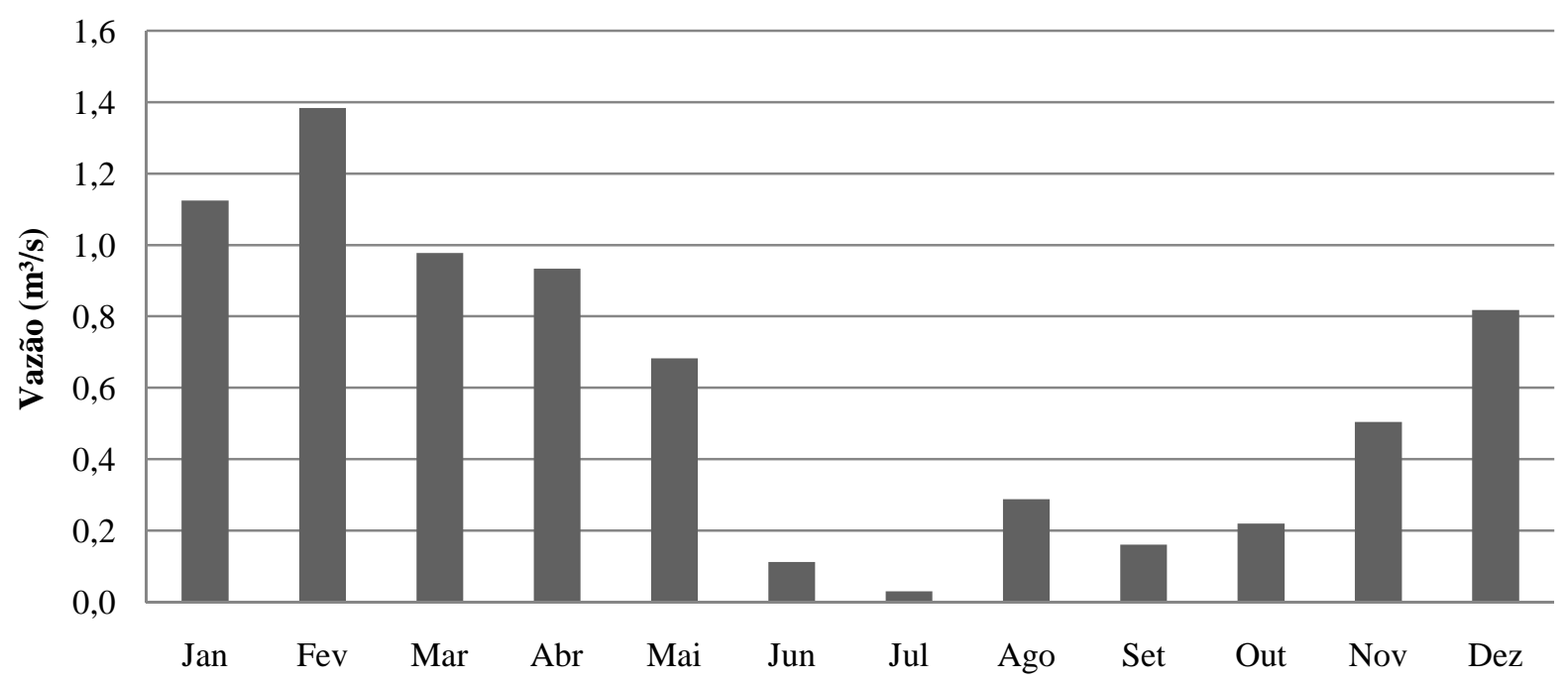

Figura 5.8 - Vazões médias mensais disponíveis atualmente para geração de energia.

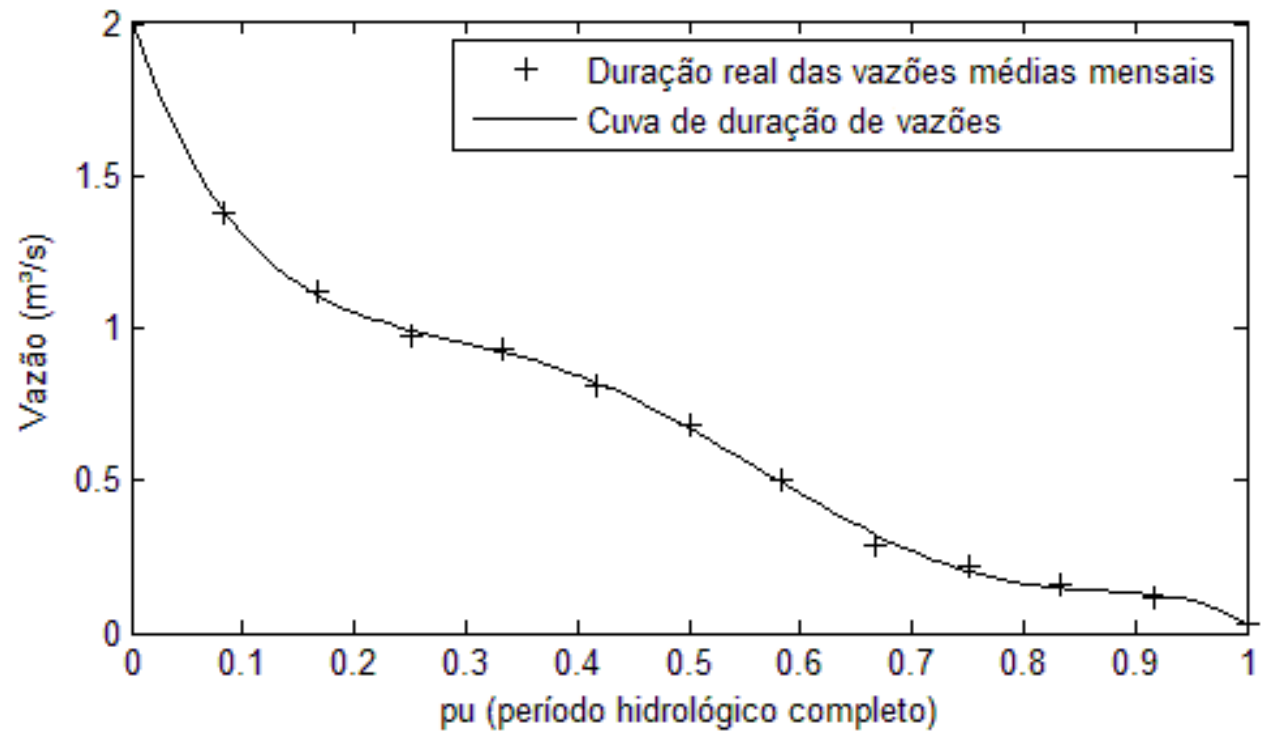

Figura 5.10 - Curva de duração de vazões disponíveis atualmente.

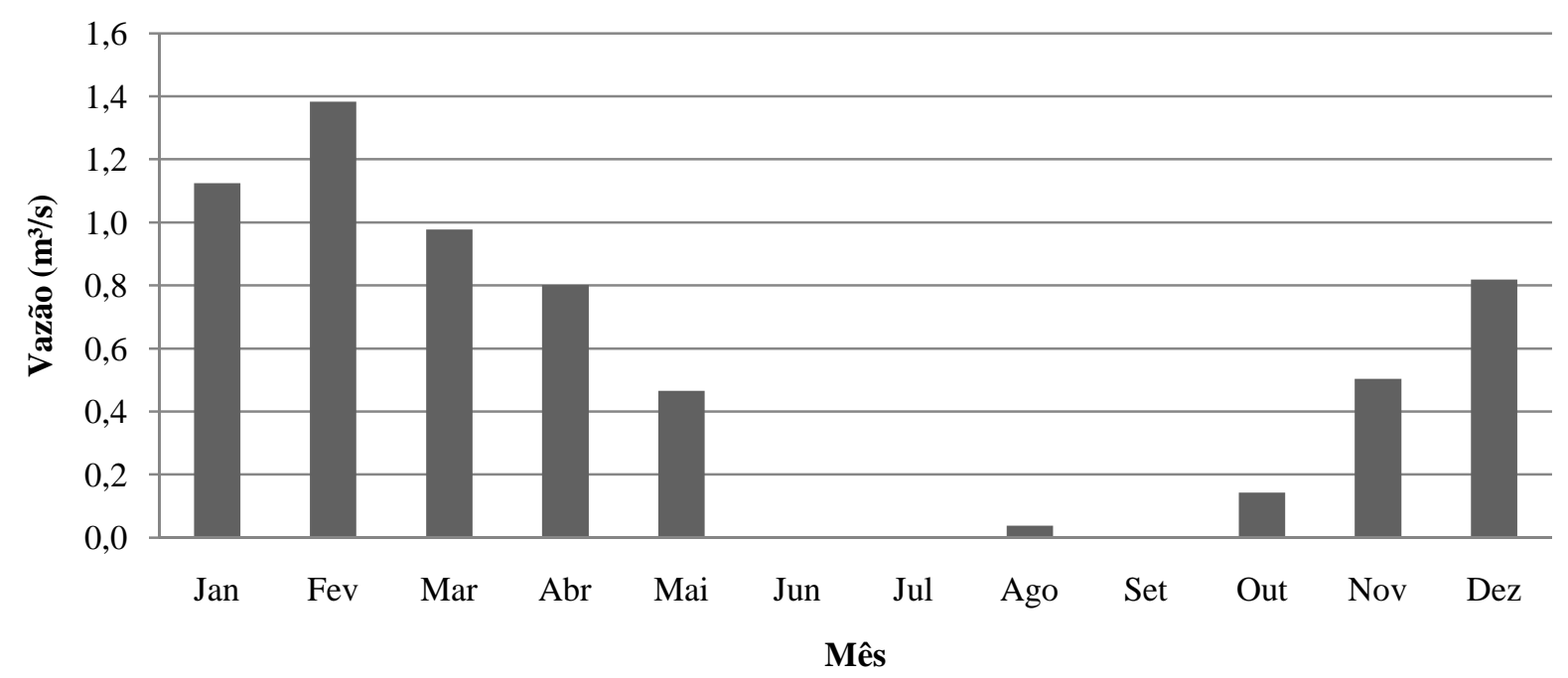

Figura 5.9 - Vazões médias mensais disponíveis para geração de energia após o projeto de irrigação. 


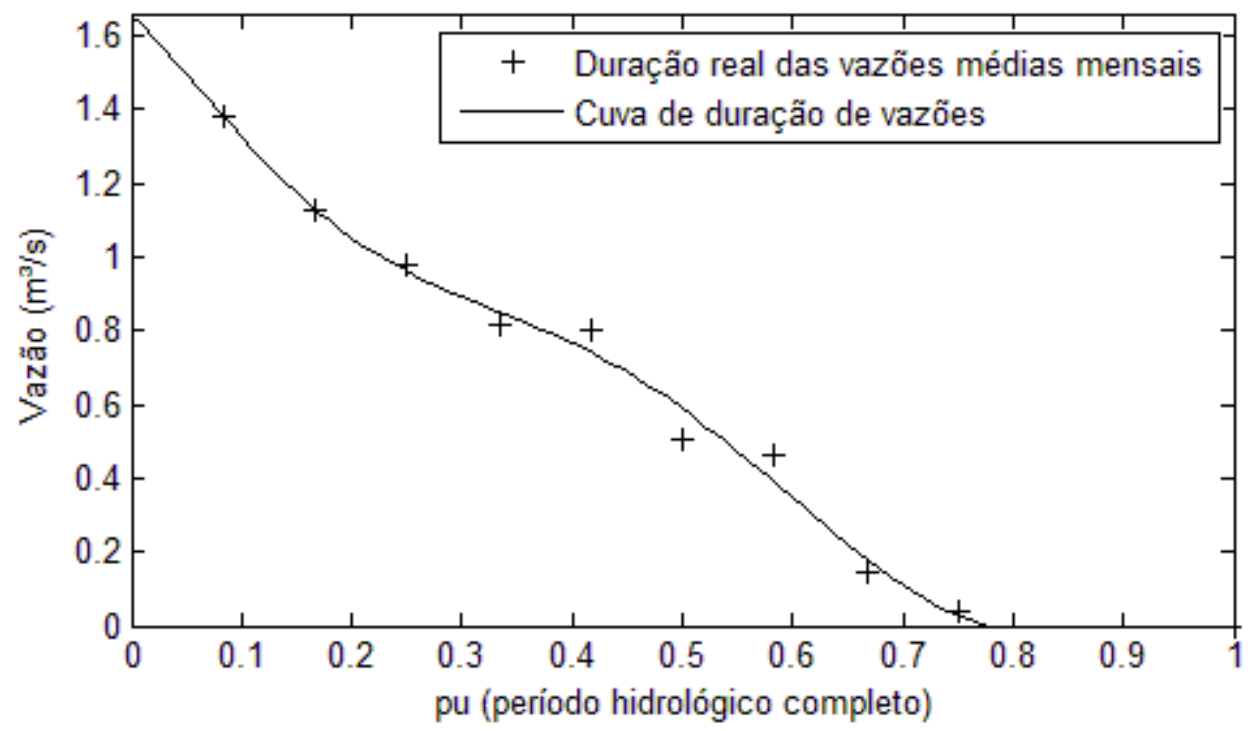

Figura 5.11 - Curva de duração de vazões disponíveis para geração de energia após a execução do projeto de irrigação.

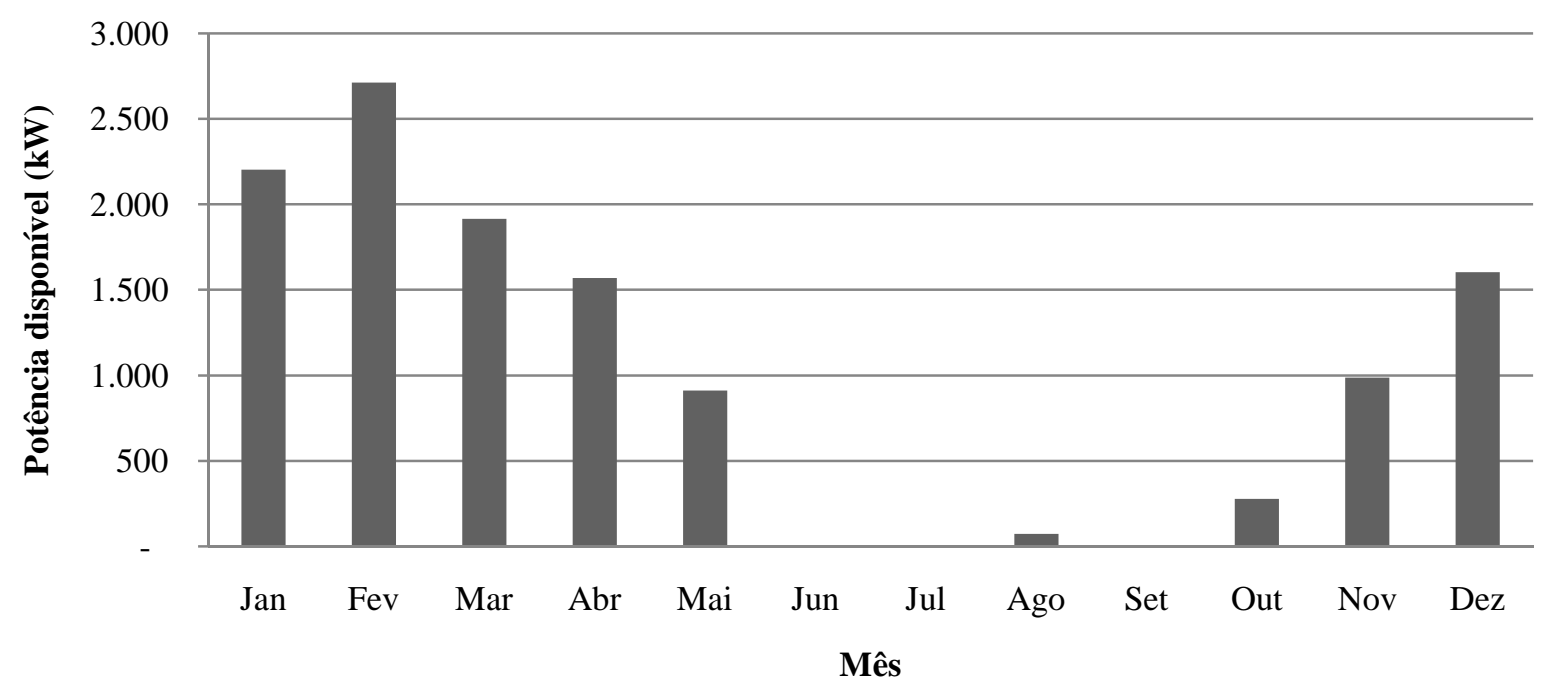

Figura 5.12 - Energia hidráulica disponível no Rio Angicos entre as cotas de $925 \mathrm{~m}$ e $725 \mathrm{~m}$.

A figura 5.12 mostra a energia hidráulica disponível do Rio Angicos entre as cotas de $925 m$ e $725 m$ após a conclusão do projeto de irrigação. Analisando essa figura é possível concluir que existe a possibilidade de ampliação da capacidade de geração no período das cheias.

Como pode ser observado na figura 5.12, não haverá potencial hídrico para geração de energia no período de julho a setembro, após a conclusão dos projetos de irrigação. Considerando que nesse período a demanda de energia será muito grande e a capacidade de geração será praticamente nula, haverá a necessidade de interligação do sistema com a concessionária local. 


\subsection{Exemplo 1 - Central Geradora Hidrelétrica 1}

A CGH 1, com potência instalada de $180 \mathrm{~kW}$, entrou em operação em janeiro de 1981 e, atualmente, supre as cargas de todas as instalações do platô inferior da propriedade: o conjunto de residências 1 e a fábrica de gelo. É uma central hidrelétrica de derivação com uma turbina Pelton e um gerador síncrono de $180 \mathrm{~kW}$. O aproveitamento apresenta uma altura bruta de $85 \mathrm{~m}$ e está localizado a jusante da CGH 2. A figura 5.13 mostra o arranjo da CGH 1. Esse arranjo foi desenhado tendo como base o levantamento topográfico mostrado na figura 5.5 e as coordenadas geográficas coletadas com auxílio de um GPS Garmim eTrex Vista H.

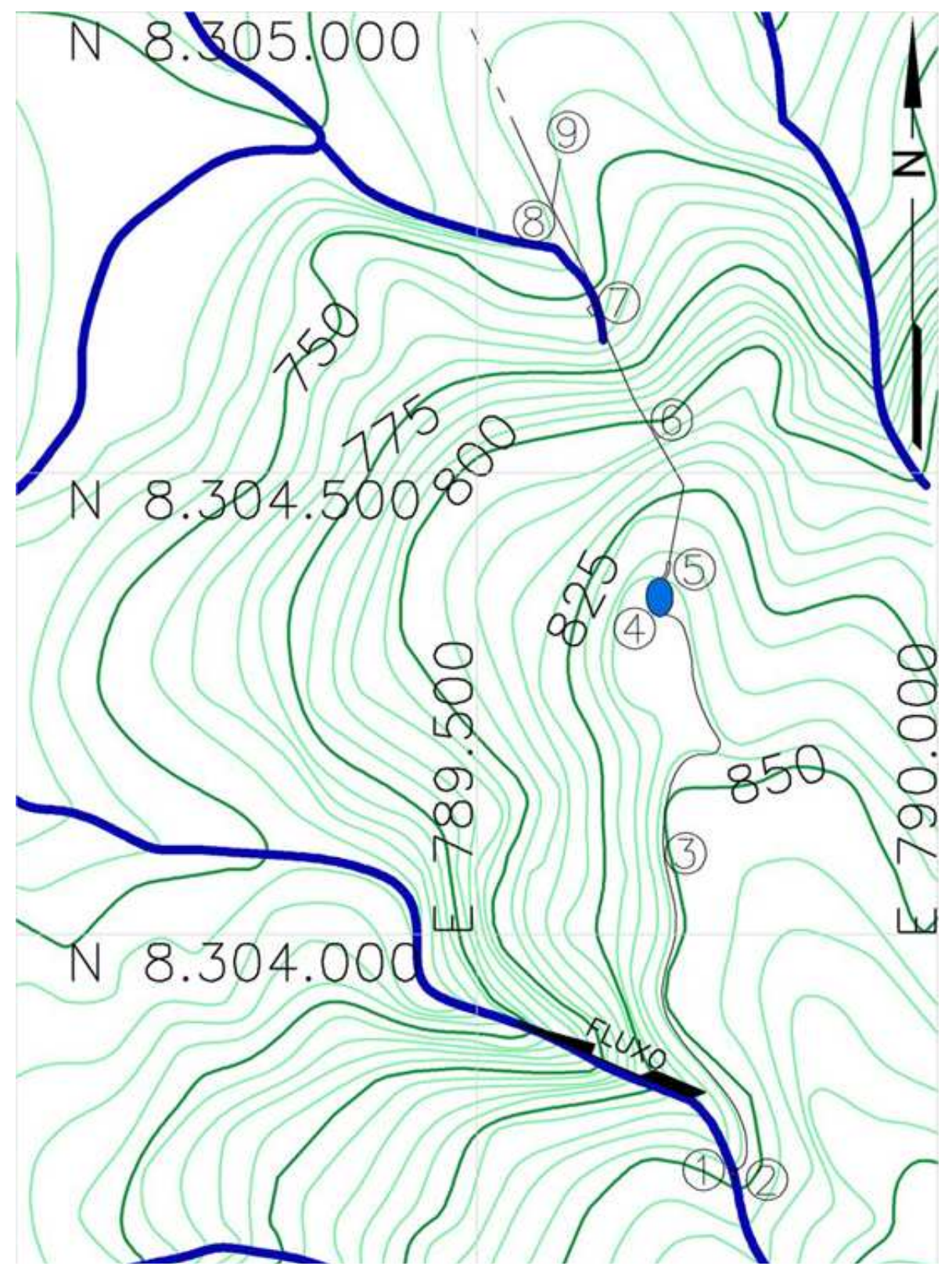

Legenda: 1 - represa; 2 - tomada d'água; 3 - canal de escoamento livre; 4 - represa de decantação; 5 câmara de carga; 6 - tubulação de alta pressão; 7 - casa de máquina; 8 - rede de distribuição; 9 Fábrica de gelo.

Figura 5.13 - Arranjo da CGH 1. 


\subsubsection{Sistema de captação}

O sistema de captação é constituído de uma barragem de alvenaria de pedra e argamassa de cimento e de um extravasador localizado no corpo da barragem. Há uma tomada d'água posicionada na margem direita do rio que capta parte da vazão do manancial para o sistema de adução.

\subsubsection{Sistema de adução}

O sistema de adução é constituído de uma adução em baixa pressão, uma câmara de carga e uma adução em alta pressão. A adução em baixa pressão é um canal de escoamento livre sem revestimento de, aproximadamente $689 \mathrm{~m}$. A jusante da adução de baixa pressão existe uma lagoa para decantação de resíduos sólidos, figura $5.14(\mathrm{a}, \mathrm{b})$. A água é transferida para a câmara de carga por meio de uma estrutura dotada de grades de proteção, figura 5.14 (c). A câmara de carga é dotada de um sistema de proteção com um desarenador, de grades de proteção, de um reservatório de água para garantir a estabilidade do sistema e de uma comporta de limpeza, figura 5.14 (d,e). A adução de alta pressão é um conduto de aço de 296 $m$, figura 5.14 (f). A tubulação é apoiada em blocos de apoio. No final da adução em alta pressão há um bloco de ancoragem na curvatura próxima à casa de máquinas .

\subsubsection{Casa de máquinas}

A casa de máquinas é uma edificação de alvenaria de tijolo e argamassa de cimento e a cobertura é feita com telha de cerâmica, figura 5.15 (a). Essa figura também mostra o início do sistema de distribuição. No interior da casa de máquinas estão instalados o grupo gerador e o quadro de proteção e controle. O grupo gerador, figura 5.15 (b), apresenta uma turbina Pelton e um gerador síncrono de $180 \mathrm{~kW}$, um volante de inércia, uma polia para o acoplamento com o gerador e um sistema de resfriamento. $\mathrm{O}$ sistema de controle da turbina, figura 5.15 (c), está acoplado na agulha do bico injetor da turbina Pelton. Para garantir o suprimento das cargas, há um gerador principal, figura 5.15 (d), e outro de reserva. Os equipamentos de comando, supervisão, controle e proteção estão localizados no quadro de proteção e controle, figura 5.15 (e). 


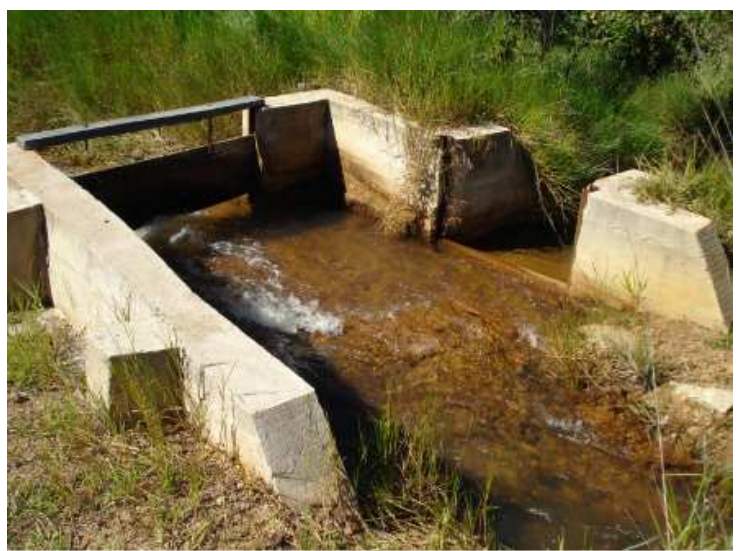

(a)

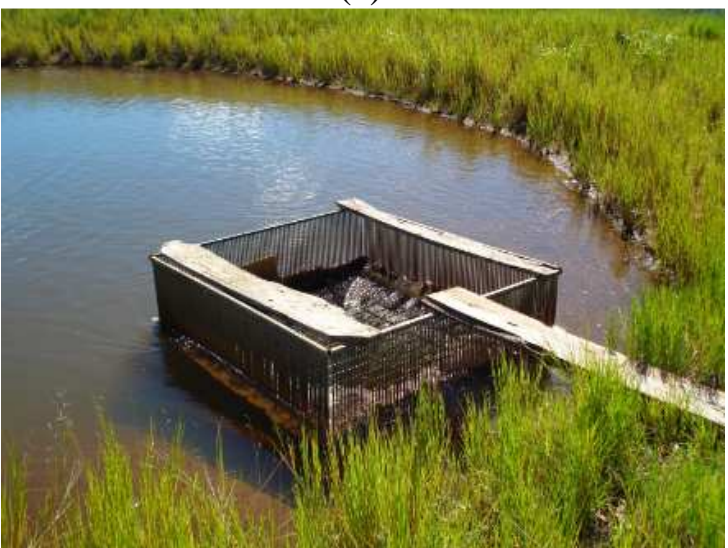

(c)

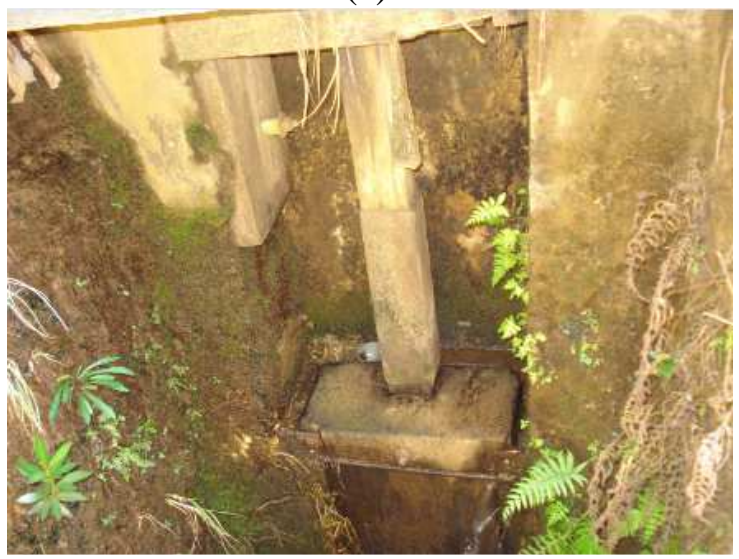

(e)

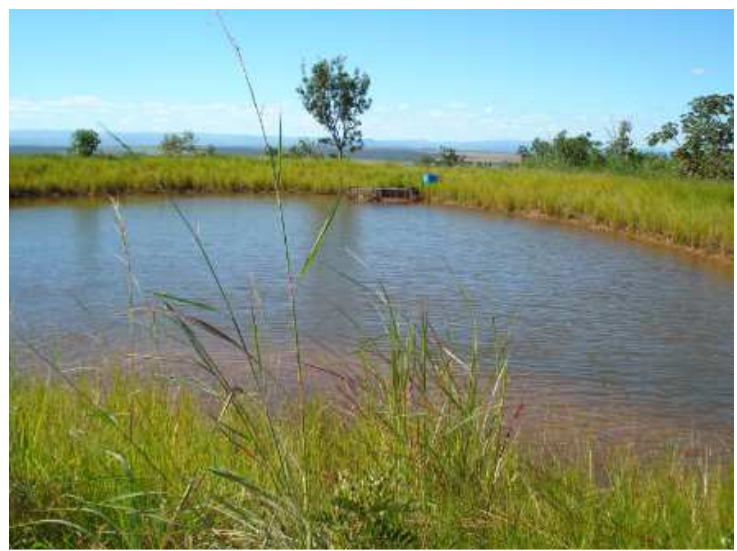

(b)

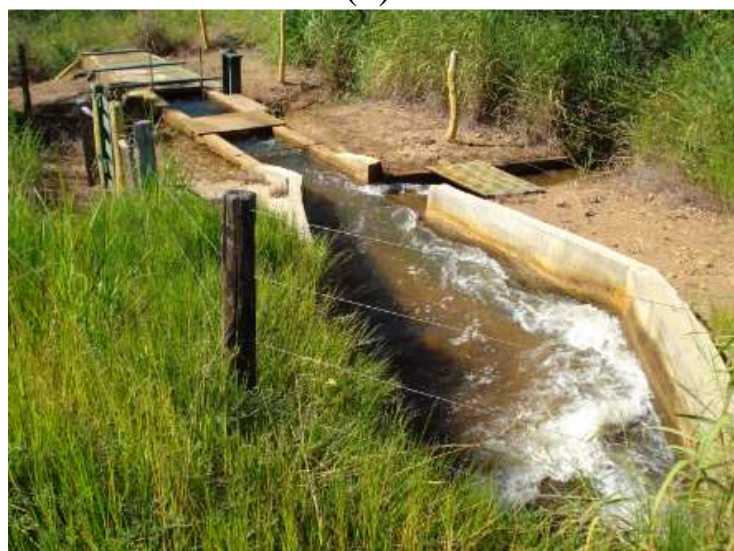

(d)

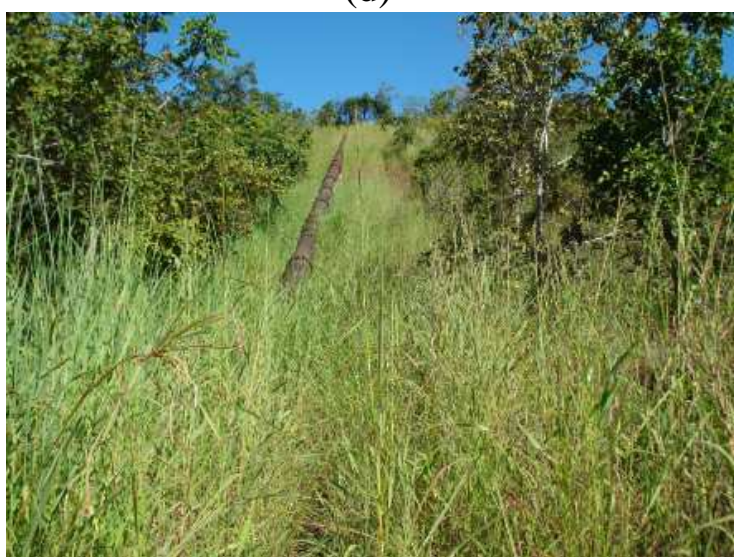

(f)

Figura 5.14 - Sistema de adução da CGH 1: (a) entrada da lagoa de decantação; (b) lagoa de decantação; (c) captação para a câmara de carga e grades de proteção; (d) câmara de carga; (e) comporta de manutenção; (f) conduto de alta pressão. 


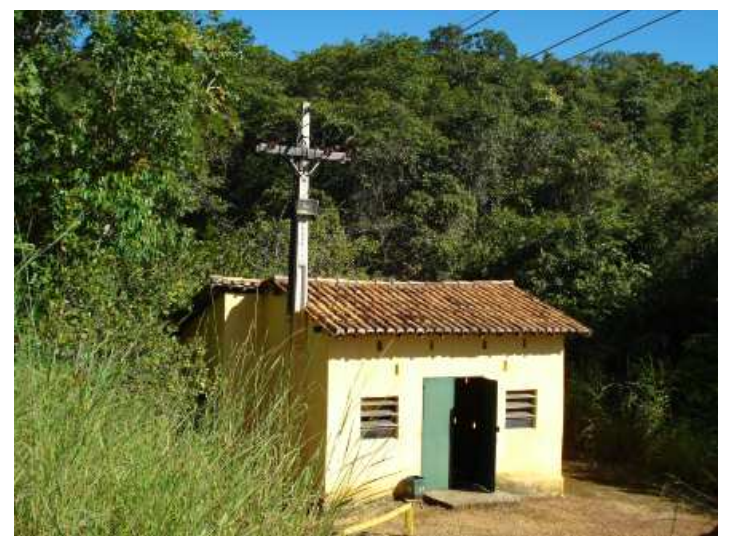

(a)

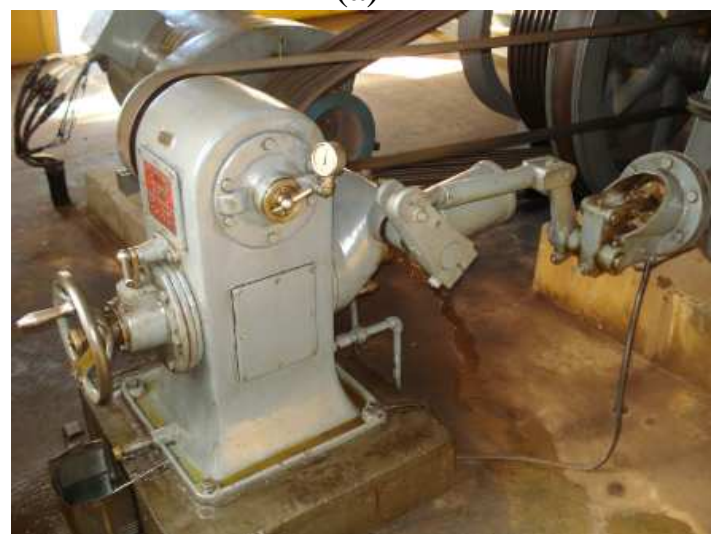

(c)

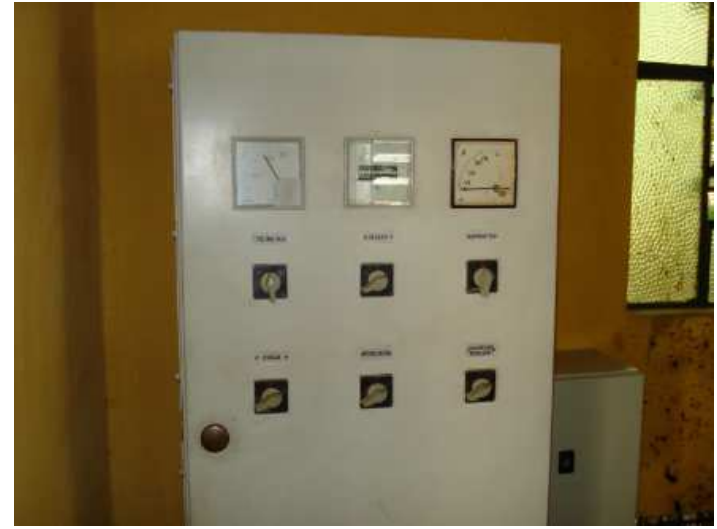

(e)

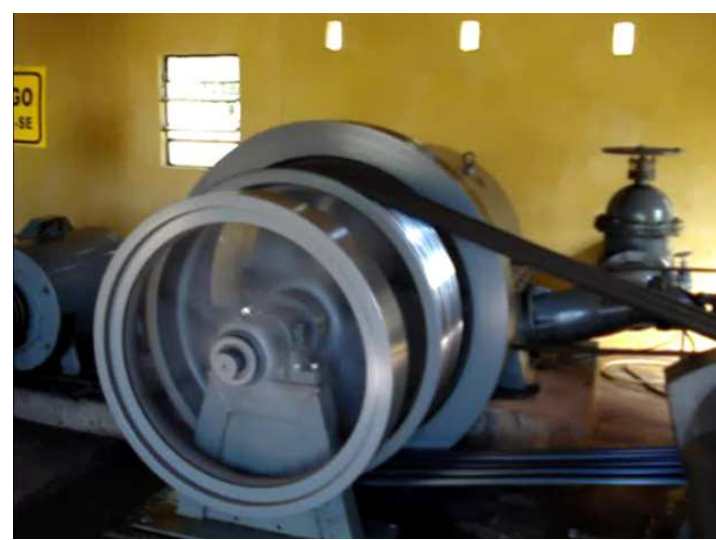

(b)

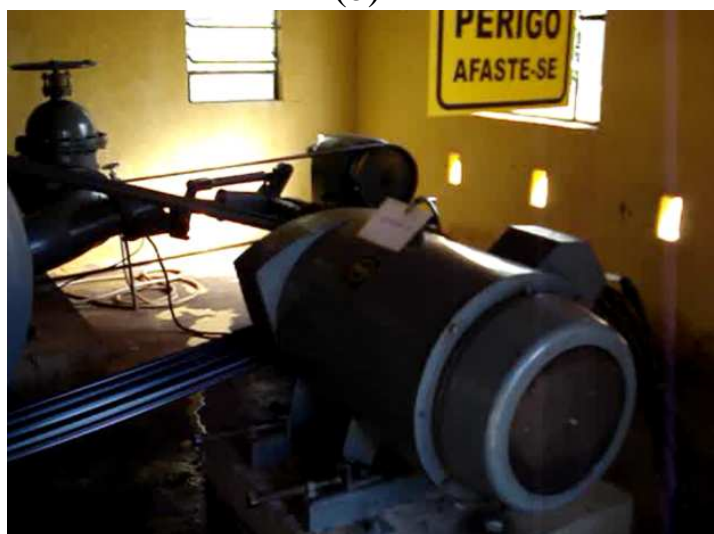

(d)

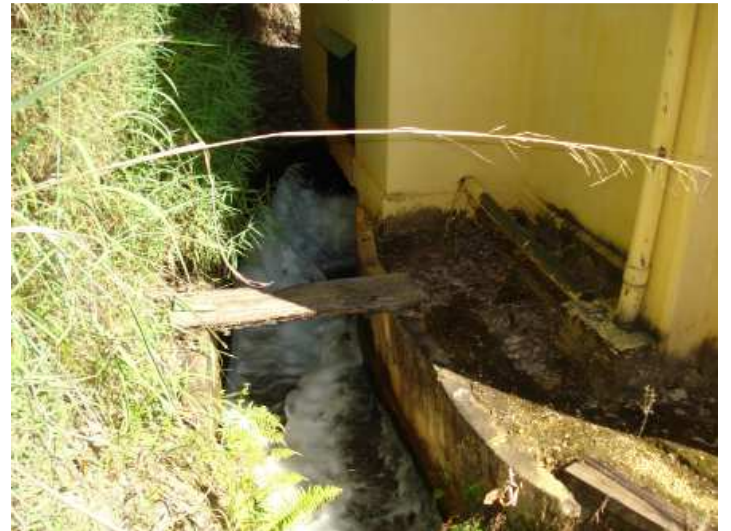

(f)

Figura 5.15 - Casa de Máquinas da CGH 1: (a) Parte externa casa de máquinas e início da linha de transmissão; (b) Turbina Pelton e volante de inércia; (c) sistema de atuação do sistema de controle; (d) Gerador principal; (e) quadro geral; (f) canal de restituição.

\subsection{Exemplo 2 - Central Geradora Hidrelétrica 2}

A CGH 2 é uma CGH com potência instalada de $40 \mathrm{~kW}$ e entrou em operação dez anos após a CGH 1 para alimentar o conjunto de residências 2 localizado no platô superior da propriedade. É uma central hidrelétrica de derivação com uma altura bruta de dez metros e possui uma turbina Francis e um gerador síncrono de $40 \mathrm{~kW}$. A figura 5.16 mostra o arranjo da central hidrelétrica. Esse arranjo foi desenhado tendo como base o levantamento 
topográfico mostrado na figura 5.16 e coordenadas geográficas coletadas com auxilio de um GPS Garmim eTrex Vista H.

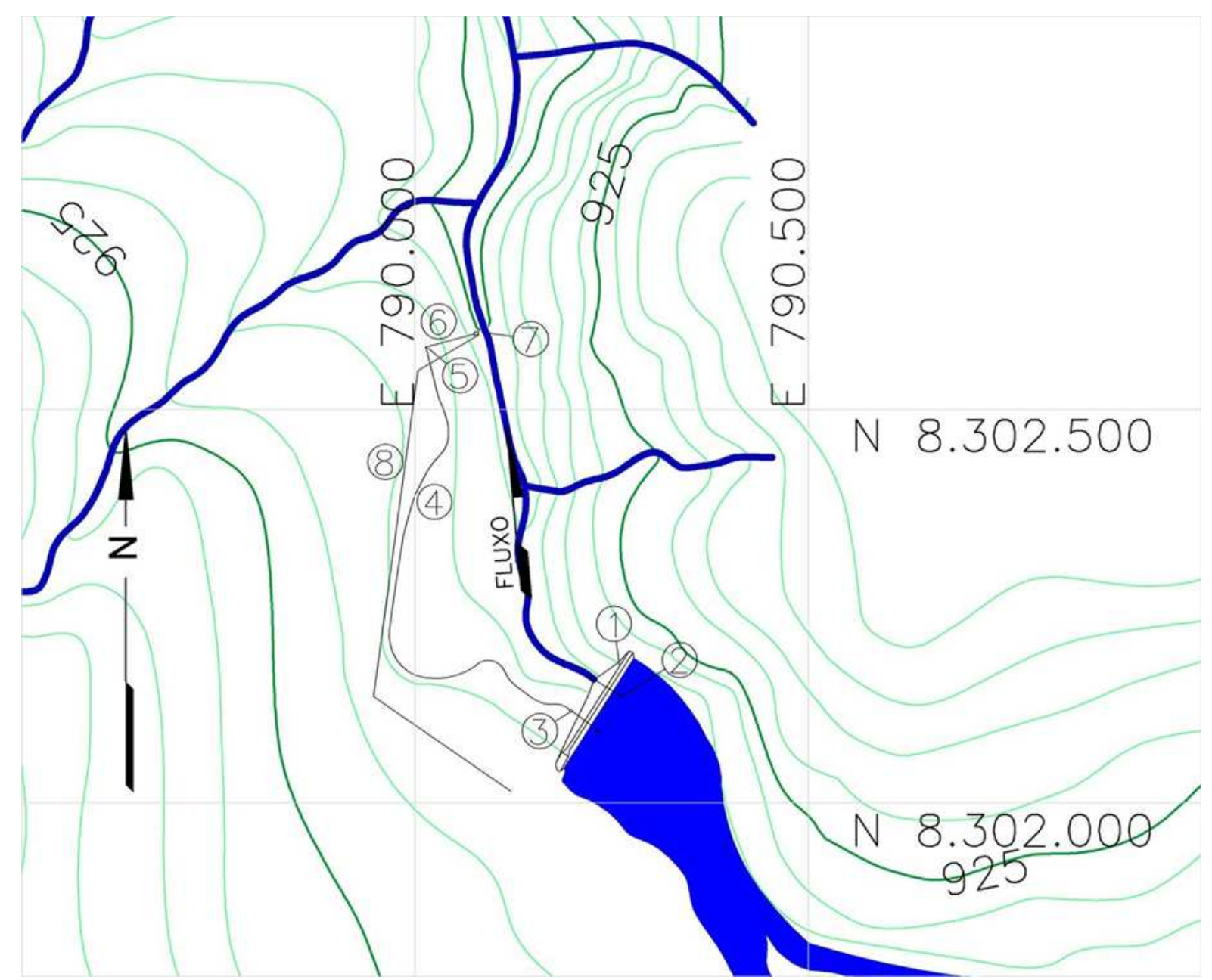

Legenda: 1 - represa; 2 - sistema de controle do nível do reservatório; 3 - tomada d'água; 4 - canal de escoamento livre; 5- câmara de carga; 6 - tubulação de alta pressão; 7 - casa de máquina; 8 - rede de distribuição.

Figura 5.16 - Arranjo da CGH 2.

\subsubsection{Sistema de captação}

O sistema de captação é constituído de uma barragem de terra, um sistema de controle do nível d'água, um extravasador e uma tomada d'água. Considerando que a barragem, figura 5.17 (a), está à montante dos três aproveitamentos ela pode ser utilizada para o armazenamento de água para as três CGHs. O sistema de controle do nível d'água, figura 5.17 (b), permite o controle da variação do nível do reservatório. Esse sistema é comumente conhecido como castelo d'água. O extravasador, figura 5.17 (c), está localizado à margem esquerda da barragem e possibilita o escoamento do excedente de água das cheias, sem comprometer a estrutura da barragem. A tomada d'água, figura 5.17 (d), apresenta a mesma estrutura do controle do nível d'água possibilitando o controle da vazão d'água destinada à geração de energia na CGH 2. 


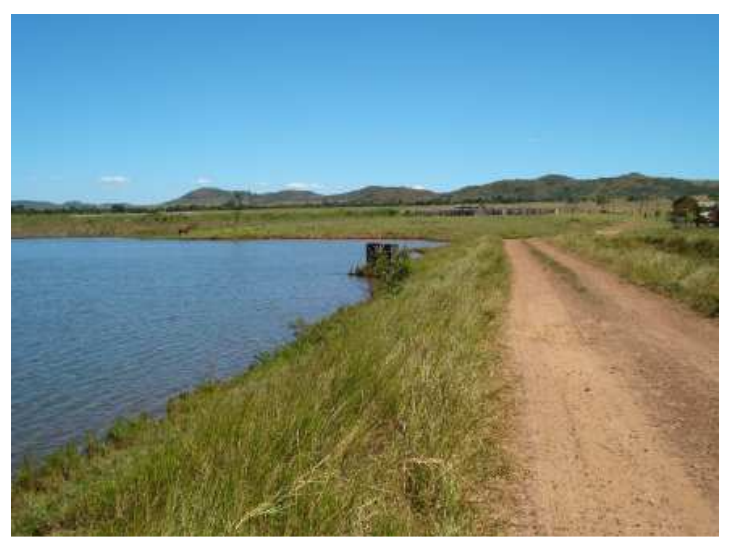

(a)

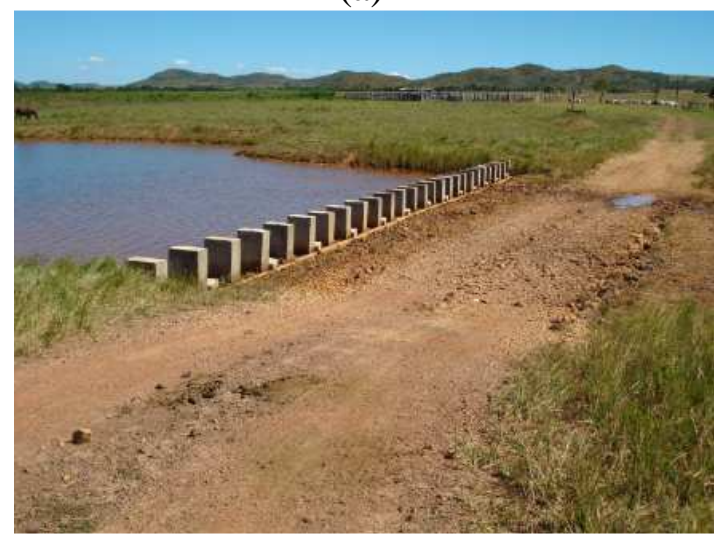

(c)

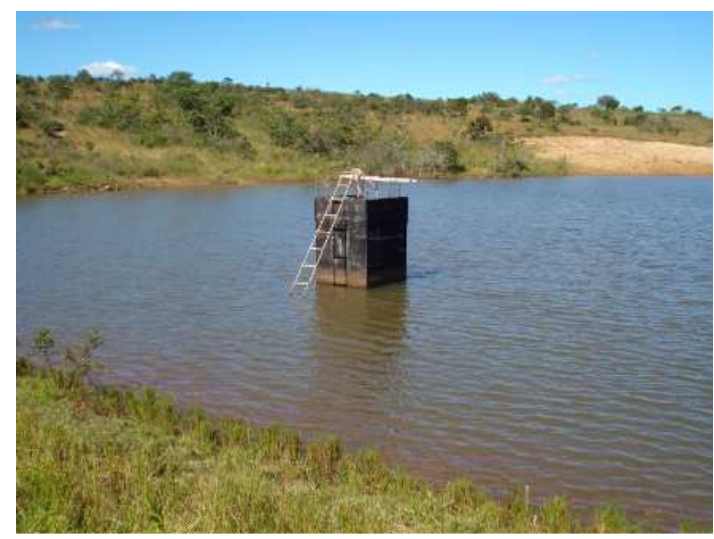

(b)

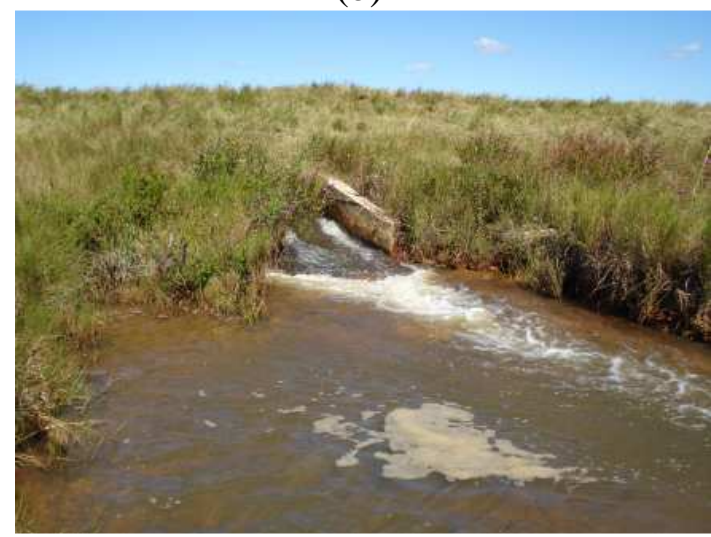

(d)

Figura 5.17 - Sistema de captação da CGH 2: (a) barragem de terra e entrada da tomada d'água; (b) sistema de controle do nível d'água; (c) extravasador; (d) saída da tomada d'água.

\subsubsection{Sistema de adução}

O sistema de adução é constituído de uma adução em baixa pressão, uma câmara de carga e uma adução em alta pressão. A adução em baixa pressão é um canal de escoamento livre sem revestimento de, aproximadamente $682 \mathrm{~m}$, figura 5.18 (a). A câmara de carga possui um sistema de proteção com um desarenador e grades de proteção, figura 5.18 (b, c, d). A adução de alta pressão possui $65 \mathrm{~m}$, figura 5.18 (f). A tubulação é apoiada em blocos de apoio e existe um bloco de ancoragem na curvatura próxima à casa de máquinas.

\subsubsection{Casa de máquinas}

A casa de máquinas é uma edificação de alvenaria de tijolo cerâmico e argamassa de cimento e a cobertura é feita com telha de cimento e fio sintético, figura 5.19 (a). Essa figura também mostra o início do sistema de distribuição. No interior da casa de máquinas estão instalados: a turbina, figura 5.19 (b), que apresenta um volante de inércia, uma polia para o acoplamento com o gerador e um sistema de resfriamento; o sistema de atuação de controle da turbina, figura 5.19 (c), que está acoplado às pás diretrizes da turbina; os dois geradores, 
figura 5.19 (d), um principal e outro de reserva; o quadro geral, figura 5.19 (e) onde estão localizados os equipamentos de comando, supervisão, controle e proteção; o ducto de sucção da turbina está localizado abaixo da casa de máquinas, figura 5.19 (f).

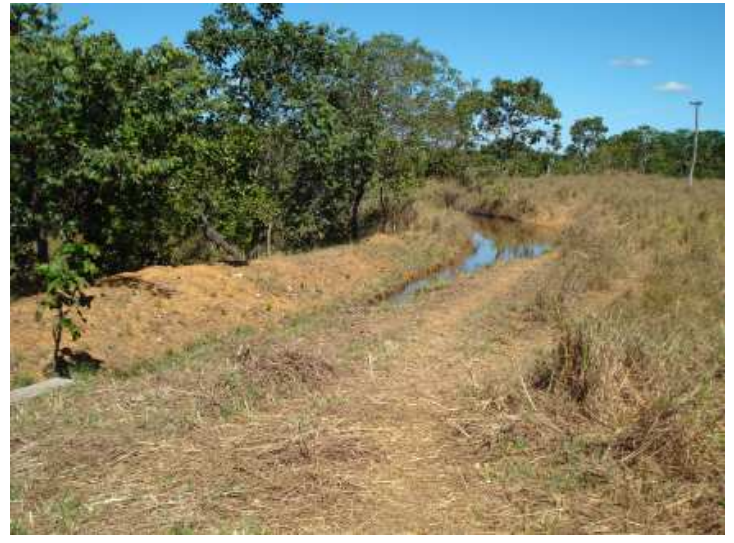

(a)

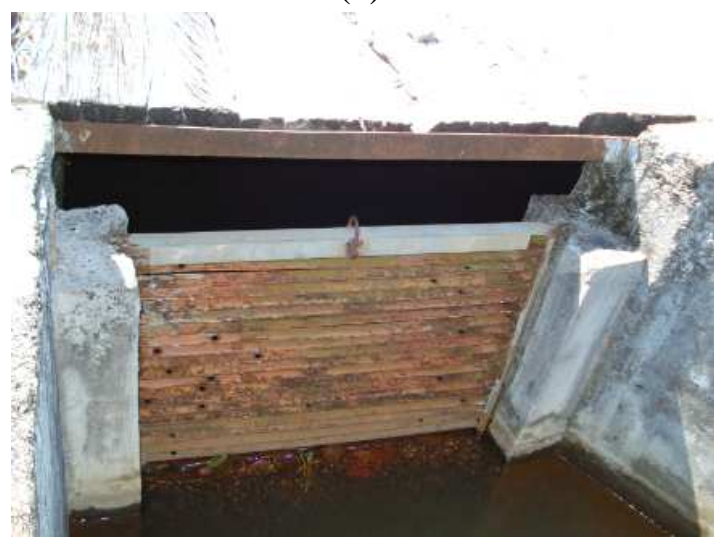

(c)

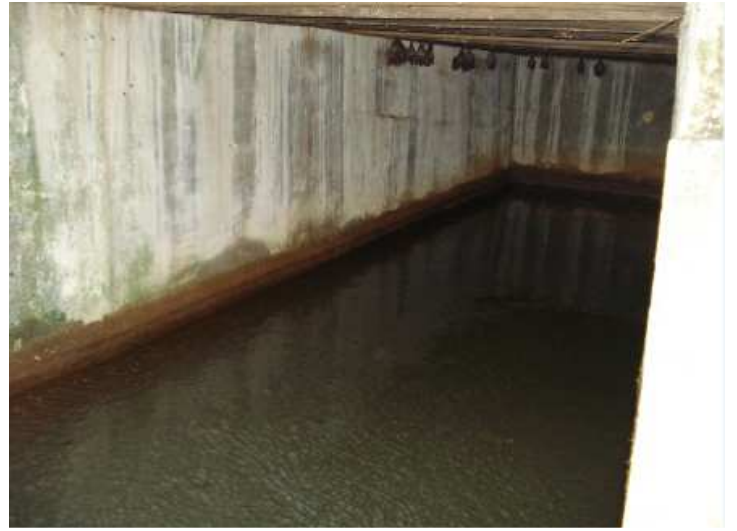

(e)

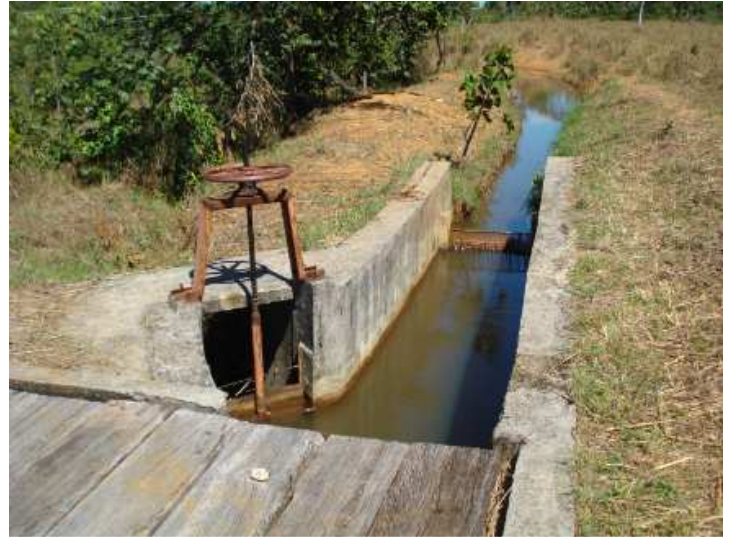

(b)

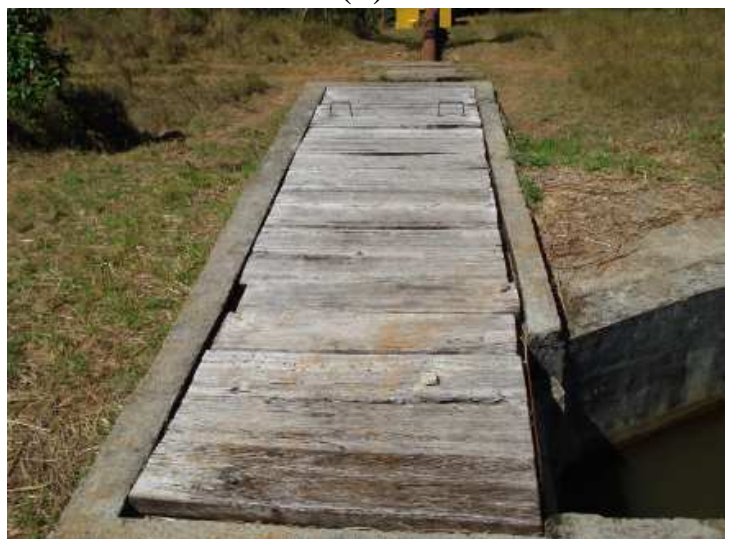

(d)

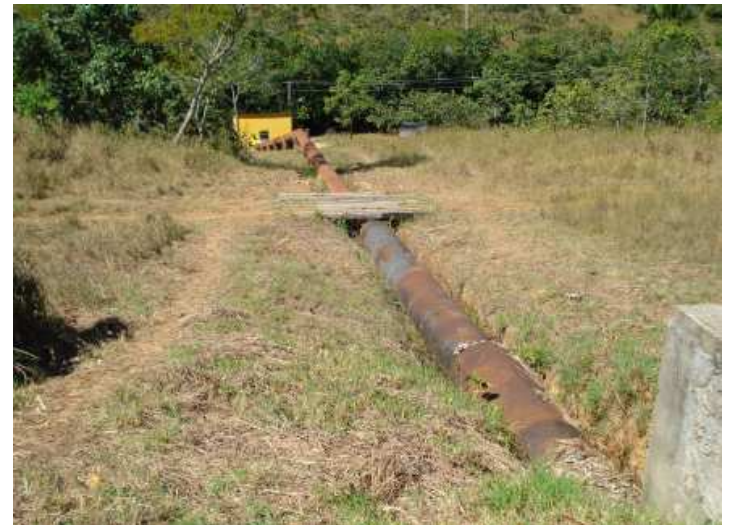

(f)

Figura 5.18 - Sistema de adução: (a) canal de escoamento livre; (b) desarenador; (c) grade de proteção e comporta de manutenção; (c) grade de proteção; (d) reservatório da câmara de carga; (e) Interior do reservatório da câmara de carga; (f) conduto de alta pressão. 


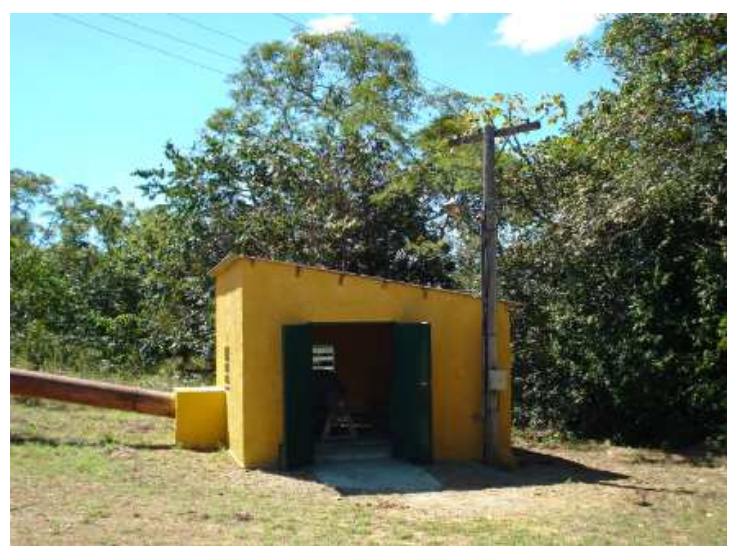

(a)

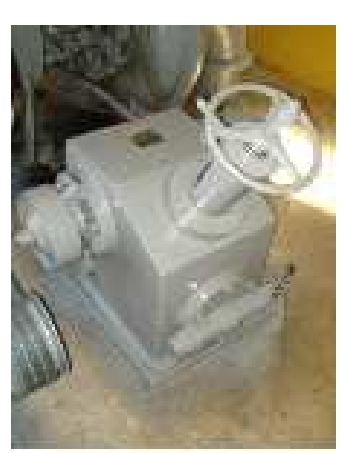

(c)

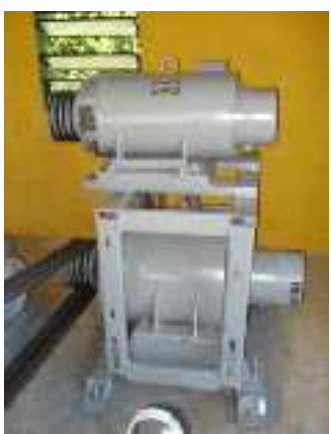

(d)

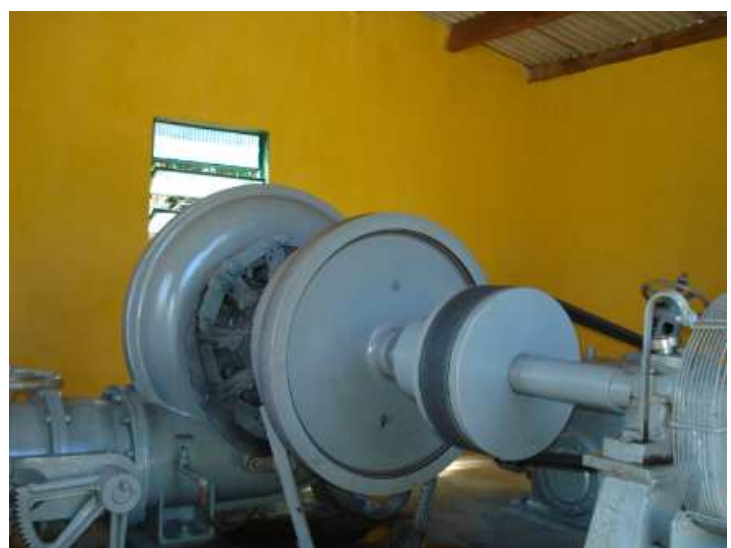

(b)

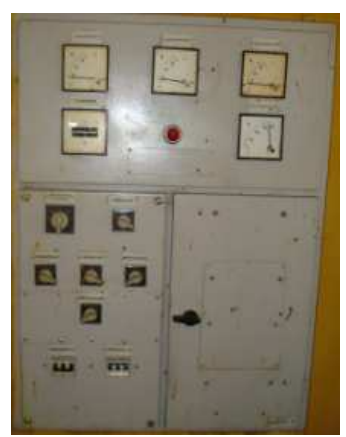

(e)

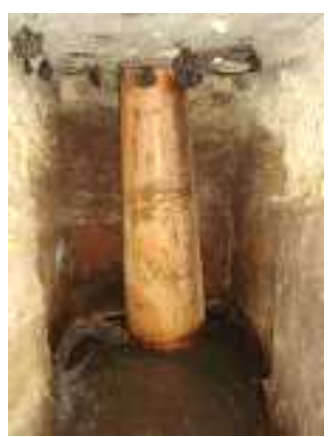

(f)

Figura 5.19 - Casa de Máquinas: (a) Casa de máquinas e início da linha de transmissão; (b) turbina; (c) sistema de controle; (d) geradores; (e) quadro geral; (f) tubo de sucção da turbina hidráulica.

\subsection{Exemplo 3 - Análise de viabilidade da CGH 3}

No trecho do Rio Angicos a montante da CGH 1 e a jusante da CGH 2 há uma queda de, aproximadamente, $50 \mathrm{~m}$. Atualmente esse potencial hídrico não é utilizado para nenhuma atividade. Nessa sessão será analisada a viabilidade de instalar um novo aproveitamento, a $\mathrm{CGH} 3$, para compor um sistema interligado com as demais CGH da propriedade e com a concessionária local, a Companhia Energética de Goiás - CELG.

Algumas considerações são feitas para o desenvolvimento desse trabalho. A primeira é que a compra de todo o excedente gerado será realizada pela concessionária local. A segunda é que não haverá interrupção da compra e que toda energia excedente será integralmente vendida.

\subsubsection{Determinação dos arranjos}

A figura 5.20 apresenta o trecho do Rio Angicos entre o sistema de restituição da CGH 2 e o sistema de captação da CGH 1. Como indicado na figura, esse trecho está entre cota 900 $m$ e $850 \mathrm{~m}$ totalizando um desnível de $50 \mathrm{~m}$. Considerando que o solo do local estudado não é 
arenoso e os canais de escoamento livre das demais CGHs da propriedade não apresentam problemas de infiltração, o arranjo escolhido é uma central hidrelétrica de derivação. A escolha desse arranjo tem como objetivo a redução de custos, pois o custo por metro de tubulação é maior que o custo por metro do canal de escoamento livre sem revestimento, conforme apresentado na tabela 4.3.

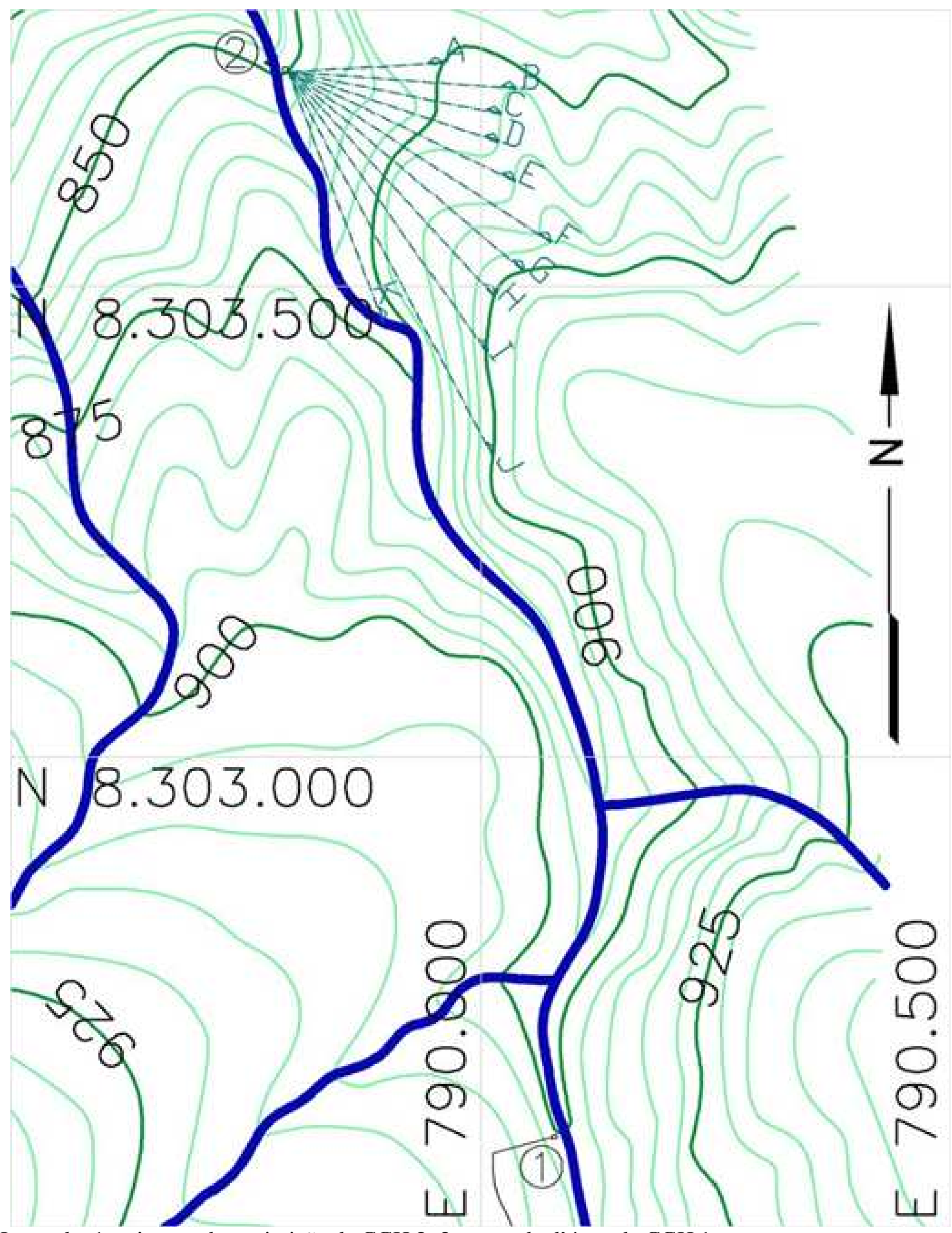

Legenda: 1 - sistema de restituição da CGH 2;2 - tomada d'água da CGH 1.

Figura 5.20 - Possibilidades de arranjo para a análise do aproveitamento CGH 3. 
Para a determinação do arranjo e da potência instalada que resultará no melhor resultado econômico, são utilizados os desenvolvimentos de análise de viabilidade econômica apresentados no capítulo 4. Para todos os arranjos, é considerado que a casa de máquinas estará posicionada na cota $850 \mathrm{~m}$. Como indicado na figura 5.20, são traçados 11 cortes onde é possível instalar o conduto de alta pressão. O apêndice VIII mostra o perfil longitudinal de cada corte. O sistema de adução em baixa pressão é posicionado ao longo de uma das cotas de $870 \mathrm{~m}$ a $900 \mathrm{~m}$. A câmara de carga, de cada possibilidade de arranjo, é posicionada em cada interseção de uma cota com um corte. Para cada possibilidade, é calculado o comprimento do sistema de adução em baixa pressão e do sistema de adução em alta pressão. A tabela 5.4 mostra as 50 possibilidades de arranjo consideradas e os respectivos comprimentos do canal de adução forçado e do conduto de alta pressão.

Tabela 5.4 - Comprimento do canal de escoamento livre e da adução em alta pressão para cada possilidade de arranjo da CGH 3.

\begin{tabular}{|c|c|c|c|c|}
\hline \multirow{2}{*}{$\begin{array}{l}\text { Cota } \\
(m)\end{array}$} & \multirow{2}{*}{ Corte } & \multicolumn{2}{|c|}{ Comprimento $(\mathrm{m})$} & \multirow{2}{*}{ Arranjo } \\
\hline & & Tubulação & Canal & \\
\hline \multirow{11}{*}{$\underset{\infty}{\stackrel{0}{\infty}}$} & $A$ & 105 & 247 & 1 \\
\hline & $B$ & 118 & 227 & 2 \\
\hline & C & 137 & 203 & 3 \\
\hline & D & 143 & 183 & 4 \\
\hline & $E$ & 133 & 163 & 5 \\
\hline & $\mathrm{F}$ & 126 & 146 & 6 \\
\hline & G & 125 & 130 & 7 \\
\hline & $\mathrm{H}$ & 129 & 114 & 8 \\
\hline & 1 & 137 & 96 & 9 \\
\hline & $\mathrm{J}$ & 152 & 72 & 10 \\
\hline & $\mathrm{K}$ & 175 & 41 & 11 \\
\hline \multirow{10}{*}{$\underset{\infty}{n}$} & $A$ & 167 & 377 & 12 \\
\hline & $\mathrm{B}$ & 161 & 355 & 13 \\
\hline & $\mathrm{C}$ & 163 & 335 & 14 \\
\hline & $\mathrm{D}$ & 163 & 315 & 15 \\
\hline & $E$ & 155 & 293 & 16 \\
\hline & $\mathrm{F}$ & 148 & 273 & 17 \\
\hline & $G$ & 147 & 255 & 18 \\
\hline & $\mathrm{H}$ & 153 & 235 & 19 \\
\hline & 1 & 166 & 211 & 20 \\
\hline & $\mathrm{J}$ & 193 & 176 & 21 \\
\hline \multirow{4}{*}{ \& } & $\mathrm{B}$ & 246 & 564 & 22 \\
\hline & C & 232 & 529 & 23 \\
\hline & D & 238 & 499 & 24 \\
\hline & $E$ & 195 & 441 & 25 \\
\hline
\end{tabular}

\begin{tabular}{|c|c|c|c|c|}
\hline \multirow{2}{*}{$\begin{array}{l}\text { Cota } \\
\text { (m) }\end{array}$} & \multirow{2}{*}{ Corte } & \multicolumn{2}{|c|}{ Comprimento $(\mathrm{m})$} & \multirow{2}{*}{ Arranjc } \\
\hline & & Tubulação & Canal & \\
\hline \multirow{5}{*}{ 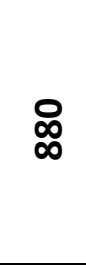 } & $\mathrm{F}$ & 167 & 401 & 26 \\
\hline & G & 161 & 380 & 27 \\
\hline & $\mathrm{H}$ & 166 & 359 & 28 \\
\hline & 1 & 184 & 331 & 29 \\
\hline & $\mathrm{J}$ & 227 & 280 & 30 \\
\hline \multirow{6}{*}{$\stackrel{\infty}{\infty}$} & $E$ & 271 & 611 & 31 \\
\hline & $\mathrm{F}$ & 260 & 561 & 32 \\
\hline & G & 227 & 516 & 33 \\
\hline & $\mathrm{H}$ & 222 & 487 & 34 \\
\hline & 1 & 257 & 440 & 35 \\
\hline & $\mathrm{J}$ & 364 & 327 & 36 \\
\hline \multirow{5}{*}{ ஓ్ } & $\mathrm{F}$ & 319 & 746 & 37 \\
\hline & G & 261 & 677 & 38 \\
\hline & $\mathrm{H}$ & 263 & 644 & 39 \\
\hline & 1 & 312 & 583 & 40 \\
\hline & $\mathrm{J}$ & 412 & 472 & 41 \\
\hline \multirow{5}{*}{ Цొ } & $\mathrm{F}$ & 337 & 882 & 42 \\
\hline & G & 305 & 831 & 43 \\
\hline & $\mathrm{H}$ & 303 & 791 & 44 \\
\hline & 1 & 344 & 732 & 45 \\
\hline & $\mathrm{J}$ & 436 & 629 & 46 \\
\hline \multirow{4}{*}{ ৪্ } & G & 333 & 1077 & 47 \\
\hline & $\mathrm{H}$ & 328 & 1033 & 48 \\
\hline & 1 & 369 & 973 & 49 \\
\hline & $\mathrm{J}$ & 467 & 861 & 50 \\
\hline
\end{tabular}




\subsubsection{Determinação da demanda}

Para a realização do desenvolvimento da análise de viabilidade econômica utilizando as vazões médias mensais, apresentado no capítulo 4, é necessário determinar a parcela da demanda que não será suprida pela CGH 1 e pela CGH 2. A figura 5.21 mostra a demanda apresentada da figura 5.7 descontada a parcela que será suprida pela CGH 1 e pela CGH 2 considerando os limites operacionais de cada CGH. Essa demanda é utilizada na análise de viabilidade econômica da CGH 3.

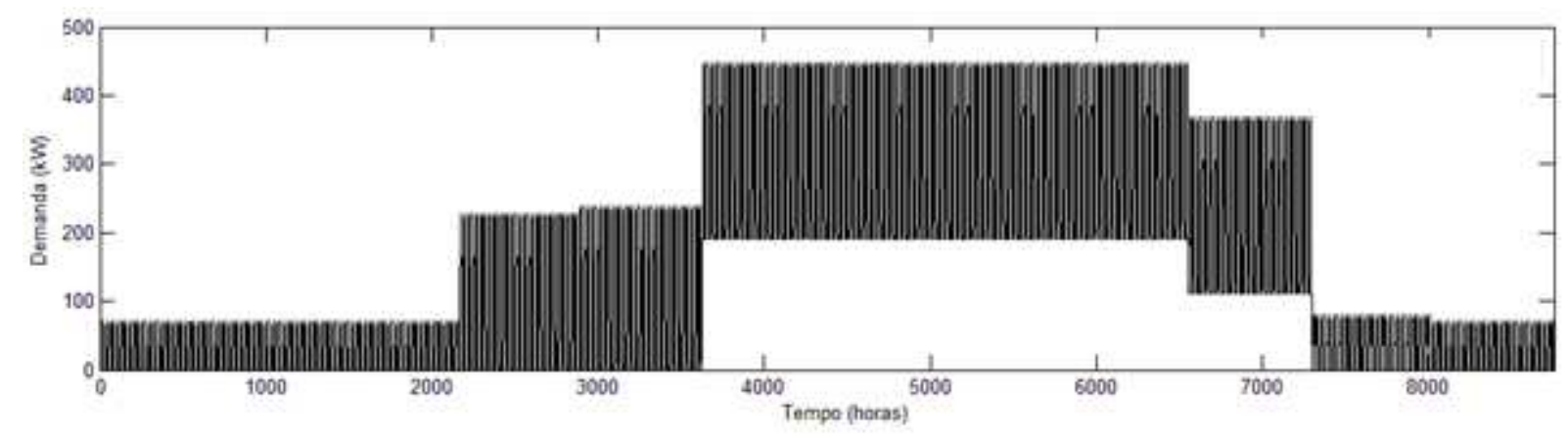

Figura 5.21 - Demanda para a CGH 3.

\subsubsection{Parâmetros utilizados no estudo de viabilidade}

A tabela 5.5 mostra os valores dos parâmetros utilizados para a análise. É considerado o mesmo sistema de captação para todos os arranjos. O estudo econômico tem um horizonte de vinte anos e é considerada uma taxa de $12 \%$ ao ano.

A tarifa de compra de energia utilizada é a série das tarifas médias mensais no centrooeste para o ano de 2009 apresentadas na tabela 5.7. A tarifa de venda de energia é calculada de acordo com a tarifa de venda proposta no projeto de lei 630/03, que é o valor de referência anual acrescido de 10\%, conforme apresentado na tabela 5.6. A tarifa de venda escolhida será referente ao ano de 2009. Os valores da tarifa de compra e de venda ao longo do ano estão apresentados na tabela 5.8 . 
Tabela 5.5 - Dados utilizados para a análise de viabilidade econômica da CGH 3.

Dados Gerais

\begin{tabular}{l|c}
\hline Número de arranjos & 50 \\
\hline Tarifa de energia constante $(R \$ / \mathrm{kWh})$ & 0,16 \\
\hline Taxa de juros $(a a)$ & 0,12 \\
\hline Horizonte da análise econômica $($ anos $)$ & 20 \\
\hline Custo unitário do terreno $(R \$ / h a)$ & 0 \\
\hline
\end{tabular}

Dados variáveis a cada arranjo

\begin{tabular}{l|c}
\hline Área utilizada $(h a)$ & 0 \\
\hline Cota a jusante $(m)$ & 850 \\
\hline Cota a montante $(m)$ & Tabela 5.4 \\
\hline Tipo de Arranjo $(\mathrm{CHR}, \mathrm{CHD}, \mathrm{CHV})$ & ThV \\
\hline Comprimento da adução em alta pressão $(m)$ & Tabela 5.4 \\
\hline Comprimento da adução em baixa pressão $(m)$ & Tabela 4.1 \\
\hline Rendimento da adução em alta pressão & 0,99 \\
\hline Rendimento da adução em baixa pressão & Michell-Banki \\
\hline Tipo de turbina & - \\
\hline Rotação da turbina (Francis) $(r p m)$ & 0,75 \\
\hline Rendimento da turbina & 0,90 \\
\hline Rendimento do gerador & Concreto \\
\hline Tipo da barragem (Terra ou concreto) & 2 \\
\hline Altura da ensecadeira $(m)$ & 5 \\
\hline Comprimento da ensecadeira $(m)$ & 3 \\
\hline Altura da barragem $(m)$ & 10 \\
\hline Comprimento da barragem $(m)$ & 30 \\
\hline Comprimento do canal de fuga $(m)$ & 2550 \\
\hline Comprimento da linha de transmissão $(m)$ &
\end{tabular}

Dados variáveis a cada mês

\begin{tabular}{l|c}
\hline Vazão disponível $\left(\mathrm{m}^{3} / \mathrm{s}\right)$ & Figura 5.9 \\
\hline Tarifa de compra $(R \$ / \mathrm{kWh})$ & Tabela 5.9 \\
\hline Tarifa de venda $(R \$ / \mathrm{kWh})$ & Tabela 5.9 \\
\hline
\end{tabular}

Dados variáveis a cada hora

Demanda $(k W)$

Figura 5.21

Tabela 5.6 - Valor referência anual e tarifa de venda calculada com base no VR. Fonte: referência [17].

\begin{tabular}{c|c|c|c} 
Ano & VR $(\boldsymbol{R} \boldsymbol{\$})$ & Tarifa de Venda $(\boldsymbol{R} \boldsymbol{\$} / \mathbf{M W h})$ & Tarifa de Venda $(\boldsymbol{R} \boldsymbol{\$} / \mathbf{k W h})$ \\
\hline 2008 & 139,44 & 153,38 & 0,158 \\
\hline 2009 & 145,77 & 160,35 & 0,160 \\
\hline 2010 & 145,41 & 159,95 & 0,159
\end{tabular}


Tabela 5.7 - Tarifa média mensal rural para cada região em 2009. Fonte: referência [16].

Tarifa rural média $(R \$ / M W h)$

\begin{tabular}{l|c|c|c|c|c|c}
\hline & $\begin{array}{c}\text { Centro } \\
\text { Oeste }\end{array}$ & Nordeste & Norte & Sudeste & Sul & Brasil \\
\hline Janeiro & 197,91 & 201,00 & 234,81 & 190,18 & 150,40 & $\mathbf{1 7 7 , 2 2}$ \\
\hline Fevereiro & 199,76 & 202,68 & 236,17 & 191,96 & 153,70 & $\mathbf{1 7 9 , 3 1}$ \\
\hline Março & 199,75 & 203,46 & 235,15 & 190,99 & 158,26 & $\mathbf{1 8 1 , 6 8}$ \\
\hline Abril & 202,78 & 203,73 & 236,58 & 194,27 & 160,92 & $\mathbf{1 8 4 , 5 3}$ \\
\hline Maio & 210,55 & 216,43 & 238,11 & 204,27 & 164,65 & $\mathbf{1 9 2 , 3 9}$ \\
\hline Junho & 209,70 & 215,55 & 237,35 & 205,80 & 164,13 & $\mathbf{1 9 3 , 4 3}$ \\
\hline Julho & 209,41 & 212,94 & 235,51 & 201,33 & 164,56 & $\mathbf{1 9 2 , 9 2}$ \\
\hline Agosto & 203,30 & 214,16 & 233,68 & 204,46 & 165,95 & $\mathbf{1 9 4 , 0 1}$ \\
\hline Setembro & 204,76 & 217,66 & 234,71 & 205,18 & 170,12 & $\mathbf{1 9 6 , 4 3}$ \\
\hline Outubro & 207,43 & 205,12 & 239,26 & 205,52 & 170,21 & $\mathbf{1 9 6 , 2 4}$ \\
\hline Novembro & 207,86 & 214,60 & 234,13 & 205,23 & 170,11 & $\mathbf{1 9 5 , 4 1}$ \\
\hline Dezembro & 206,06 & 215,30 & 222,76 & 201,57 & 168,16 & $\mathbf{1 9 2 , 5 6}$
\end{tabular}

Tabela 5.8 - Valores de tarifa de energia $(R \$ / k W h)$.

\begin{tabular}{c|c|c|c|c|c|c|c|c|c|c|c|c} 
& jan & fev & mar & abr & mai & jun & jul & ago & set & out & nov & dez \\
\hline $\begin{array}{c}\text { Compra } \\
(R \$ / k W h)\end{array}$ & 0,198 & 0,200 & 0,200 & 0,203 & 0,211 & 0,210 & 0,209 & 0,203 & 0,205 & 0,207 & 0,208 & 0,206 \\
\hline $\begin{array}{c}\text { Venda } \\
(R \$ / k W h)\end{array}$ & 0,160 & 0,160 & 0,160 & 0,160 & 0,160 & 0,160 & 0,160 & 0,160 & 0,160 & 0,160 & 0,160 & 0,160
\end{tabular}

\subsubsection{Resultados obtidos}

A figura 5.22 e a figura 5.23 apresentam os resultados das análises de viabilidade econômica da CGH 3. Nas figuras apresentadas, é possível analisar que, para todos os arranjos, existe uma faixa de vazão de projeto e potência instalada que torna o empreendimento viável. Todos os indicadores mostram que os arranjos com uma queda bruta maior apresentam um melhor retorno econômico.

A tabela 5.9 e a tabela 5.10 apresentam o arranjo e a potência instalada que maximizam cada indicador. São apresentados os valores da estimativa de custo e do benefício anual referente a cada respectivo arranjo e potência instalada que maximizam cada indicador. A partir dessa tabela é possível verificar que todos os indicadores apontaram o arranjo 48 como o mais viável economicamente. É possível notar que os indicadores da análise utilizando a série de vazões médias mensais apresentaram um melhor resultado, pois essa análise considera uma remuneração maior para a parcela de potência que irá suprir a demanda da propriedade. 


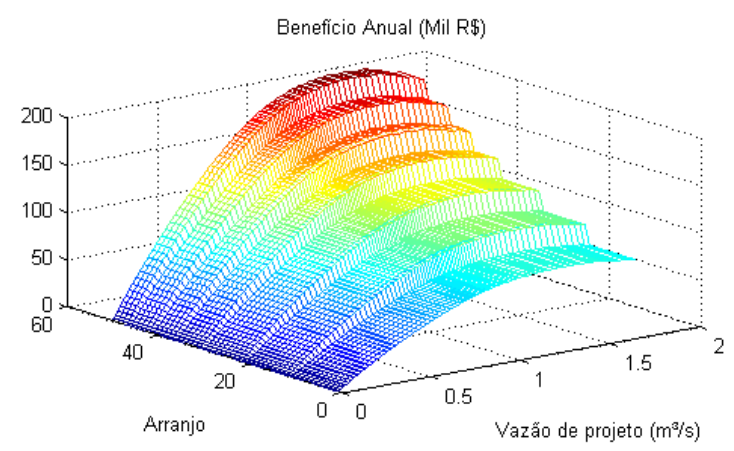

(a)

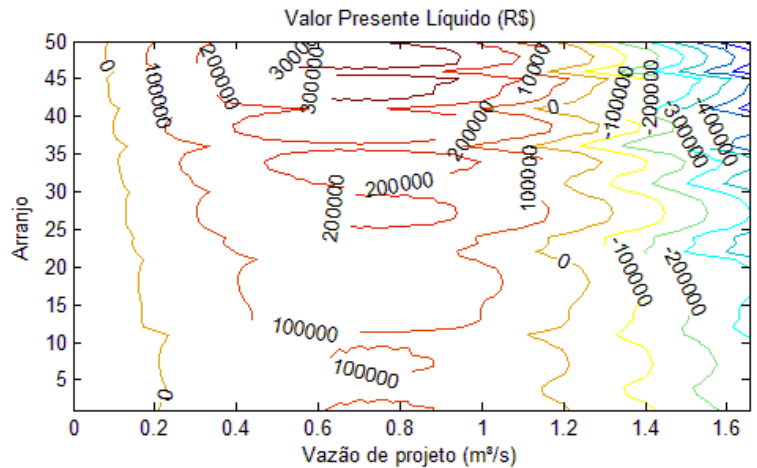

(c)

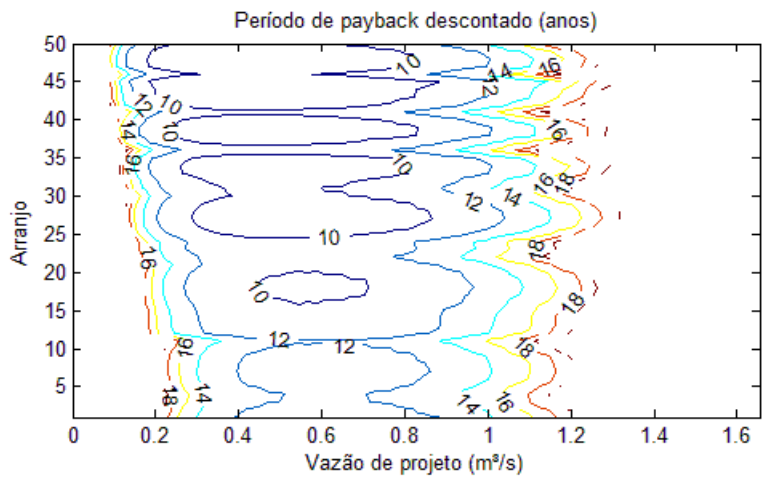

(e)

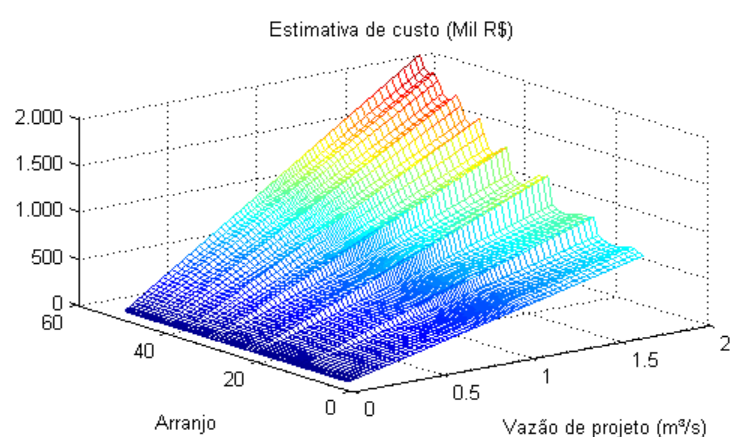

(b)

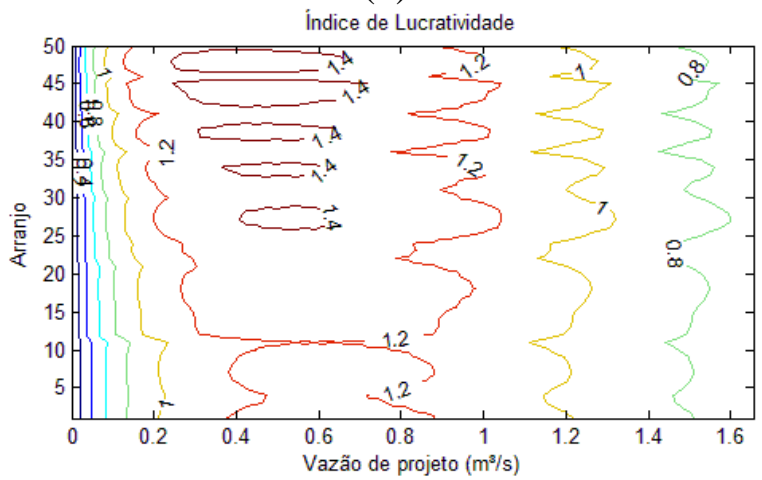

(d)

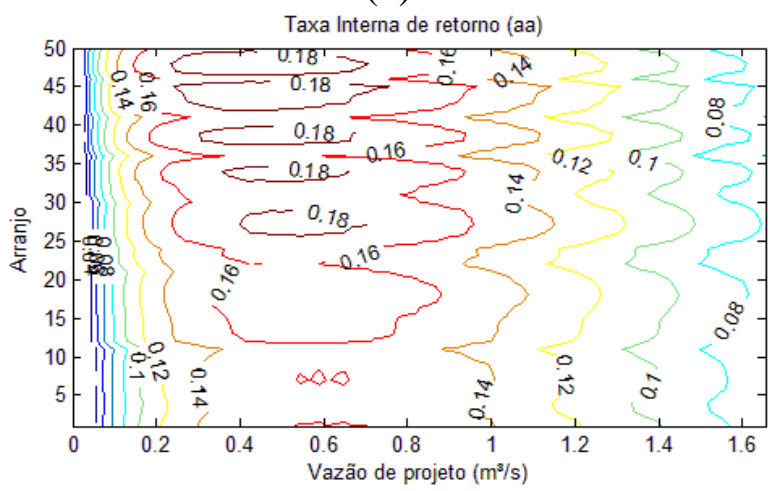

(f)

Figura 5.22 - Resultados da análise econômica utilizando a curva de duração de vazões: (a) Benefício anual (Mil $R \$$ ); (b) Estimativa de custo $(M i l R \$)$; (c) Valor presente líquido $(R \$)$; (d) Índice de lucratividade; (e) Período de payback descontado (anos); (f) Taxa interna de retorno (aa).

Tabela 5.9 - Arranjo e potência instalada que otimiza cada indicador do estudo de viabilidade econômica utilizando a curva de duração de vazões.

\begin{tabular}{|c|c|c|c|c|c|c|}
\hline Indicador & Valor & Arranjo & $\begin{array}{c}\text { Potência } \\
\text { instalada } \\
(k W) \\
\end{array}$ & $\begin{array}{c}\text { Investimento } \\
\text { inicial } \\
(R \$) \\
\end{array}$ & $\begin{array}{c}\text { Benefício } \\
\text { anual } \\
(\boldsymbol{R} \$)\end{array}$ & $\begin{array}{c}\text { Custo } \\
(R \$ / k W)\end{array}$ \\
\hline $\begin{array}{l}\text { Valor presente } \\
\text { líquido }\end{array}$ & $\mathrm{R} \$ 371.762,69$ & 48 & 240,49 & $1.006 .822,32$ & $184.563,28$ & $4.186,55$ \\
\hline $\begin{array}{l}\text { Índice de } \\
\text { Lucratividade }\end{array}$ & 1,76 & 48 & 132,95 & $599.196,60$ & $117.713,46$ & $4.506,93$ \\
\hline $\begin{array}{l}\text { Período de } \\
\text { Payback }\end{array}$ & 8,34 (anos) & 48 & 132,95 & $599.196,60$ & $117.713,46$ & $4.506,93$ \\
\hline $\begin{array}{l}\text { Taxa interna de } \\
\text { retorno }\end{array}$ & $19(\% a a)$ & 48 & 132,95 & $599.196,60$ & $117.713,46$ & $4.506,93$ \\
\hline
\end{tabular}




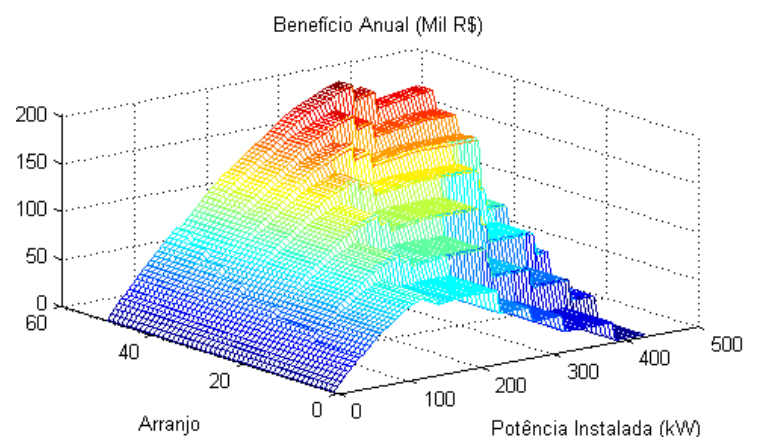

(a)

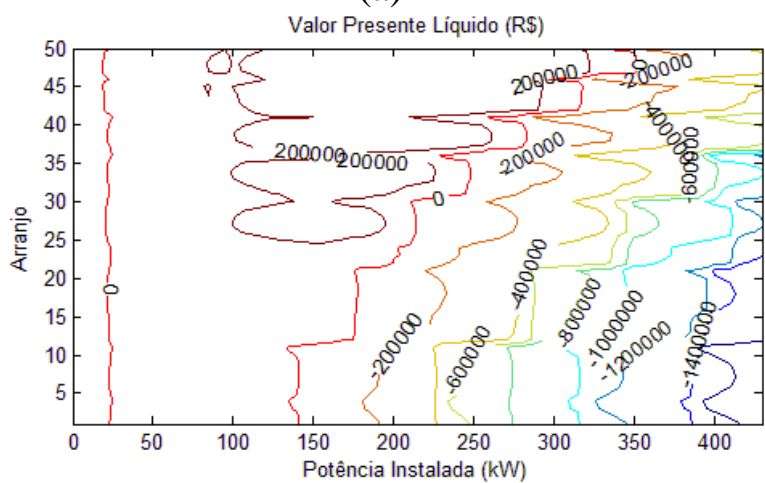

(c)

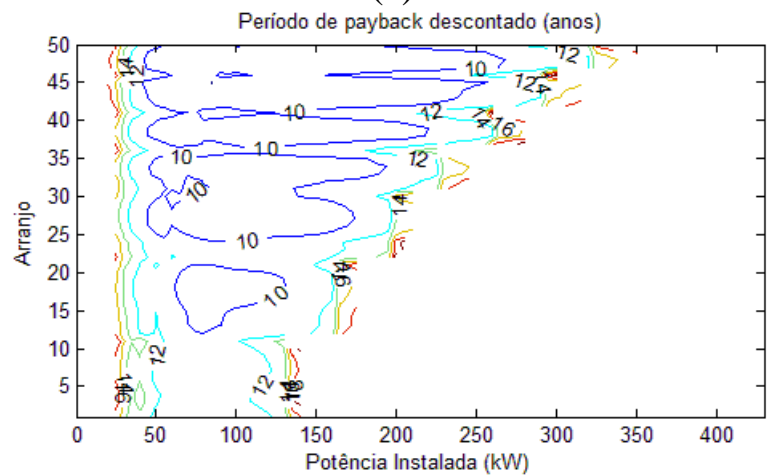

(e)

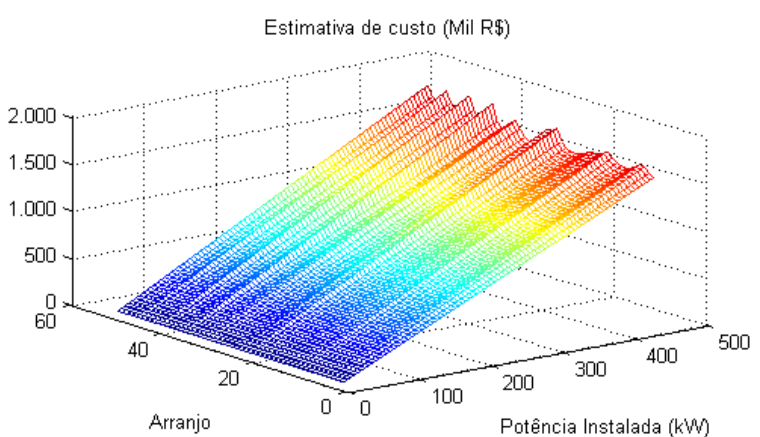

(b)

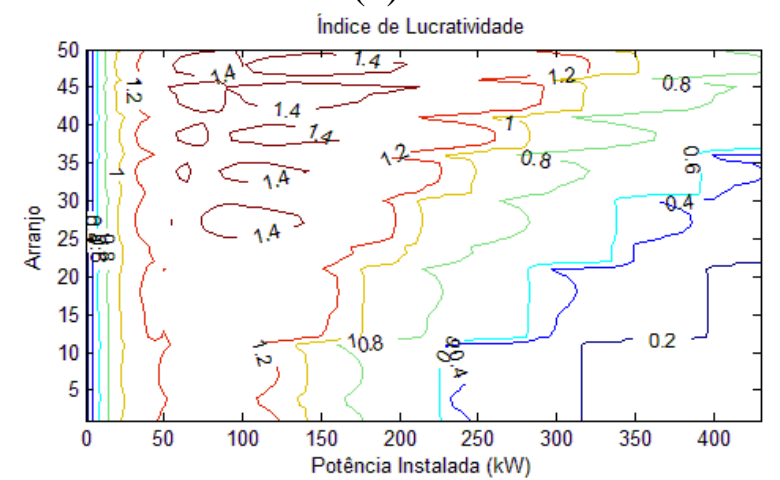

(d)

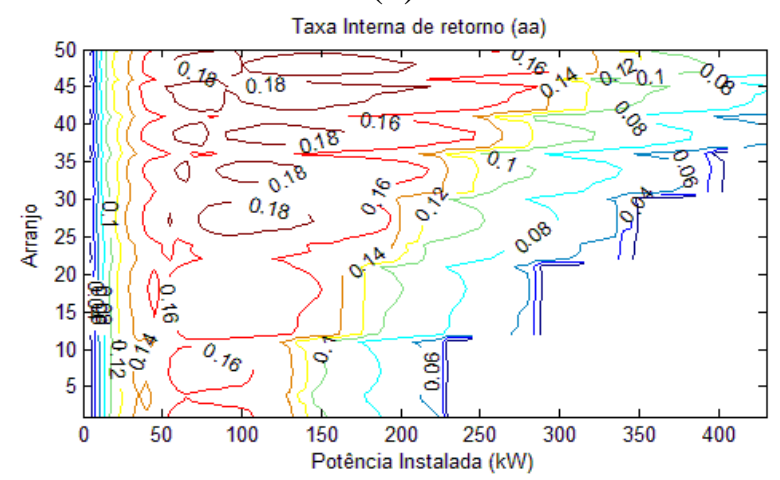

(f)

Figura 5.23 - Resultado da análise econômica utilizando as vazões médias mensais: (a) Benefício anual (Mil $R \$$ ); (b) Estimativa de custo $(M i l R \$)$; (c) Valor presente líquido $(R \$)$; (d) Índice de lucratividade; (e) Período de payback descontado (anos); (f) Taxa interna de retorno (aa).

Tabela 5.10 - Arranjo e potência instalada que otimiza cada indicador do estudo de viabilidade econômica utilizando a série de vazões médias mensal.

\begin{tabular}{l|r|r|r|r|r|r}
\multicolumn{1}{c|}{ Indicador } & \multicolumn{1}{|c|}{ Valor } & Arranjo & $\begin{array}{c}\text { Potência } \\
\text { instalada } \\
(\boldsymbol{k} \boldsymbol{W})\end{array}$ & $\begin{array}{c}\text { Investimento } \\
\text { inicial } \\
(\boldsymbol{R} \boldsymbol{\phi})\end{array}$ & $\begin{array}{c}\text { Benefício } \\
\text { anual } \\
(\boldsymbol{R} \boldsymbol{\phi})\end{array}$ & $\begin{array}{c}\text { Custo } \\
(\boldsymbol{R} \boldsymbol{\$} / \boldsymbol{k} \boldsymbol{W})\end{array}$ \\
\hline $\begin{array}{l}\text { Valor presente } \\
\text { líquido }\end{array}$ & $\mathrm{R} \$ 375.762,78$ & 48 & 250,00 & $1.046 .658,26$ & $190.431,99$ & $4.186,63$ \\
\hline $\begin{array}{l}\text { Indice de } \\
\text { Lucratividade }\end{array}$ & 1,76 & 48 & 95,00 & $459.139,60$ & $92.033,68$ & $4.833,05$ \\
\hline $\begin{array}{l}\text { Período de } \\
\text { Payback }\end{array}$ & $8,06($ anos) & 48 & 95,00 & $459.139,60$ & $92.033,68$ & $4.833,05$ \\
\hline $\begin{array}{l}\text { Taxa interna de } \\
\text { retorno }\end{array}$ & $19(\% a a)$ & 48 & 95,00 & $459.139,60$ & $92.033,68$ & $4.833,05$ \\
\end{tabular}


A escolha do arranjo e da potência instalada dependerá do perfil do empreendedor. Entretanto, será determinado um arranjo e uma potência instalada para a realização de uma análise da CGH 3 em diferentes cenários. Com base nos resultados apresentados na figuras 5.22, na figura 5.23, na tabela 5.9 e na tabela 5.10, o arranjo escolhido é o arranjo 48 e a potência instalada é $95 \mathrm{~kW}$. O arranjo 48 com potência instalada de $95 \mathrm{~kW}$ apresenta a

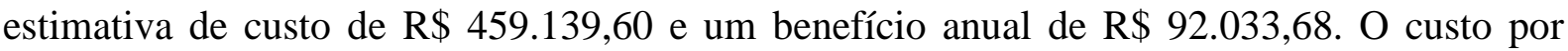
unidade de potência é de $\mathrm{R} \$ 4.833,05$ e está próximo do valor utilizado como referência nesse trabalho, $\mathrm{R} \$ 5.500$.

\subsection{Análise em diferentes cenários}

São considerados três cenários para a análise das três CGHs apresentadas. No cenário 1, toda a energia gerada é vendida. No cenário 2, existe o consumo de energia na propriedade e o excedente é vendido. No cenário 3 , não há venda do excedente de energia.

Para a CGH 1 e a CGH 2 é considerada a vazão disponível atual, não considerando a execução do projeto de irrigação. É desconsiderado o custo referente à barragem da CGH 1 , pois essa barragem não foi construída especificamente para a geração de energia. Os dados utilizados para a realização dessa análise estão apresentados na tabela 5.11. A tabela 5.12, a tabela 5.13 e a tabela 5.14 apresentam o resultado dessa análise para a CGH 1, a CGH 2 e a CGH 3, respectivamente.

Considerando os resultados apresentados na tabela 5.13, é possível verificar que a CGH 2 é inviável para os três cenários considerando as tarifas utilizadas e a taxa de juros de $12 \%$ aa. Portanto, nessas condições, a construção dessa CGH é economicamente inviável se a propriedade fosse alimentada pela concessionária local. Esse investimento é economicamente viável em um horizonte de análise de vinte anos, nos cenários 1 e 2 , se a taxa de juros fosse menor que a taxa interna de retorno, $10 \%$. Como esse empreendimento foi realizado para o abastecimento de cargas isoladas a sua viabilidade deve ser analisada considerando o custo da geração proveniente de outras fontes.

Por outro lado, a CGH 1 e a CGH 3 são economicamente viáveis para os cenários 1 e 2. Dessa forma, as duas CGHs são economicamente viáveis em um ambiente de geração distribuída. A existência de demanda na propriedade aumenta a viabilidade econômica do empreendimento, pois a tarifa de remuneração da parcela de potência consumida na propriedade é a tarifa da energia que a propriedade deixou de comprar e essa tarifa é maior que a tarifa de venda. 
Tabela 5.11 - Dados utilizados para a análise de viabilidade econômica das CGHs.

CGH 1

CGH 2

CGH 3

Dados Gerais

\begin{tabular}{l|c|c|c}
\hline Tarifa de energia constante $(R \$ / k W h)$ & 0,16 & 0,16 & 0,16 \\
\hline Taxa de juros $(a a)$ & 0,12 & 0,12 & 0,12 \\
\hline Horizonte da análise econômica $($ anos $)$ & 20 & 20 & 20 \\
\hline Custo unitário do terreno $(R \$ / h a)$ & 0 & 0 & 0 \\
\hline
\end{tabular}

Dados variáveis para cada arranjo

\begin{tabular}{l|c|c|c}
\hline Área utilizada $(h a)$ & 0 & 0 & 0 \\
\hline Cota a jusante $(m)$ & 755 & 900 & 850 \\
\hline Cota a montante $(m)$ & 850 & 910 & 895 \\
\hline Tipo de Arranjo (CHR, CHD, CHV) & CHV & CHV & CHV \\
\hline Comprimento da adução em alta pressão $(m)$ & 296 & 65 & 303 \\
\hline Comprimento da adução em baixa pressão $(m)$ & 689 & 682 & 791 \\
\hline Rendimento da adução em alta pressão & 0,97 & 0,98 & 0,95 \\
\hline Rendimento da adução em baixa pressão & 0,99 & 0,99 & 0,99 \\
\hline Tipo de turbina & Pelton & Francis & M.-Banki \\
\hline Rotação da turbina (Francis) $(r p m)$ & & 900 & \\
\hline Rendimento da turbina & 0,75 & 0,75 & 0,75 \\
\hline Rendimento do gerador & 0,90 & 0,90 & 0,90 \\
\hline Tipo da barragem (Terra ou concreto) & Concreto & Terra & Concreto \\
\hline Altura da ensecadeira $(m)$ & 2 & 0 & 2 \\
\hline Comprimento da ensecadeira $(m)$ & 3 & 0 & 5 \\
\hline Altura da barragem $(m)$ & 3 & 0 & 3 \\
\hline Comprimento da barragem $(m)$ & 5 & 0 & 10 \\
\hline Comprimento do canal de fuga $(m)$ & 20 & 3 & 30 \\
\hline Comprimento da linha de transmissão $(m)$ & 870 & 665 & 2550 \\
\hline
\end{tabular}

\begin{tabular}{l|c|c|c}
\hline \multicolumn{4}{c}{ Dados variáveis para cada mês } \\
\hline Vazão disponível $\left(\mathrm{m}^{3} / \mathrm{s}\right)$ & Figura 5.8 & Figura 5.8 & Figura 5.8 \\
\hline Tarifa de compra $(R \$ / \mathrm{kWh})$ & Tabela 5.9 & Tabela 5.9 & Tabela 5.9 \\
\hline Tarifa de venda $(R \$ / \mathrm{kWh})$ & Tabela 5.9 & Tabela 5.9 & Tabela 5.9 \\
\hline
\end{tabular}

Dados variáveis a cada hora

Demanda $(k W)$

Figura 5.20

Legenda: * Demanda atual do conjunto de residências 1 ; **Demanda atual do conjunto de residências 2 . 
Tabela 5.12 - Resultado da análise de viabilidade econômica aplicada a CGH 1.

\begin{tabular}{l|r|r|r} 
Indicador & \multicolumn{1}{|c|}{ Cenário 1 } & \multicolumn{1}{c|}{ Cenário 2 } & \multicolumn{1}{c}{ Cenário 3 } \\
\hline Energia gerada no ano $(\boldsymbol{k W h})$ & $1.231 .137,30$ & $1.231 .137,30$ & $535.220,00$ \\
\hline Estimativa de custo $(\boldsymbol{R} \$)$ & $614.729,90$ & $614.729,90$ & $614.729,90$ \\
\hline Benefício anual $(\boldsymbol{R} \boldsymbol{)})$ & $196.981,97$ & $220.732,00$ & $109.385,14$ \\
\hline Valor presente líquido $(\boldsymbol{R} \boldsymbol{\$})$ & $856.615,80$ & $1.034 .015,31$ & $202.316,20$ \\
\hline Índice de Lucratividade & 2,39 & 2,68 & 1,33 \\
\hline Período de Payback $($ anos $)$ & 4,15 & 3,60 & 9,91 \\
\hline Taxa interna de retorno & 0,32 & 0,36 & 0,17 \\
\hline Custo $(\boldsymbol{R} \boldsymbol{\$} \boldsymbol{k} \boldsymbol{W})$ & $3.415,17$ & $3.415,17$ & $3.415,17$ \\
\hline Fator de Capacidade & 0,78 & 0,78 & 0,34
\end{tabular}

Tabela 5.13 - Resultado da análise de viabilidade econômica aplicada a CGH 2.

\begin{tabular}{|c|c|c|c|}
\hline Indicador & Cenário 1 & Cenário 2 & Cenário 3 \\
\hline Energia gerada no ano $(\boldsymbol{k} W h)$ & $202.377,18$ & $202.377,18$ & $8.520,00$ \\
\hline Estimativa de custo $(R \$)$ & $283.299,35$ & $283.299,35$ & $283.299,35$ \\
\hline Benefício anual $(R \$)$ & $32.380,35$ & $32.753,14$ & $1.736,14$ \\
\hline Valor presente líquido $(R \$)$ & $-41.436,16$ & $-38.651,62$ & $-270.331,36$ \\
\hline Índice de Lucratividade & 0,85 & 0,86 & 0,05 \\
\hline Período de Payback (anos) & 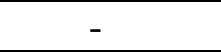 & - & - \\
\hline Taxa interna de retorno & 0,10 & 0,10 & - \\
\hline Custo $(R \$ / k W)$ & $7.082,48$ & $7.082,48$ & $7.082,48$ \\
\hline Fator de Capacidade & 0,58 & 0,58 & 0,02 \\
\hline
\end{tabular}

Tabela 5.14 - Resultado da análise de viabilidade econômica aplicada a CGH 3 .

\begin{tabular}{l|r|r|r} 
Indicador & \multicolumn{1}{|c|}{ Cenário 1 } & \multicolumn{1}{c}{ Cenário 2 } & \multicolumn{1}{c}{ Cenário 3 } \\
\hline Energia gerada no ano $(\boldsymbol{k W h})$ & $521.657,90$ & $521.657,90$ & $157.080,00$ \\
\hline Estimativa de custo $(\boldsymbol{R} \boldsymbol{\phi})$ & $459.139,60$ & $459.139,60$ & $459.139,60$ \\
\hline Benefício anual $(\boldsymbol{R} \boldsymbol{\phi})$ & $83.465,26$ & $92.033,68$ & $39.111,90$ \\
\hline Valor presente líquido $(\boldsymbol{R} \boldsymbol{\$})$ & $164.299,49$ & $228.300,79$ & $-166.995,48$ \\
\hline Índice de Lucratividade & 1,36 & 1,50 & 0,64 \\
\hline Período de Payback $($ anos $)$ & 9,54 & 8,06 & - \\
\hline Taxa interna de retorno & 0,17 & 0,19 & 0,06 \\
\hline Custo $(\boldsymbol{R} \boldsymbol{\$} / \boldsymbol{k} \boldsymbol{W})$ & $4.833,05$ & $4.833,05$ & $4.833,05$ \\
\hline Fator de Capacidade & 0,63 & 0,63 & 0,19
\end{tabular}

A CGH 1 apresenta viabilidade econômica no cenário 3 mesmo com um baixo fator de capacidade. O risco de um empreendimento com essa característica é bastante reduzido, pois a sua viabilidade não depende da garantia de venda do excedente de energia, entretanto o retorno econômico é prejudicado nesse cenário. A CGH 3 não apresenta viabilidade econômica nesse cenário em virtude do baixo fator de capacidade. Isso indica que essa CGH só é viável em um ambiente de geração distribuída. O risco desse empreendimento é relativamente maior, pois sua viabilidade depende da garantida de venda de energia durante o seu período de payback descontado, dez anos. 
O aumento do fator de capacidade com a inserção das CGHs em um ambiente de geração distribuída foi de 0,34 para 0,78 , de 0,02 para 0,58 e de 0,19 para 0,63 , para a CGH 1 , a CGH 2 e a CGH 3, respectivamente. Esses resultados mostram o aumento do fator de capacidade quando as CGHs são inseridas em um ambiente de geração distribuída.

\subsection{Conclusões}

As análises mostram que a CGH 1 apresenta bons resultados econômicos nos três cenários nas atuais condições de demanda e vazão disponível. Isso indica que mesmo se a propriedade fosse alimentada pela concessionária local e não fosse possível a venda do excedente de energia essa CGH é economicamente viável.

$\mathrm{Na}$ análise considerando a possibilidade de venda do excedente gerado, a CGH 2 apresenta um fator de capacidade próximo ao fator de capacidade da CGH 3, porém é inviável economicamente considerando as tarifas utilizadas nesse trabalho. Isso ocorre porque o custo por unidade de potência é bastante elevado, quando comparado ao custo por unidade de potência da CGH 3. Entretanto a CGH 2 deve ser mantida em operação, pois o único custo atual é a manutenção e operação.

As análises apresentadas mostram que a viabilidade econômica da CGH 3 depende da garantia de venda do excedente de energia. Nessas condições, apresenta um bom retorno econômico com uma taxa interna de retorno de $19 \%$, valor presente líquido de $\mathrm{R} \$ 521.657,90$ e índice de lucratividade de 1,50.

Os valores por unidade de potência da CGH 1 e da CGH3 estão próximos do valor usado como referência nesse trabalho, $\mathrm{R} \$ 5.500,00$. Entretanto a custo por unidade de potência da CGH2 é de $\mathrm{R} \$ 7.082,00$, que pode ser explicado pelo extenso sistema de adução para resultar uma altura bruta relativamente pequena. 


\section{CONCLUSÕES}

As análises apresentadas nesse trabalho mostram que a geração de energia proveniente de CGHs pode ser uma alternativa de investimento economicamente viável. Porém, tanto a configuração do arranjo, quanto a escolha da potência instalada devem ser criteriosamente estudadas, pois um dimensionamento incorreto pode comprometer a viabilidade econômica do empreendimento. As análises mostram que o fator de capacidade de uma CGH pode ser consideravelmente reduzido quando essa opera em um sistema isolado. Isso reduz o retorno econômico podendo comprometer a sua viabilidade econômica. Dessa forma, a garantia de venda do excedente de energia pode ser determinante para garantir a viabilidade econômica do empreendimento.

O capitulo 5 apresentou um exemplo em que a vazão disponível do manancial será completamente utilizada para irrigação nos períodos de estiagem. Esse fato inviabiliza a construção da CGH 3 se o sistema da propriedade for interligado com a rede de distribuição da concessionária local. Se o excedente de energia gerada for vendido, essa alternativa é viável e terá uma taxa interna de retorno de $19 \%$ ao ano considerando um horizonte de análise de vinte anos.

Esse trabalho mostrou que, se houver a garantia de venda do excedente de energia a geração proveniente de CGHs pode ser viável mesmo nos casos em que não há vazão disponível nos períodos de estiagem. Assim como no exemplo apresentado, existem outras propriedades rurais com projetos de irrigação que possuem infra-estrutura de captação de água para irrigação e são atendidas por uma rede de distribuição trifásica. A garantia de venda de energia pode viabilizar o investimento em geração nessas propriedades e em propriedades com potencial hídrico disponível para instalação de CGHs, mas com baixa demanda de potência.

As análises realizadas consideraram apenas as tarifa de energia de mercado e não consideram a redução de custo referente à utilização de estruturas, de materiais e de equipamentos mais econômicos. Uma sugestão para os próximos trabalhos é a análise do impacto das alternativas econômicas apresentadas no capítulo 3 na viabilidade econômica das CGHs. Outra sugestão é a realização da análise considerando o custo de outras fontes de energia e o custo da interligação com a concessionária local. 


\section{REFERÊNCIAS BIBLIOGRÁFICAS}

[1] ANEEL - Agência Nacional de Energia Elétrica - Guia do Empreendedor de Pequenas Centrais Hidrelétricas. Brasília, 2003. 703 p.

[2] Braga, A.V. Modelagem, ajuste e implementação de um Sistema de Controle de Tensão para o Gerador de Indução. 2002. 97. 97p. Dissertação (Mestrado) - Universidade Federal de Itajubá.

[3] Cunha, Y. P. S. A. - Microcentrais hidrelétricas baseadas no gerador de indução em operação isolada e frequiência fixa - dissertação de mestrado, UFG, 2007. 108 f.

[4] DNAEE - Eletrobrás - Manual de Microcentral Hidrelétrica - Ed. Eletrobrás, 1985.

[5] DNAEE - Eletrobrás - Manual de Minecentral Hidrelétrica - Ed. Eletrobrás, 1985.

[6] Eletrobrás - Manuais de Minicentrais hidrelétricas e PCH's - RJ - BR - 1982/1985.

[7] Elias, M./ Lima, S.P.L - PCH Fazenda Santa Maria (Projeto Básico). Brasília-DF, 11 de junho de 2001.

[8] Mongin J./ Machado R - Inventário hidrelétrico simplificado do Rio Angicos. Novembro de 2010.

[9] Rondina, J.M, - Geração Distribuída Utilizando Micro-Centrais Hidro-Elétricas com Tecnologia Assíncrona - FEELT-UFU, Uberlândia, 2007, 117 páginas.

[10] Sen. P.C. Principles of electric machines and power electronics-2nd ed. John Wiley \& Sons, 1997.

[11] Souza, Z. - Comportamento de Máquinas de Fluxo Frias - IEI - Itajubá MG BR 1968.

[12] Souza, Z./ Santos, A.H.M./ Bortoni, E.C. - Centrais Hidrelétricas: estudos para implantação - Rio de Janeiro: ELETROBRÁS, 1990.

[13] Tiago G.L.F. [et al.] - Pequenos Aproveitamentos Hidroelétricos (Soluções Energéticas para a Amazônia) - Brasília : Ministério de Minas e Energia, 2008.

[14] <http://portalibre.fgv.br/main.jsp?lumChannelId=402880811D8E34B9011D92B7684C 11DF.>Acesso em: 1/8/2010.

[15] <http://www.aneel.gov.br/ area.cfm?id_area=106> Acesso em: 10/3/2010.

[16] <http://www.aneel.gov.br/area.cfm?idArea=550> Acesso em: 2/8/2010.

[17] <http://www.ccee.org.br/> Acesso em: 2/8/2010. 


\section{APÊNDICE}




\section{Apêndice I - Dados para realização da análise de viabilidade econômica}

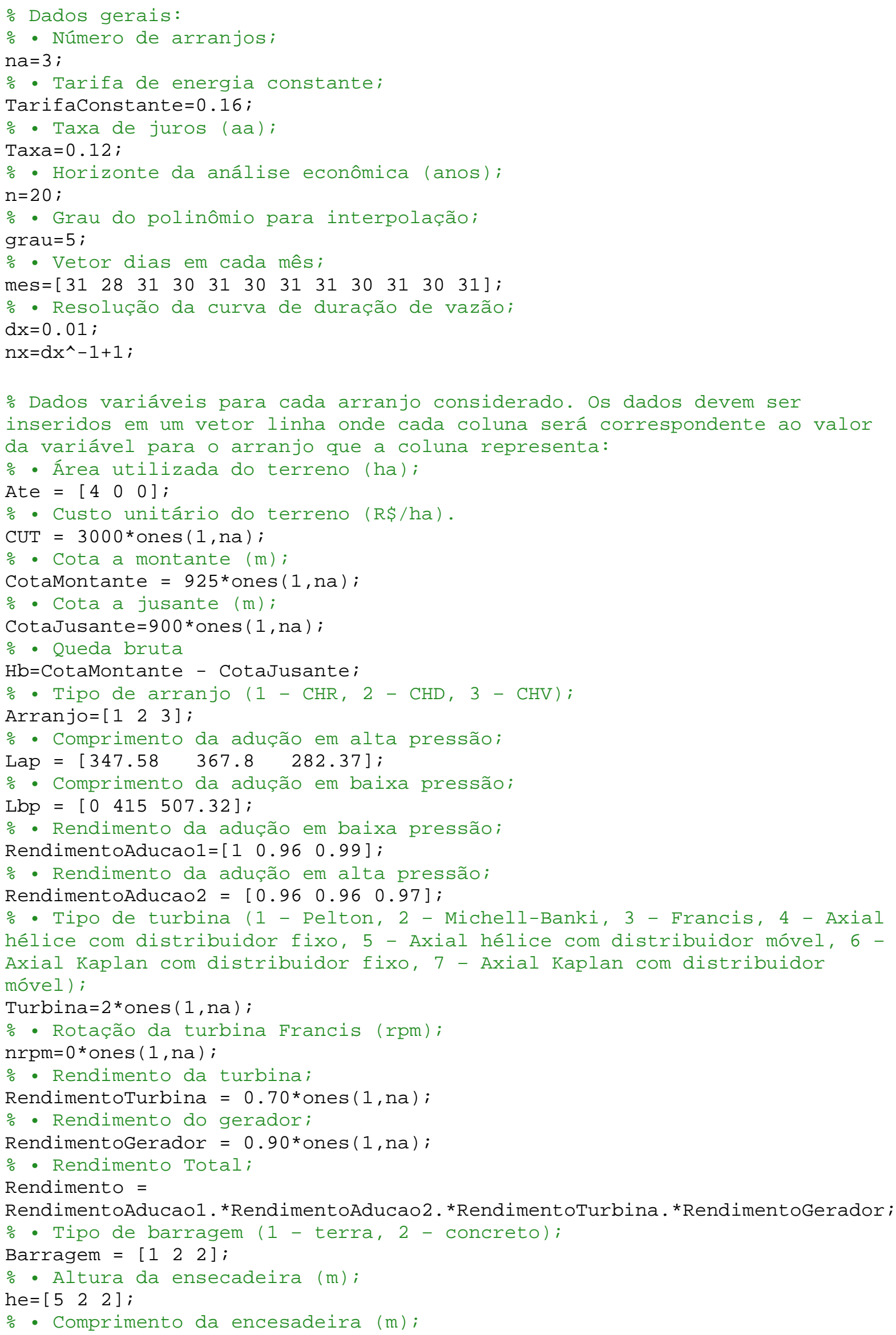




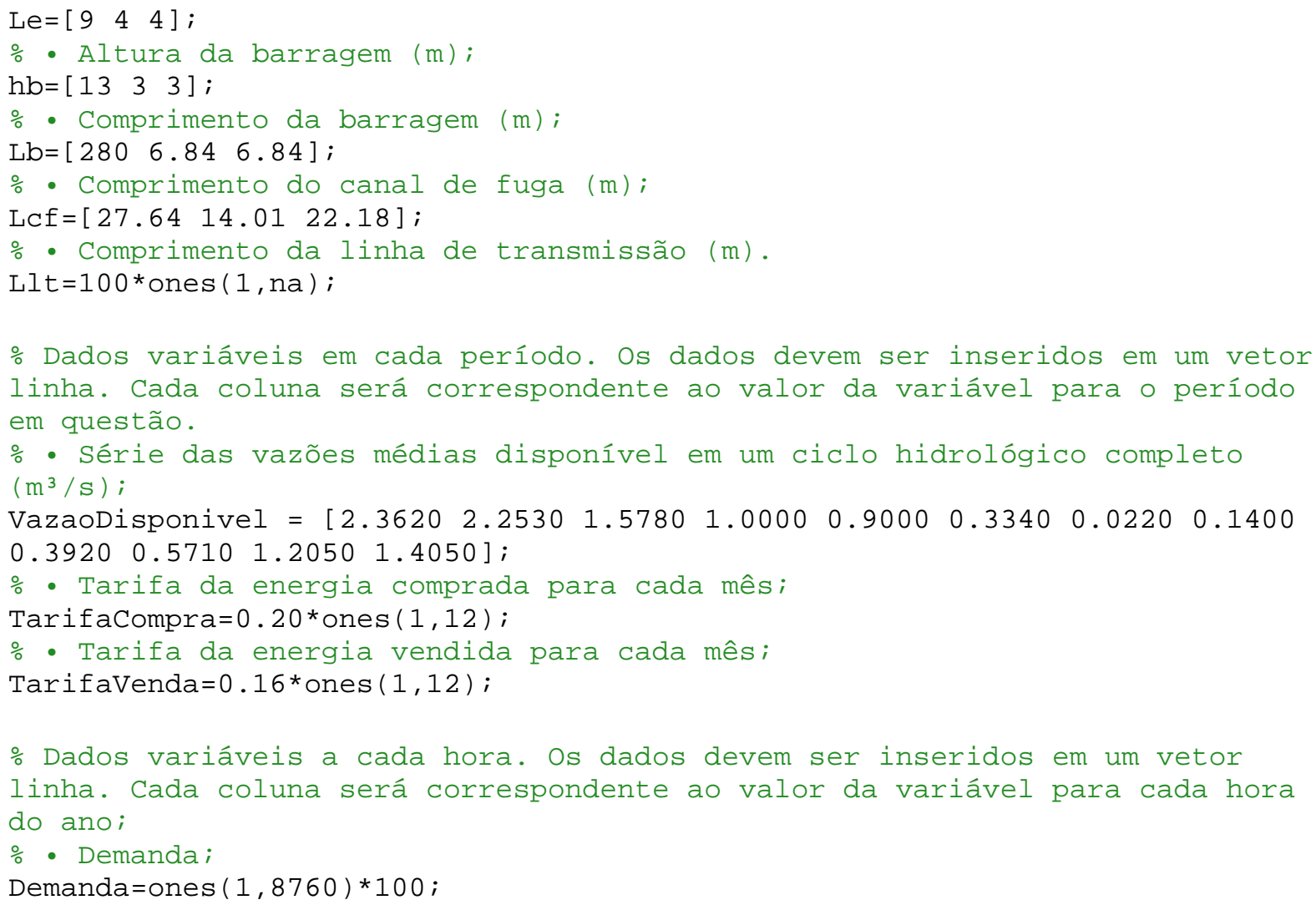




\section{Apêndice II - Função para determinação da curva de duração de vazões}

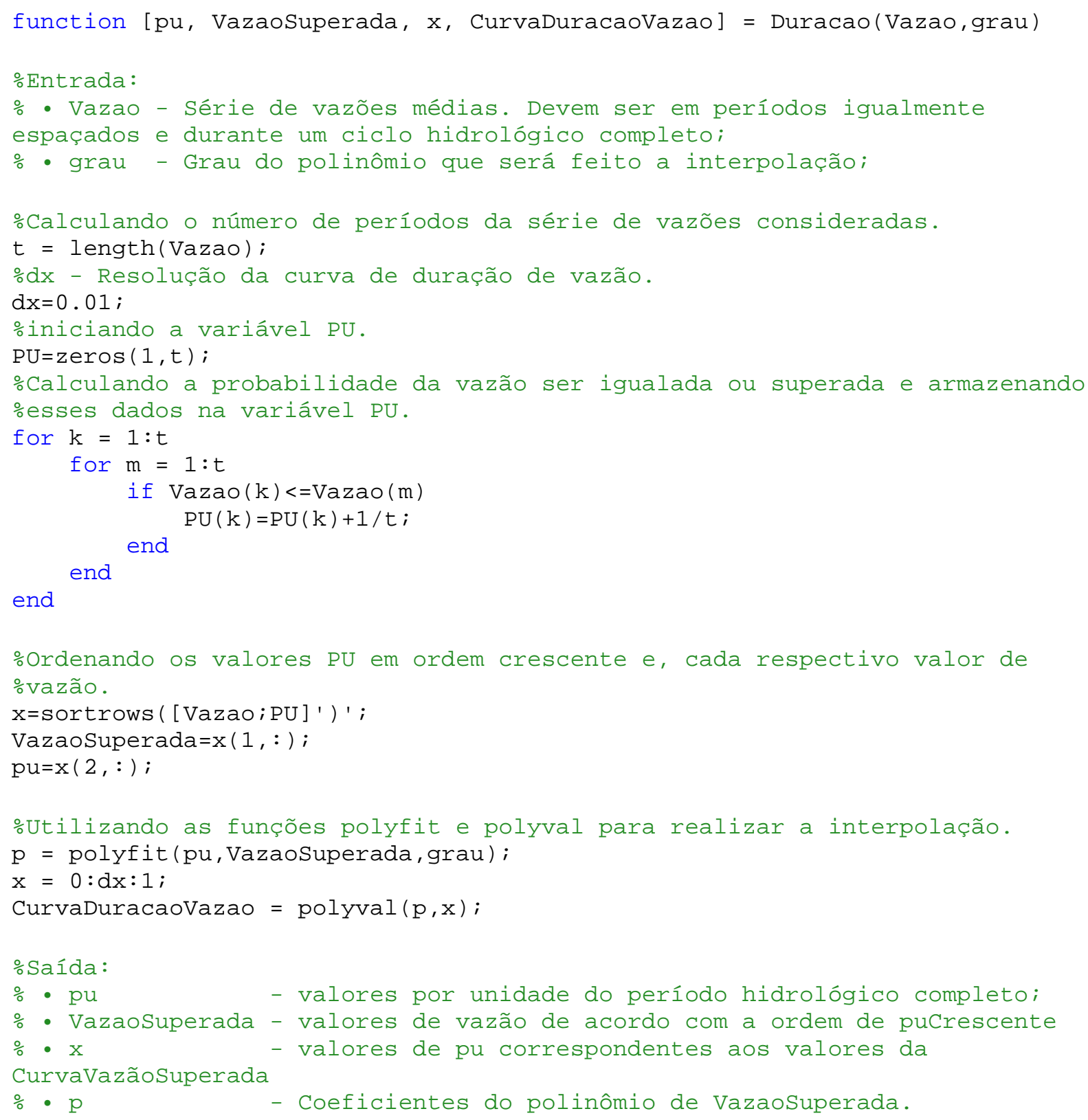




\section{Apêndice III - Função para determinação da estimativa de custo}

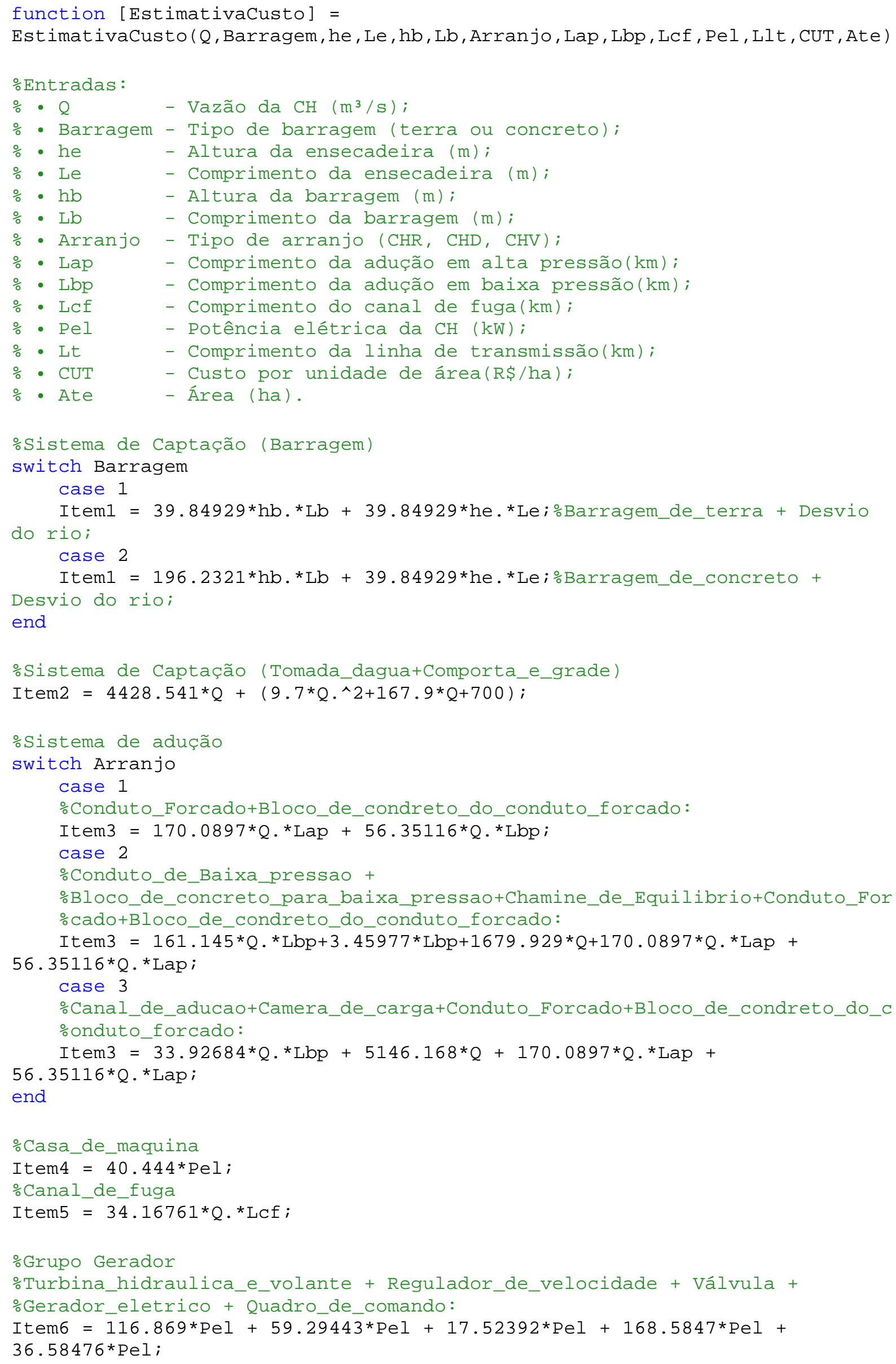


․ Sistema_de_Protecao

Item $7=12.64893 * \mathrm{Pel}$;

-Subestacao

Item8 $=71.58089 * \mathrm{Pel}$;

oLinha_de_transmissao

Item9 $=0.007293741{ }^{*}$ Llt. $*$ Pel;

\%Terreno

Item10 $=$ CUT *Ate :

Eventuais

Item11=328.2715*Pel;

\%Administração

Item $12=33.05 * \mathrm{Pel}$;

ongenharia

Item13=64.4391*Pel;

EstimativaCusto $=$

2.73* (24414.80+1.73* Pel+(Item1+Item2+Item3+Item4+Item5+Item6+Item7+Item8+It em $9+$ Item $10+$ Item $11+$ Item12+Item13)*1.00793);

○. Saída:

- EstimativaCusto - Estimativa de Custo. 


\section{Apêndice IV - Algoritmo para o cálculo dos indicadores econômicos}

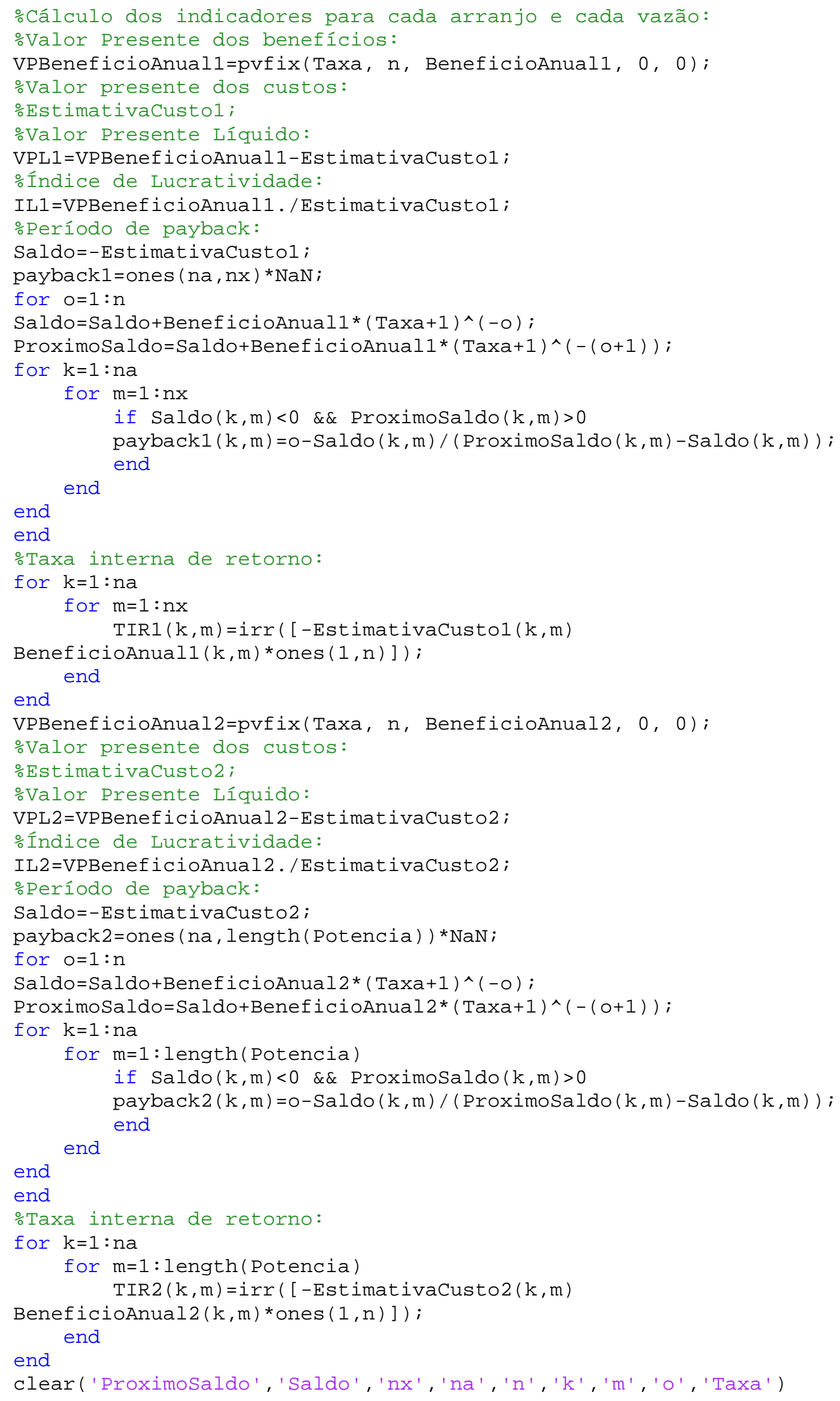




\section{Apêndice V - Outras funções}

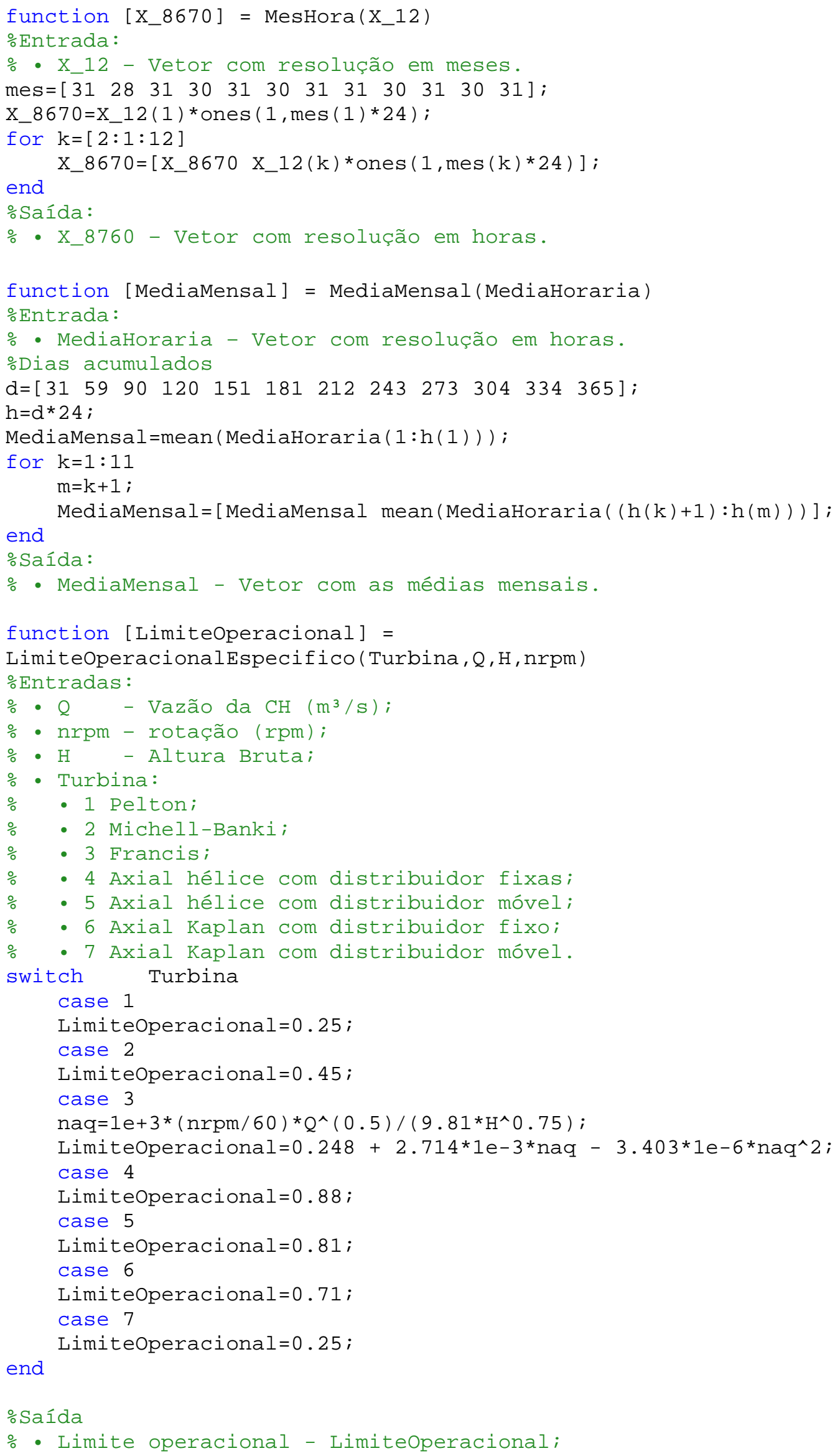




\section{Apêndice VI - Desenvolvimento da análise de viabilidade econômica com a utilização da curva de duração de vazões}

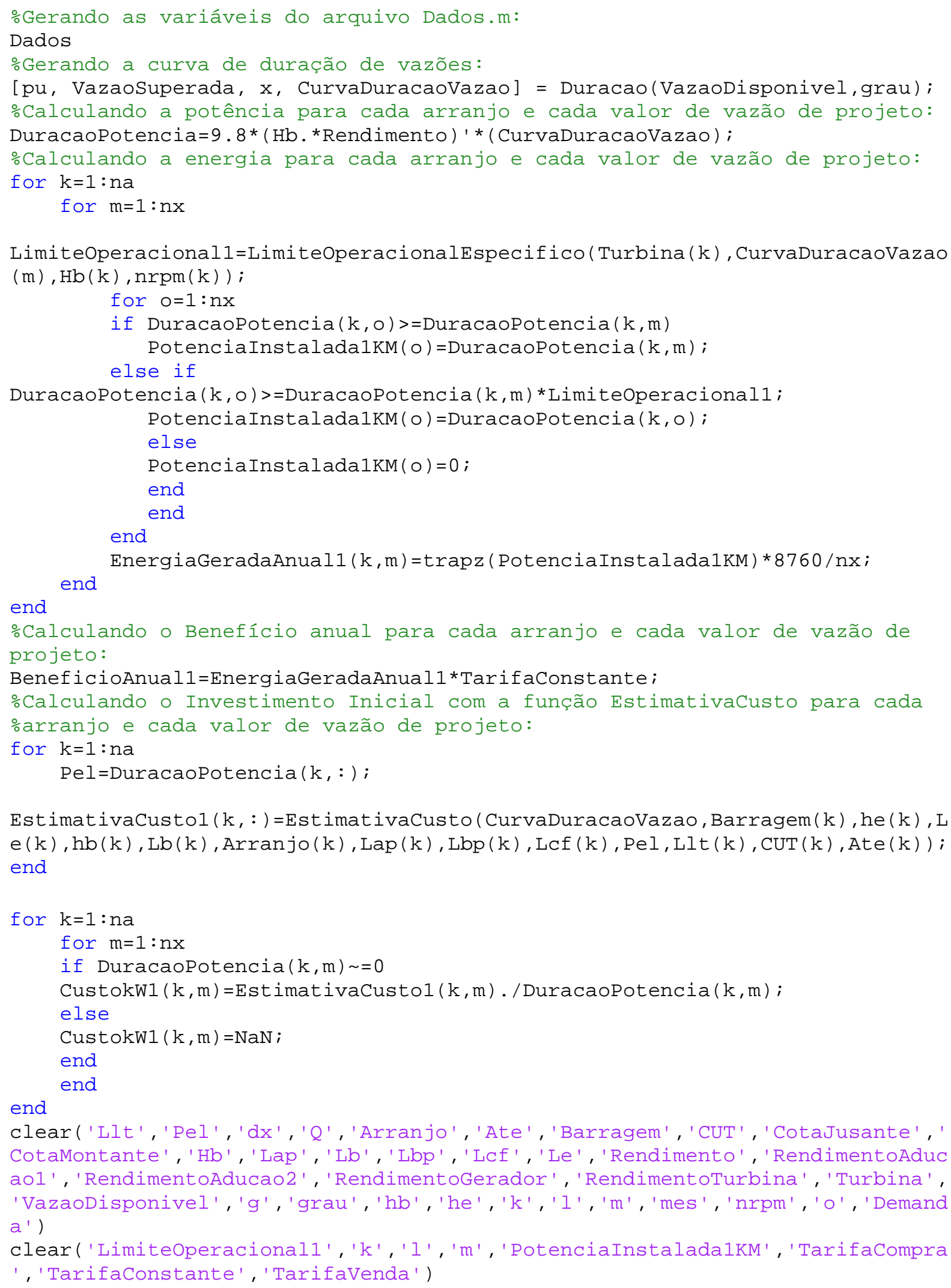




\section{Apêndice VII - Desenvolvimento da análise de viabilidade econômica com a utilização das vazões médias mensais}

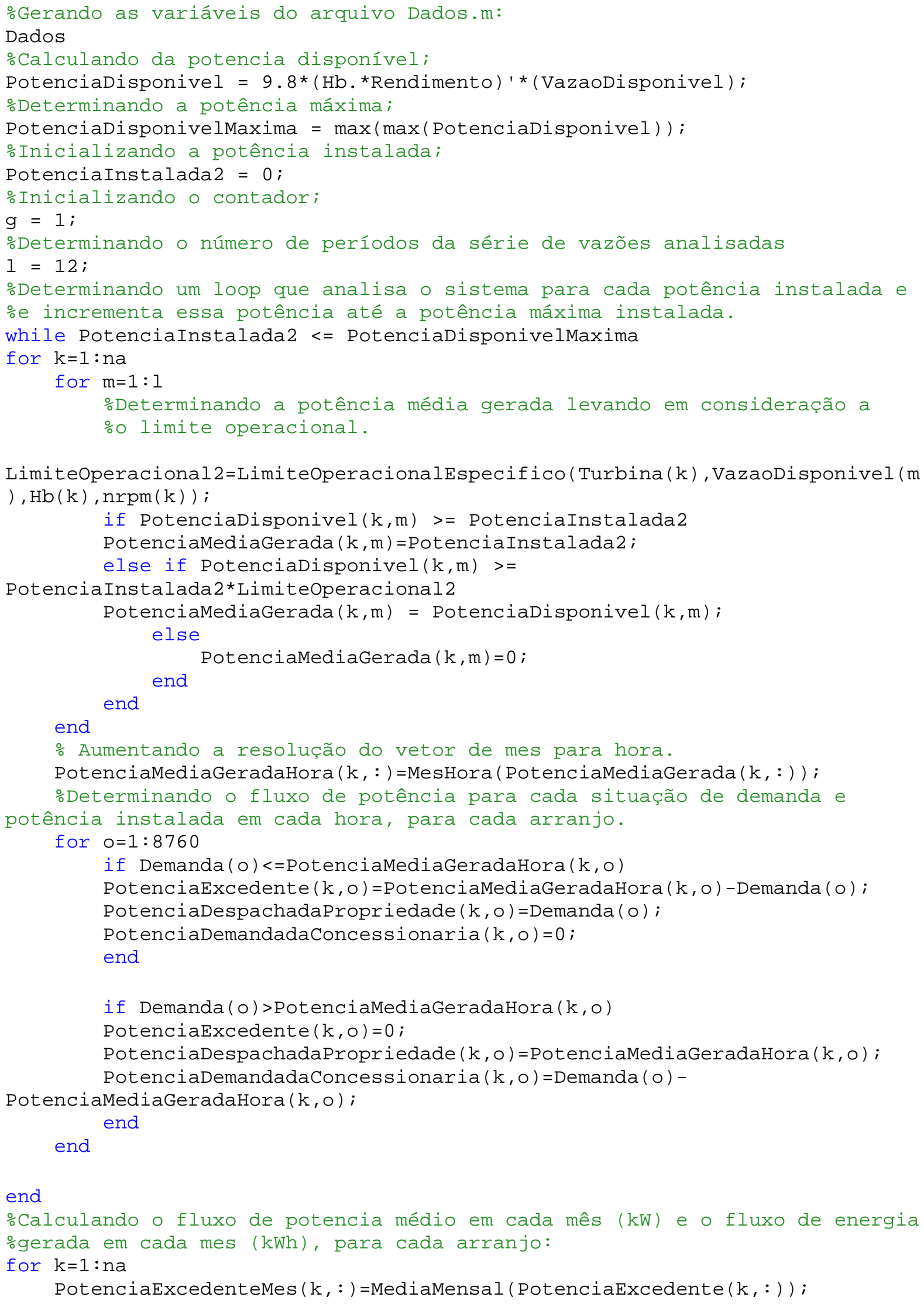


PotenciaDespachadaPropriedadeMes $(\mathrm{k}, \mathrm{:}$ ) =MediaMensal (PotenciaDespachadaProprie dade $(\mathrm{k},:))$;

PotenciaDemandadaConcessionariaMes $(k,:)$ ) MediaMensal (PotenciaDemandadaConces sionaria $(k,:))$;

end

oCalculando o fluxo de energia no ano e o benefício, para cada arranjo.

EnergiaGeradaAnualK = PotenciaMediaGerada*mes '*24;

BeneficioAnualK $=$

PotenciaExcedenteMes * (mes. *TarifaVenda) ' *24+PotenciaDespachadaPropriedadeMe

$\mathrm{s} *$ (mes. *TarifaCompra) '*24;

FaturaConcessionariaAnualK $=$

PotenciaDemandadaConcessionariaMes * (mes. *TarifaVenda) '*24;

oDeterminando o investimento inicial para arranjo, calculando a vazão

correspondente à potência predeterminada;

for $k=1$ : na

Pel=PotenciaInstalada2;

$\mathrm{Q}=\mathrm{Pel} /($ Rendimento $(\mathrm{k}) * \mathrm{Hb}(\mathrm{k}) * 9.8)$;

EstimativaCustoK $(k, 1)=$ EstimativaCusto $(Q, \operatorname{Barragem}(k)$, he $(k)$, Le $(k), h b(k), L b(k)$ , Arranjo (k), Lap (k), Lbp (k), Lcf (k), Pel, Llt (k), CUT (k), Ate (k)) ; end

EstimativaCusto2 $(:, g)$ = EstimativaCustoK;

BeneficioAnual2 $(:, g)$ = BeneficioAnualK;

FaturaConcessionariaAnual $(:, g)=$ FaturaConcessionariaAnualK;

EnergiaGeradaAnual2 $(:, g)$ = EnergiaGeradaAnualK;

oIncrementando a potência;

PotenciaInstalada2 = PotenciaInstalada2+5;

oIncrementando o contador;

$g=g+1$

end

Potencia=ones $($ na, 1$)$ * [0:5:PotenciaInstalada2-5] ;

for $k=1: n a$

for $\mathrm{m}=1$ : length (Potencia)

if Potencia $(\mathrm{k}, \mathrm{m}) \sim=0$

CustokW2 $(\mathrm{k}, \mathrm{m})=$ EstimativaCusto2 $(\mathrm{k}, \mathrm{m})$. /Potencia $(\mathrm{k}, \mathrm{m})$;

else

CustokW2 $(k, m)=\mathrm{NaN}$;

end

end

end

clear('Llt',

'Pel', 'dx', 'Q', 'Arranjo', 'Ate', 'Barragem', 'CUT', 'CotaJusante', 'CotaMontante ', 'Hb', 'Lap', 'Lb', 'Lbp', 'Lcf', 'Le', 'Rendimento', 'RendimentoAducao1', 'Rendim entoAducao2', 'RendimentoGerador', 'RendimentoTurbina', 'Turbina', 'Vazaodispon ivel', 'g', 'grau', 'hb', 'he','k', 'l', 'm', 'mes', 'nrpm', 'o')

clear('PotenciaMediaGeradaHora' , 'TarifaCompra' ', 'TarifaConstante', 'TarifaVen da', 'PotenciaMediaGerada' , 'PotenciaInstalada2', 'Potenciadisponivel', 'Potenc iaDisponivelMaxima' ', 'PotenciaExcedente', 'PotenciaExcedenteMes', 'PotenciaDem andadaConcessionaria', 'k' ', 'l', 'm' , 'PotenciaDemandadaConcessionariaMes', 'Pot enciaDespachadaPropriedade', 'PotenciaDespachadaPropriedadeMes ', 'FaturaConce ssionariaAnual', 'BeneficioAnualK', 'BeneficioAnualk', 'EnergiaGeradaAnualK', ' EstimativaCustoK', 'Limiteoperacional2' , 'FaturaConcessionariaAnualK', 'Potenc iaInstalada1KM' ) 
Apêndice VIII - Perfil longitudinal dos cortes mostrados na figura 5.20.

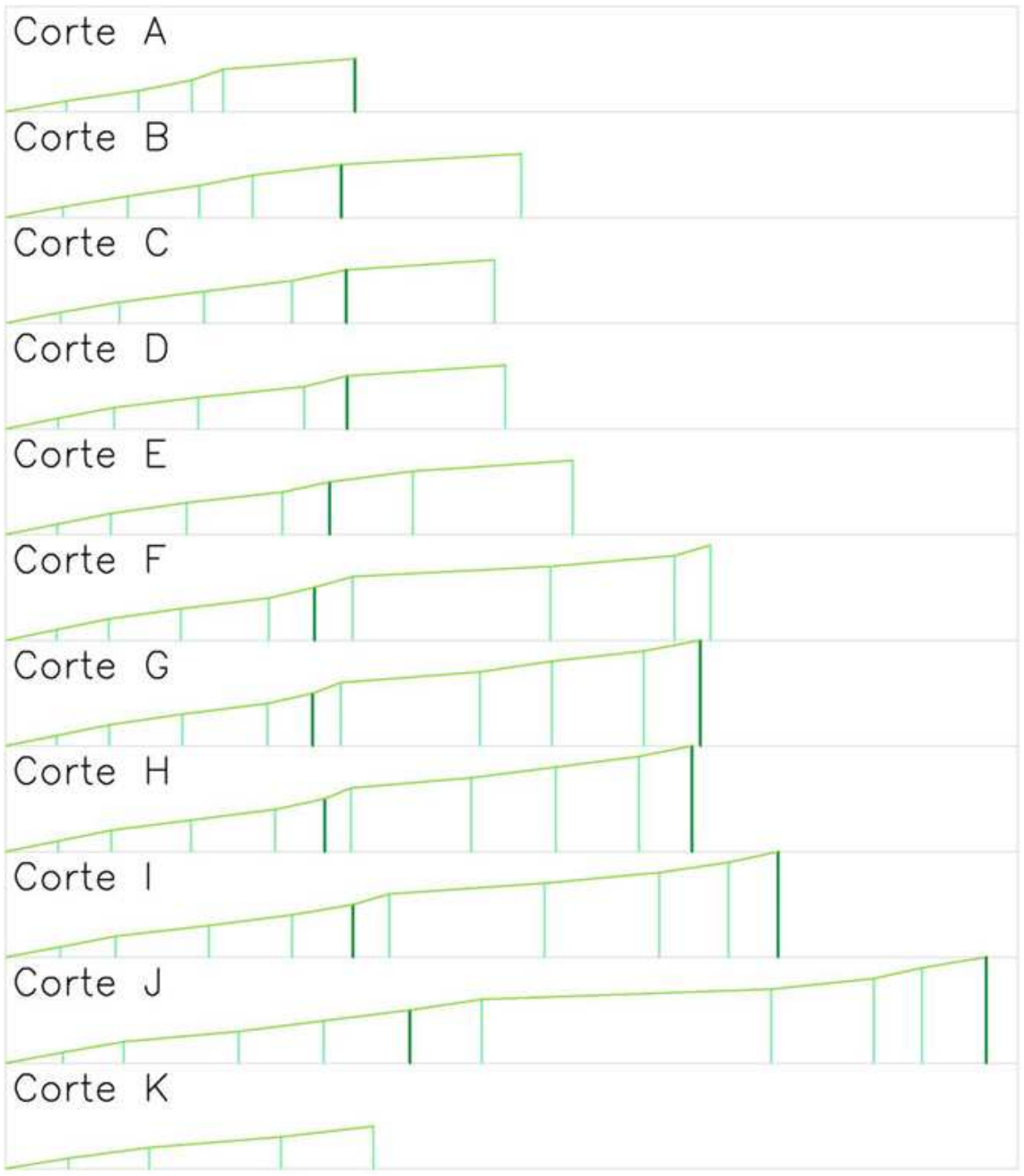

82 